\title{
Thermal Performance of Growth at Consumption Maximum (C- Max) and Routine Metabolic Rate (RMR) in Brook Trout Salvelinus fontinalis from four Populations in Central Appalachia
}

\author{
Cory Michael Hartman \\ chartma7@mix.wvu.edu
}

Follow this and additional works at: https://researchrepository.wvu.edu/etd

Part of the Aquaculture and Fisheries Commons

\footnotetext{
Recommended Citation

Hartman, Cory Michael, "Thermal Performance of Growth at Consumption Maximum (C-Max) and Routine Metabolic Rate (RMR) in Brook Trout Salvelinus fontinalis from four Populations in Central Appalachia" (2019). Graduate Theses, Dissertations, and Problem Reports. 7436.

https://researchrepository.wvu.edu/etd/7436

This Thesis is protected by copyright and/or related rights. It has been brought to you by the The Research Repository @ WVU with permission from the rights-holder(s). You are free to use this Thesis in any way that is permitted by the copyright and related rights legislation that applies to your use. For other uses you must obtain permission from the rights-holder(s) directly, unless additional rights are indicated by a Creative Commons license in the record and/ or on the work itself. This Thesis has been accepted for inclusion in WVU Graduate Theses, Dissertations, and Problem Reports collection by an authorized administrator of The Research Repository @ WVU. For more information, please contact researchrepository@mail.wvu.edu.
} 
Thermal Performance of Growth at Consumption Maximum (C-Max) and Routine Metabolic Rate (RMR) in Brook Trout Salvelinus fontinalis from four Populations in Central Appalachia

\author{
Cory M. Hartman
}

THESIS

\begin{abstract}
Submitted to the Davis College of Agriculture, Natural Resources, and Design at West Virginia University
\end{abstract}

in partial fulfillment of the requirements for the degree of

MASTER OF SCIENCE

in

\begin{abstract}
WILDLIFE AND FISHERIES RESOURCES
\end{abstract}

\author{
Patricia M. Mazik, Ph.D., Chair \\ John A Sweka, Ph.D. \\ Quinton E. Phelps, Ph.D. \\ Division of Forestry and Natural Resources
}

Morgantown, West Virginia

2019

Keywords: Brook Trout, RMR, Routine Metabolic Rate, Bioenergetics, Growth, C-Max,

Respiration, Metabolism, Consumption, Conversion Efficiency

Copyright 2019 (Cory M. Hartman) 


\begin{abstract}
:
Thermal Performance of Growth at Consumption Maximum (C-Max) and Routine Metabolic Rate (RMR) in Brook Trout (Salvelinus fontinalis) from four Populations in Central Appalachia
\end{abstract}

\author{
Cory M. Hartman
}

\begin{abstract}
Growth of an individual is the end result of many physiological processes stemming from the consumption of food items. These processes can be influenced by many variables including temperature. Current bioenergetics models for Brook Trout Salvelinus fontinalis suggest growth increases with temperature until an inflection point of $20.2^{\circ} \mathrm{C}$. With a warming climate, and water temperatures expected to rise, the ability of a population to adapt to the warming environment is crucial to the survival of the species. For this study we sought to see how spatial variation would influence the specific consumption, conversion efficiency, and specific growth at consumption maximum (CMax), as well as the routine metabolic rate (RMR) of four source populations of Brook Trout in West Virginia's Central Appalachian Mountains. To accomplish this, we subjected individual fish to identical experimental regimes at three temperatures $(12,16$, and $20^{\circ} \mathrm{C}$ ). Experiments included 12 days of maximum consumption (C-Max) experiments followed by routine metabolic rates being measured. The effects of source population and temperature differences were determined using a general linear model and significant differences in model coefficients $(\mathrm{p} \leq 0.05)$. By the end of the study we found that the low elevation stream, which also experiences higher summer mean temperatures, significantly converted the energy of prey items more efficiently and in turn grew significantly faster at elevated water temperatures. Routine metabolic rates were found to be significantly $(\mathrm{p} \leq 0.05)$ different with two populations having a higher intercept but a lower slope coefficient than the other two populations. These findings give hope that a population of cold-water fish can survive climate change if temperatures rise at a slow enough pace to allow for adaptation.
\end{abstract}




\section{$\underline{\text { Acknowledgements }}$}

This thesis represents the culmination of several years' work and dedication to accomplish. The completion of this thesis would not have been possible without the support of many people. I am forever indebted to all who made this possible.

To my committee members: Dr. Patricia Mazik, Dr. John Sweka, and Quinton Phelps, all of whom were encouraging, helpful, and willing to work with me on such short notice to get this thesis completed. Quinton, thank you for reminding me to not "reinvent the wheel," and to keep my chin up when I would feel overwhelmed. John, thank you so much for being so willing to help me with the statistical analysis and interpretation involved with this project, without your help I would never have been able to have such sound findings to report. Pat, thank you so much for all you have done for me over the years, without you and your support I would not be where I am today if not for all that you have done for me over the years.

To my Dad: Thank you for being my hunting buddy over the years to help realign my frustrations, even if I did do most of the work. Thank you for always being there to support me in all things school and research related. Without your expertise and connections, I know I would not have been able to get this far, even if it did take a few "forgotten years" to get here. All those times I thought I was getting the "short end of the stick" with various projects was actually just preparing me for the career I am in now. I know I will always look back on these last seven and a half years of school as some of the best times of my life.

To my Mom: Thanks for all you did to help me make it through this part of my life without killing anyone, most notably dad. Thanks for the warm meals and a bed to sleep in and tending to my dogs at o' dark thirty when I would much rather be sleeping. Thanks for being the person I could talk things through with to help me choose the best route or option.

To my Siblings: Thank you guys for being there to help Melinda or Myself out whenever needed. Allen and Danielle, thanks for bringing the nieces around for a distraction as well as a place to stay for Melinda and I during transition times. Eric, thanks for taking care of my dogs and cleaning up after me when I was too lazy to do much else. Without your support I know I would have not been able to get here today.

To those who helped me along the way with this project to make it a reality. John Howell, thank you for constructing the recirculating system I used for these experiments. Jerry Nestor, thank you for helping me construct the respiration chambers. Anthony Mesa I appreciate you learning the protocol so I could have time to myself when I needed it. Ross Andrew and Chris Schwinghamer, thanks for the analytical and data management help. Zac Crouse, Jack Fisk and Sierra Delaney, thank you guys for helping to collect the fish used for this project.

Finally, this thesis is dedicated to my wife, Melinda. Thank you for putting up with me while I completed this part of my life and the undying love you always show me. Without your support and sacrifice the completion of this thesis would not have been possible. Not having you as my rock would have meant I could not do this. You made this all possible. Melinda, I love you, and I am excited to see where the future takes us! 


\section{Foreword}

This thesis contains three chapters. The first Chapter, "Literature Review and will not be published and is used to introduce the broader understanding of the subject matter in the research. This Chapter was written following the American Fisheries Society's Guidelines to Authors.

The second chapter "Thermal Performance of Brook Trout in Consumption, Conversion Efficiency and Growth of four Central Appalachian Streams in West Virginia" is written in the "North American Journal of Fisheries Management" style as I hope to publish this chapter with this journal. This research plays an important part in both the management and ecology of Appalachian Brook Trout, lending itself to be a useful tool for fisheries management.

The third chapter has already been written following "Transactions of the American Fisheries Society" journal guidelines for authors. This Chapter is entitled "Thermal Performance of Routine Metabolic Rates from four Populations of Brook Trout in West Virginia's Central Appalachian Mountains." I hope to publish this article in Transactions of the American Fisheries Society to get my research to as many people as possible and to broaden my horizons and publish in several journals.

\section{TABLE OF CONTENTS}

\section{Chapter 1 "Literature Review and Introduction"}

Title

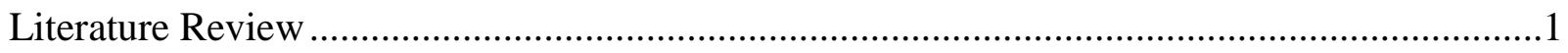

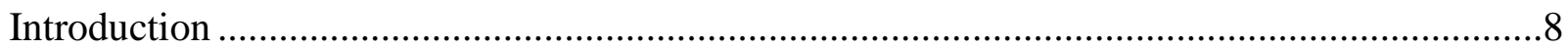

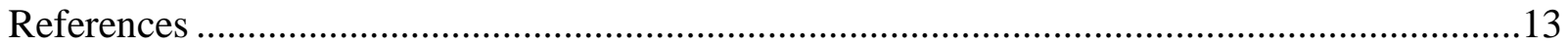

\section{Chapter 2 "Thermal Performance of Brook Trout in Consumption, Conversion Efficiency and Growth of four Central Appalachian Streams in West Virginia”}

Title and Abstract

Introduction

Methods

Results

Discussion 


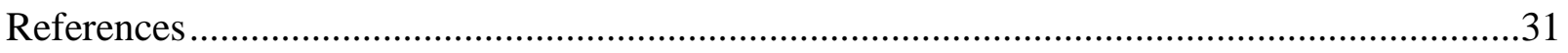

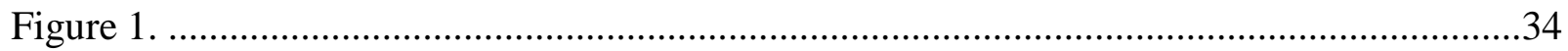

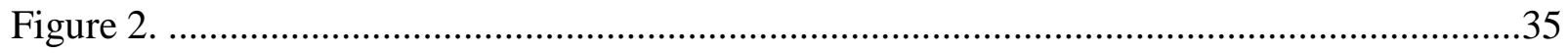

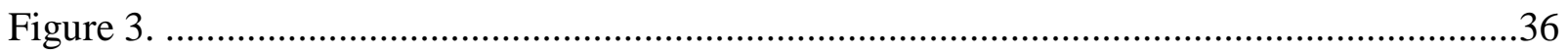

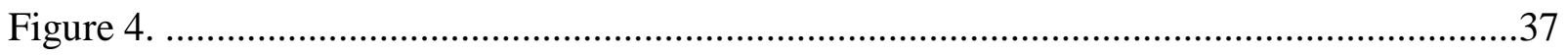

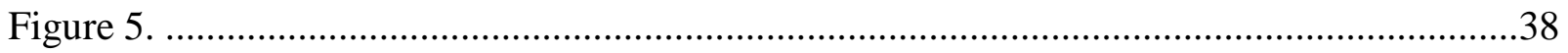

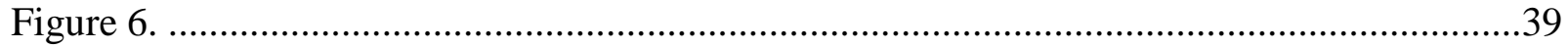

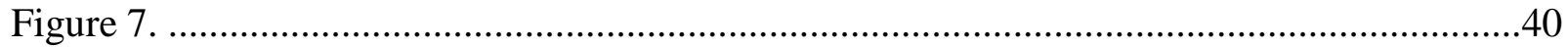

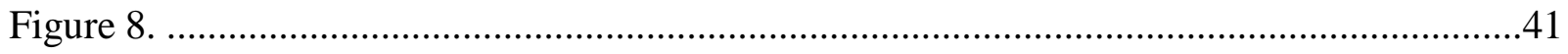

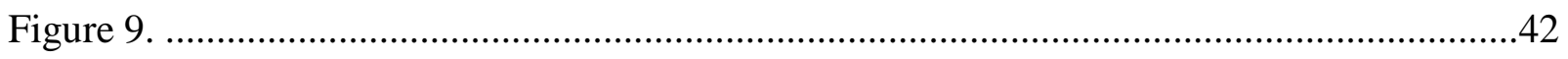

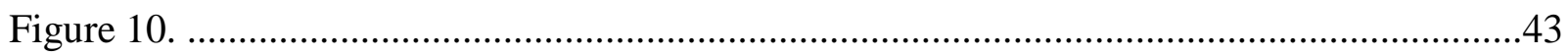

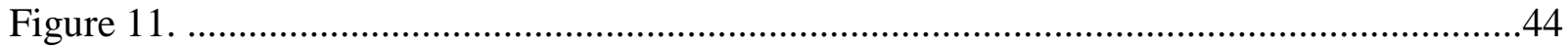

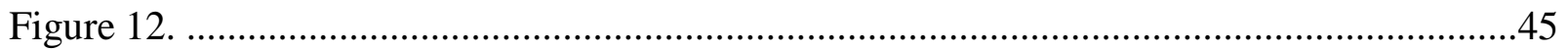

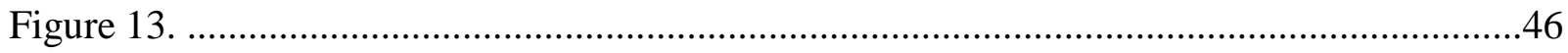

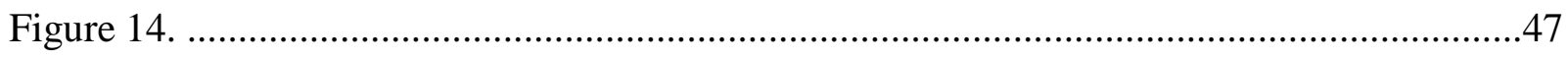

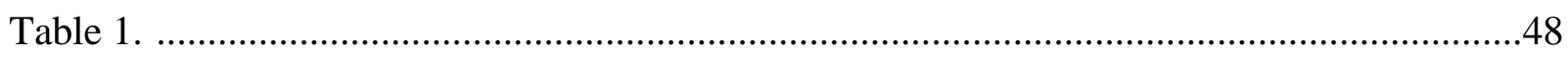

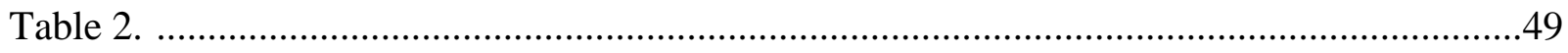

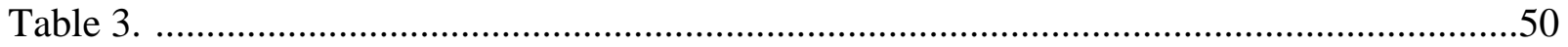

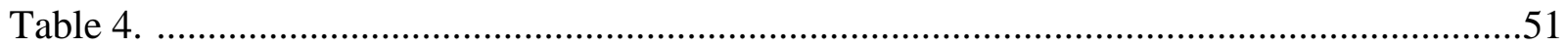

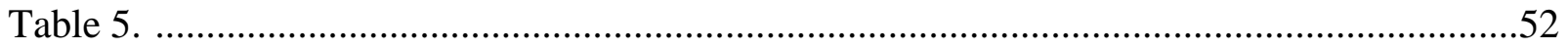

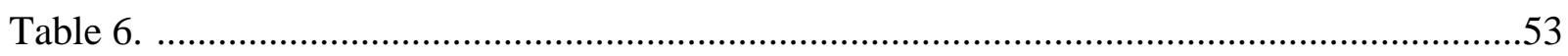

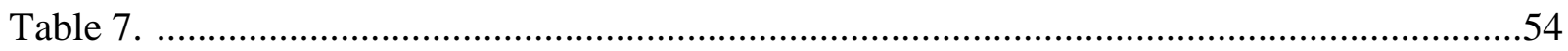

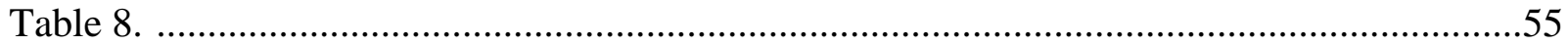

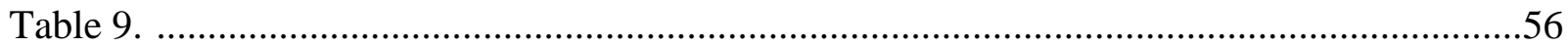

\section{Chapter 3 "Thermal Performance of Routine Metabolic Rates from four Populations of} Brook Trout in West Virginia's Central Appalachian Mountains.”

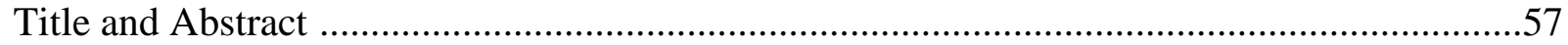

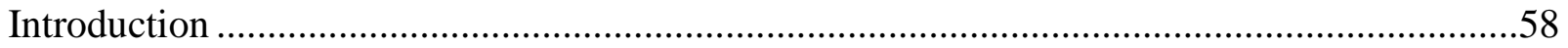

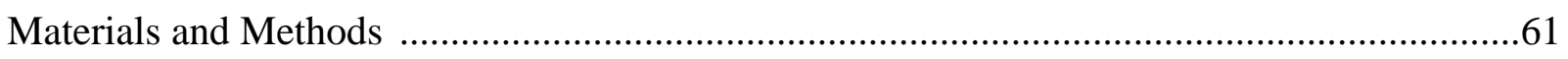

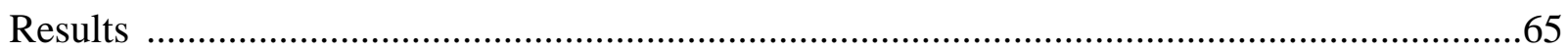




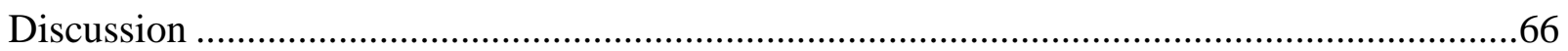

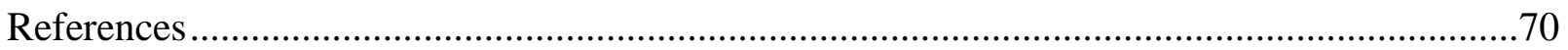

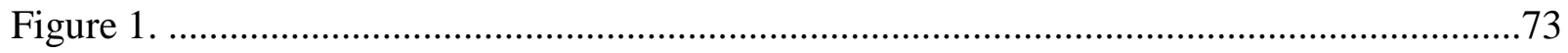

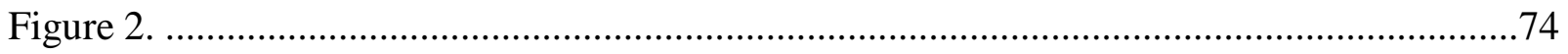

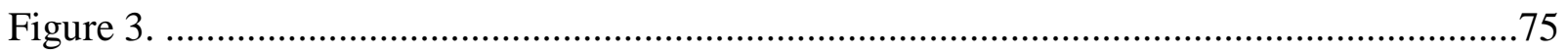

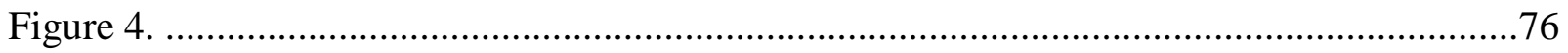

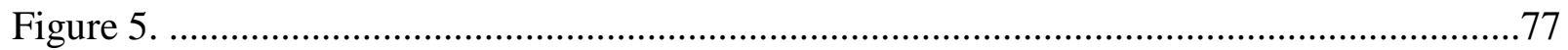

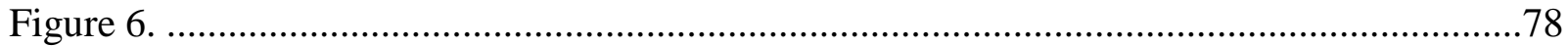

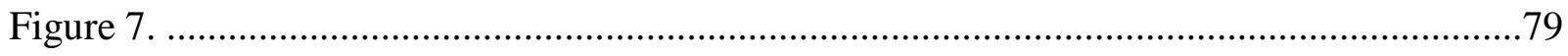

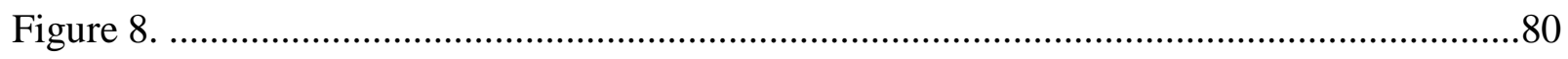

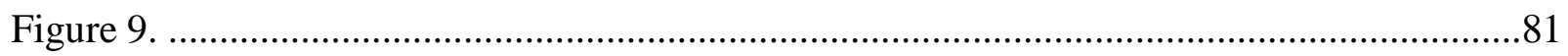

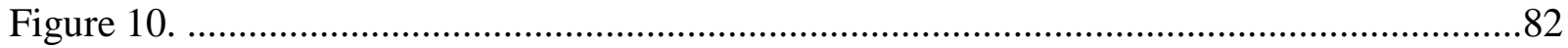

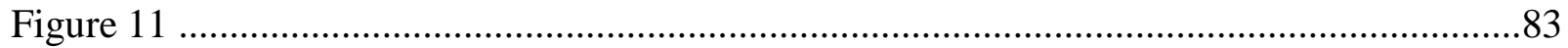

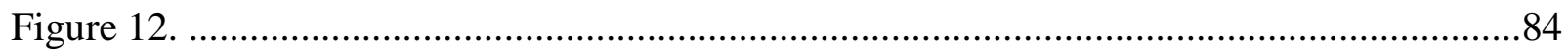

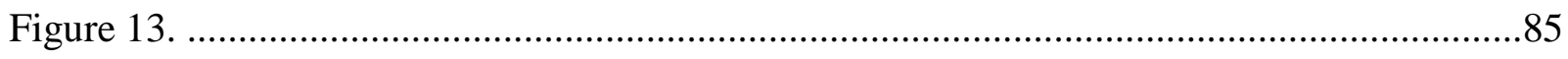

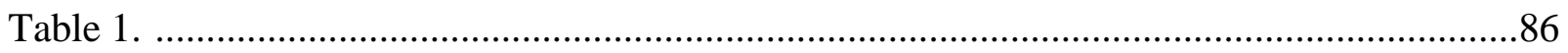

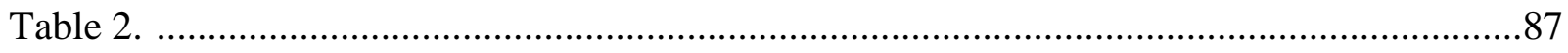

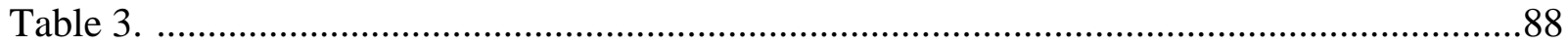

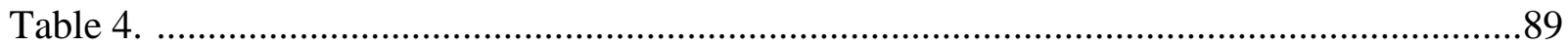

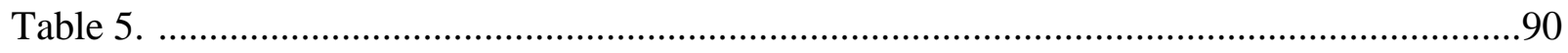




\section{Chapter 1 -Literature Review and Introduction}

\section{Literature Review}

Bioenergetics- The term bioenergetics refers to the ways in which animals dispose of the energy they acquire (Ney 1993). Bioenergetics models are essentially an energy budget dealing with energy gained with energy spent using mathematical equations. Winberg (1956) was one of the first to produce the energy budget for fish. The equation representing the energy budget of a fish can be described as simply: Consumption = Respiration + Waste Losses + Growth. Though the previous model is the simplest description of a fish's metabolism, most terms can be broken down further to better explain the appropriations of the energy budget. The respiration value can be further divided to include standard metabolism (RS), activity (RA), and digestion of food (RD). The waste losses term encompasses egestion (F), and excretion (U). Adding these values to the simple equation above along with consumption $(\mathrm{C})$ and growth $(\mathrm{G})$, provides a more detailed energy budget equation of: $\mathrm{C}=\mathrm{RS}+\mathrm{RA}+\mathrm{RD}+\mathrm{F}+\mathrm{U}+\mathrm{G}$.

Initial bioenergetics models were bolstered by Kitchell et al. (1977) producing the Wisconsin Model, which allows investigators to estimate consumption as a proportion of a temperature and size driven maximum. The Wisconsin model was the foundation for bioenergetics software packages produced by Hewett and Johnson (1987, 1992), as well as a more recent version of the software package titled Fish Bioenergetics 4.0 (Deslauriers et al. 2017). The energy budget used in Fish Bioenergetics 4.0 is similar to the detailed energy budget above and can be written as: $\mathrm{C}=(\mathrm{R}+\mathrm{A}+\mathrm{SDA})+(\mathrm{F}+\mathrm{U})+(\mathrm{SG}+\mathrm{GG})$. For this equation, consumption (C) is equal to the sum of respiration (R), active metabolism (A), and specific dynamic action (SDA), plus the sum of egestion (F) and excretion (U), plus the sum of somatic growth (SG) and gonadal growth (GG). Consumption and respiration of fish species are both 
temperature and size dependent, while waste losses can be thought of as either a constant proportion of consumption, or temperature, size, and ration dependent (Hanson et al. 1997).

Hartman and Sweka (2003) were the first to create a bioenergetics model parameterized specifically for Brook trout Salvelinus fontinalis. Using laboratory studies, they were able to determine which equations commonly used in the Fish Bioenergetics 3.0 (Hanson et al. 1997) program accurately represented consumption and respiration for Brook Trout. Egestion and excretion parameters were assumed similar to those used for Brown Trout Salmo trutta, and the Elliot (1976) equation for waste losses was used in the model. As Brook Trout size increased, the specific consumption rate decreased. The satiation level of a Brook Trout increased with temperature until approximately $20.2^{\circ} \mathrm{C}$ before sharply decreasing. Consumption data were best described by the temperature dependent equation for coldwater species (Thornton and Lessem 1987). Specific metabolic rates of Brook Trout also decreased with increasing size. Interestingly, the specific metabolic rate peaked at $12.6^{\circ} \mathrm{C}$, then unexpectedly decreased at $16.5^{\circ} \mathrm{C}$, and reached another peak at $21^{\circ} \mathrm{C}$. In the end, the temperature-dependent equation including an activity term (Kitchell et al. 1977) provided the best fit for Brook Trout respiration. In addition to calculating specific parameters for consumption and respiration, Hartman and Sweka (2003) attempted to validate their estimates using laboratory experiments. The bioenergetics model fitted with their parameters underestimated final weight of Brook Trout by $1.0 \%$ and growth rate by $1.4 \%$. Consumption was underestimated by $19.7 \%$ on average. In trying to understand the unusual dip at $16.5^{\circ} \mathrm{C}$ Sweka et al. (2004) determined that Brook Trout gastric evacuation rates were lower than expected compared to those of other trout species. The higher than expected metabolism measures at lower temperatures could be related to an incomplete evacuation of stomach contents causing specific dynamic action to raise the value. 
The unexpected decrease in specific metabolic rate at $16.5^{\circ} \mathrm{C}$ noted by Hartman and Sweka (2003), and the knowledge of varying gastric evacuation times, prompted a new study by Hartman and Cox (2008) to re-evaluate Brook Trout metabolism over a range of temperatures. Their goal was to improve the metabolic parameters of the model by estimating a new activity rate multiplier for the respiration equation (Kitchell et al. 1977), which they hypothesized yielded the low consumption estimates noted by Hartman and Sweka (2003). Hartman and Cox (2008) replicated metabolic studies on Brook Trout in the laboratory and found a consistent increase in specific metabolic rate until it peaked at approximately $21^{\circ} \mathrm{C}$, rather than the depression at $16.5^{\circ} \mathrm{C}$ that was observed by Hartman and Sweka (2003). They subsequently changed the activity rate multiplier from 1 to 2.89 and developed new estimates for the rest of the parameters in the respiration equation of the model. The new parameter estimates improved model accuracy to predict final weight, growth, and consumption all within $2.3 \%$.

As suggested above, bioenergetics models are not without their faults. Chipps and Wahl (2008) compared growth and food consumption estimates of 17 species, including Chinook Oncorhynchus tshawytscha and Sockeye Salmon Oncorhynchus nerka as well as Lake Trout Salvelinus namaycush, derived from bioenergetics models with those from experimentally derived estimates of growth and food consumption published since 1980. They found a wide range of disagreement between bioenergetics and experimental estimates for these two model outputs ranging from -84 to $770 \%$ in laboratory and field studies. It was also surmised that uncertainty can vary considerably both between and within species, and that model error usually increases when trying to account for variation across seasons and at different consumption rates. The authors summarize three potential sources of error in bioenergetics estimates: consumptiondependent error, physiological adaptations and additional abiotic effects, and the influence of 
prey dynamics. For the purposes of this literature review, the focus will be on the two sources of error associated with my project, consumption-dependent error as well as physiological adaptations.

Bajer et al. (2004) describes consumption-dependent error as error in model estimates attributed to variation in ration-size. Consumption-dependent error results with the overestimation of consumption for fish feeding at relatively low rations, and the underestimation of consumption for fish feeding at relatively high rations. This error can also occur when predicting growth rate. Growth rate is underestimated for fish growing quickly and overestimated for fish growing slowly. Several research articles have proposed explanations for this error including Madenjian and O'Connor (1999). Madenjian and O'Connor (1999) suggested that underestimation of consumption for Lake Trout Salvelinus namaycush fed ad libitum was due to an increase in standard metabolic rate that is not accounted for in the model. Additionally, Chipps and Wahl (2004) described metabolic compensation; a decrease in the standard metabolism of Western Mosquitofish Gambusia affinis feeding at low levels, that they hypothesized caused the overestimation of prey consumption by the bioenergetics model. This error is a result of modeling consumption dependent parameters, such as egestion, excretion and specific dynamic action, as constant proportions of energy consumed. Chipps and Wahl (2008) suggest the parameters used for egestion, excretion and specific dynamic action should be modeled as a function of ration-size.

Chipps and Wahl (2008) also discuss several cases of localized physiological adaptations. Two distinct groups of White Sturgeon Acipenser transmontanus in the Upper Columbia River, British Columbia, exhibited different mass-specific metabolic rates, temperature-dependent feeding rates, and seasonal growth patterns. These variations result in different age at maturity 
between the two groups (van Poorten and McAdam 2010). Because the seasonal thermal regime was similar between the sites, the authors attributed the discrepancy to variation in prey availability between the two locations occupied by different groups. In a 2002 paper by Munch and Conover, bioenergetics parameters were calculated for Atlantic Silverside Menidia menidia from localized populations in Nova Scotia, Canada and South Carolina, United States. Munch and Conover (2002) reported the average bioenergetics parameters of metabolism, specific dynamic action, consumption, and growth differed by approximately $28 \%$. The largest discrepancy was found to be with the largest variation found with mass specific consumption, varying by a difference of $167 \%$.

Metabolism- Metabolism describes the totality of energy consuming, manipulative and storage chemical reactions by organisms (Nelson 2016). In the late 18th century AntoineLaurent Lavoisier proclaimed that animal respiration is essentially the controlled combustion of foodstuffs. "Respiration is nothing but a slow combustion of carbon and hydrogen, similar in all respects to that of a lamp or a lighted candle, and from this point of view, animals which breathe are really combustible substances burning and consuming themselves" (Lavoisier and Laplace, 1783; translation from West, 2013). Metabolism is measured in one of two ways, the first being a direct measure known as direct calorimetry which aims to account for the waste heat produced by all reactions of metabolism within an organism by measuring the heat produced by an organism in a small, sealed chamber. By sealing the organism in the chamber and using a thermometer to measure the temperature increase, researchers could determine the joules, or energy units, needed to facilitate the temperature change. Direct calorimetry is often very difficult to measure even in endothermic, terrestrial, air breathing animals because of various heat loss of the chamber to the environment, accuracy of the measurements devices and stress 
levels induced to the study organism in such a small enclosure. Factor in the ability of water to absorb heat and their lack of internal thermoregulation, direct calorimetry is nearly impossible for aquatic poikilothermic organisms such as fish. Unlike direct calorimetry, indirect calorimetry calculates heat that living organisms produce by measuring either their production of carbon dioxide and nitrogen waste, or from their consumption of oxygen. It is important to note that direct calorimetry is tracking the inefficiencies of all metabolic transformations, creating heat, not just those consuming $\mathrm{O}_{2}$ or producing $\mathrm{CO}_{2}$. Direct calorimetry is considered the most rigorous measure of metabolic activity despite itself actually being an indirect measure of metabolic processes (Kaiyala and Ramsay, 2011).

While direct calorimetry has always used thermometers of one kind or another to measure the changes of temperature within the metabolic chamber, indirect calorimetry has utilized various methods. Early indirect calorimetry relied on manometric or gravimetric techniques to determine the production or consumption of the gases used, such as weighing the $\mathrm{CO}_{2}$ absorbed by alkaline hydroxides. It wasn't until the late $19^{\text {th }}$ century, with the advent of the Winkler titration method, that the methods needed to readily measure oxygen consumption of aquatic organisms in water became available without the need for sophisticated gas analysis equipment. The Winkler method converts manganese (II) hydroxide into manganese (III) hydroxide by quantitatively consuming dissolved oxygen. The manganese (III) hydroxide is then used to oxidize iodide ion, which can then be accurately measured by titration with thiosulphate (Winkler, 1888). The Winkler method was the gold standard until such time that polarographic $\mathrm{O}_{2}$ electrode was developed (Clark 1956). The Clark electrode, an electrochemical sensor, was made of a silver-silver chloride anode covered with an oxygen permeable membrane and a noble-metal cathode. When a voltage is applied the instrument could read out real time dissolved 
oxygen in solution. This allowed for real time monitoring of DO changes, increased measurement accuracy and contributed to wider uses such as flow through respirometers. The downfall of these probes was they consumed oxygen themselves, measures varied greatly with pressure changes, and they were easily susceptible to membrane stretching and clogging with biological material. The most contemporary device for measuring $\mathrm{O}_{2}$ in solution is the fluorescent optical oxygen sensors, or optodes (Demas et al. 1999). Oxygen optodes are based on the principle of luminescence quenching by oxygen, consume no oxygen when used, and allow for faster response rates on measures.

While looking at metabolic measures in fish there are four main types that can be measured, and each has its own time and place to be used. Each of these metabolic measures occur in a metabolic chamber often referred to as a respirometer. Basal metabolic rate (BMR) is the absolute minimum an individual will respire to maintain the subsistence of an organism. BMR constitutes things such as the base organ function doing no work, while excluding things such as food digestion, circulation, or movements. BMR is viewed as impossible to measure for a whole organism, because the circulatory and respiratory functions required to maintain an animal alive involve some expenditure of energy above BMR (Krogh 1914). Standard metabolic rate (SMR) takes into consideration the need for more than just subsistence of an organism. SMR is considered to be the true minimum metabolic rate of an organism, taking into account things such as organ functions such as respiration, circulation and osmoregulation. Small movements are not permitted to achieve these results and usually involved immobilizing the organism in some fashion prior to measurements being taken. By immobilizing the individual, only the background, involuntary metabolic rates are being measured (Chabot et al 2016). Routine metabolic rate (RMR) occurs when individuals are permitted minor activity within the 
respirometer, such as fin movements to maintain position in the respirometer or minor swimming. There is no way to quantify movement so RMR may vary from near BMR to maximum metabolic rate (MMR), assuring the need to monitor individuals for excessive movement. The final measure of metabolic rates in fishes is the MMR. MMR is defined as the maximum rate of oxygen consumption that a fish can achieve at a given temperature under any ecologically relevant circumstance (Norin and Clark 2016). MMR measurements are taken soon after exhaustive exercise and can be achieved in either a swim-tunnel respirometer where a fish is made to swim against a current to exhaustion (Soofiani and Priede 1985) or by chasing and prodding a fish until it no longer responds to stimulation (Reidy et al. 1995).

\section{Introduction}

An understanding of changes in climatic trends is essential to the management of riverscapes. Global climate change can modify habitable areas of aquatic ecosystems as a result of increasing water temperatures, and therefore geographical distribution of ectotherms (Somero 2010). Mean air temperatures near the surface are expected to rise $3.5-4.2^{\circ} \mathrm{C}$ over the next 50 years (Bernstein et al. 2008). If this trend in air temperatures closely reflects water temperatures as suggested by Meisner (1990), Stefan and Preud'homme (1993), and Pilgrim et. al. (1998), cold water salmonid species could have a $20 \%$ decrease of abundance (Casselman 2002) as a result of increased metabolic processes and reduced growth. Due to their environment, Brook Trout (Salvelinus fontinalis) are easily susceptible to climate change because of warming waters. As water temperature increases, the metabolic rate of ectotherms increases until a maximum temperature, $20.2^{\circ} \mathrm{C}$ for Brook Trout (Hartman and Cox 2008), is exceeded. As temperature continues to increase beyond $20.2^{\circ} \mathrm{C}$, performance drops off sharply and metabolic rates demand 
more energy than can be eaten resulting in a net loss of energy (Hartman and Cox 2008). While Brook Trout can withstand quick spikes in temperature up to $28.7^{\circ} \mathrm{C}$ (Carline and Machung 2001), a realistic sustainable short-term temperature is $25^{\circ} \mathrm{C}$ (Beitinger and Bennett 2000). Without the ability to migrate to higher latitudes or cooler riverine systems Brook Trout will be forced to adapt to these changing climates or die off.

Adaptation of Brook Trout to warming water temperatures can occur at both the individual level and the population level (Meier et al. 2014). At the individual level, seasonal acclimation to temperatures allows for a greater range of thermal tolerance (Jobling 1995). Population level adaptation is a result of natural selection, selecting against the lesser tolerant individuals who cannot thrive and reproduce under the increased temperatures. These thermal tolerances have also been shown to vary between population origins (Stitt et al. 2014), suggesting that selective pressures have allowed past individual level characteristics to be found within the whole population of a given area. Since high elevation headwater streams are fairly stable in their thermal patterns, with low mean temperatures, there may not be a need for variation of thermally tolerant individuals. As a result of a stable temperature regimes, individual variation of thermal tolerances might not be present in a headwater population. If this is the case, those who would carry the genes to thrive in warmer waters will not be present and would be unable to exploit conditions in which they would be favored, resulting in a bottleneck of population adaptations to a changing climate from individual variations.

In cool water systems, temperature has the greatest effect on the growth of an individual Brook Trout (Hartman and Cox 2008). As water temperatures increase metabolic rates increase, requiring more energy to maintain standard metabolic procedures (Hartman and Cox 2008). Dissolved oxygen becomes less available for aerobic metabolic processes at elevated 
temperatures resulting in less energy available for assimilation of body mass, or growth. Some individuals have faster metabolism than others (Oleksiak et. al 2005). Current fish bioenergetics models are based on the average of fish sampled to make models cleaner and ignore the variability of individuals (Brandt and Hartman 1993, Hartman and Cox 2008). This leads to a disconnect between the potential adaptation of individual populations through individual variation compared to the mean population in response to increased headwater stream temperatures. This difference in response to rising temperatures can be compounded when food availability influences energy conversion efficiency. It is suggested that fish of the same species in the same drainage can vary in energy conversion efficiency, which is thought to be a response of different levels of energy being available (Morinville and Rasmussen 2003). As a result of these varying conversion efficiencies even within a stream, the source population of fish can influence the bioenergetics models. Convenience drives many models today to use hatchery strains of fish, often times many generations removed from the wild counterparts. Using the hatchery strains that have been selectively breed for optimal, fast growth in the rearing facilities can lead to a disconnect between what is a perceived reality and that of what is really happening in the wild.

Understanding how much energy is used by a fish to survive is crucial to understanding how much energy in needed to promote growth of an individual. Unlike humans that have determinant growth potential meaning we hit a "full-sized" frame, fish can keep growing larger and larger due to indeterminate growth. This indeterminate growth can only take place after routine metabolic costs are met. Metabolism experiments using routine metabolic rate (RMR) are used to determine how much energy a fish uses in normal functional operation of the individual, i.e. just sustaining life for itself by circulation, osmoregulation, spontaneous 
swimming, and routine activity (Barbieri et al. 2002). To determine the RMR, a fish is placed into a closed vessel and allowed to respire for a period of time. Total consumption of oxygen $\left(\mathrm{MO}_{2}\right)$, defined as: oxygen initial -oxygen end, within the vessel is recorded. The measured consumption of oxygen can then be converted to energy consumed by the individual by use of calorimetry (Nelson 2016). Energy equivalents of oxygen consumption states that for every mg1 of oxygen consumed, 3.38 - 3.42 calories (14141.92-14309.28 joules) of energy are used (Elliott and Davison 1975). Knowing how much energy must be consumed for day to day operations of the fish helps bioenergetics models simulate how much more energy than the RMR must be consumed to account for the growth of an individual.

Consumption experiments are designed to allow researchers to determine the growth an individual can achieve over a short period of time. These are usually carried out at differing temperatures (Elliot 1976, Hartman and Cox 2008, Mayfield and Cech 2004) on a known input of energy content (joules of energy). To obtain the growth an average fish can achieve per energy consumed experimental fish are subject to a quantifiable feeding regiment for the duration of the experiment. The feeding regiments usually consist of one of two ration sizes: satiation, or approximately half-satiation rations (Hartman 2017, Kitchell et al. 1977). The satiation feeding regiment is often referred to as the growth at consumption maximum (c-max). Food that is offered typically consists of a readily available food with known energy content that is easily eaten and digested by the fish. Meal worms Tenebrio molitor are typically chosen as the food source due to the ease of keeping them and the availability through bait wholesalers (Whitledge et al. 2006, Whitledge et al. 1998) bait shops and convenience stores. Fish are fed on a schedule and consumption recorded. Fish mass is recorded before and after the trials to 
determine growth of the fish. Resulting growth is then analyzed to express the conversion efficiency of the fish using the equation $\frac{\operatorname{Growth}(g)^{d a y}}{\operatorname{Consumed}(g)^{d a y}}$.

To understand the potential of generational adaptation and species survival, growth and metabolism experiments can shed light into the resiliency of Brook Trout populations to the temperature effects of climate change. By looking at four populations within the state of West Virginia, we can hope to gain knowledge of how thermal variations in a population's life history may influence the genetic adaptation to cope in a warming climate. Armed with this information, we can understand the tolerances of populations to survive climate change. This will help fisheries managers to identify the more sensitive streams and populations to develop strategies to maintain populations in the face of climate change. To look at how temperature changes influence the source populations growth and metabolism, we conducted two separate experiments, growth at maximum consumption (C-max) and routine metabolic rate, concurrently on four source populations of Brook Trout from West Virginia's Central Appalachian Mountains. 


\section{References}

Bajer, P. G., G. W. Whitledge, and R. S. Hayward. 2004. Widespread consumption-dependent systematic error in fish bioenergetics model and its implications. Canadian Journal of Fisheries and Aquatic Sciences 61:2158-2167.

Barbieri, E., I.R. Oliveira, and P. Serralheiro. 2002, The use of metabolism to evaluate the toxicity of dodecy benzen sodium sulfonate on the Mugil platanus. Journal of Experimental Marine Biology and Ecology 277: 109-127.

Beitinger, T.L. and W.A. Bennett. 2000. Quantification of the role of acclimation temperature in temperature tolerance of fishes. Environmental. Biology of Fishes. 58(3):277-288.

Bernstein, L., P. Bosch, O. Canziani, Z. Chen, R. Christ, and K. Riahi. 2008. IPCC, 2007: Climate Change 2007. Synthesis Report.

Brandt, S. B., and K.J. Hartman. 1993. Innovative approaches with bioenergetics models: future applications to fish ecology and management. Transactions of the American Fisheries Society, 122(5), 731-735.

Carline, R.F. and J. F. Machung. 2001. Critical Thermal Maxima of Wild and Domestic Strains of Trout. Transactions of the American Fisheries Society. 130:6.

Casselman, J.M. 2002. Effects of temperature, global extremes, and climate change on year-class production of warmwater, coolwater, and coldwater fishes in the Great Lakes Basin. American Fisheries Society, Symposium 32:39-60. Bethesda, Maryland

Chabot, D., J.F. Steffensen and A.P. Farrell. 2016. The determination of standard metabolic rate in fishes. Journal of Fish Biology 88(1):81-121.

Chipps, S. R., and D. H. Wahl. 2004. Development and evaluation of a Western Mosquitofish bioenergetics model. Transactions of the American Fisheries Society 133:1150-1162.

Chipps, S. R., and D. H. Wahl. 2008. Bioenergetics modeling in the 21st century: reviewing new insights and revisiting old constraints. Transactions of the American Fisheries Society 137:298-313.

Clark, L. C. Jr. 1956. Monitor and control of blood and tissue O2 tensions. Transactions of the American Society for Artificial Internal Organs 2:41-48.

Deslauriers, D., S. R. Chipps, J. E. Breck, J. A. Rice and C. P. Madenjian. 2017 Fish Bioenergetics 4.0: An R-Based Modeling Application. Fisheries 42(11):586-596.

Demas, J. N., B.A. Degraff and P.B. Coleman. 1999. Oxygen sensors based on luminescence quenching. Analytical Chemistry 71:793-800. 
Elliott, J. M., and W. Davison. 1975. Energy equivalents of oxygen consumption in animal energetics. Oecologia 19(3):195-201.

Elliott, J. M..1976. The energetics of feeding, metabolism and growth of brown trout (Salmo trutta) in relation to body weight, water temperature and ration size. The Journal of Animal Ecology 923-948.

Hanson, P. C., T. B. Johsnon, D. E., Schindler, and J. F. Kitchell. 1997. Fish Bioenergetics 3.0. University of Wisconsin. Sea Grant Institute, Madison, Wisconsin.

Hartman, K. J., and M. K. Cox. 2008. Refinement and Testing of a Brook Trout Bioenergetics Model. Transactions of the American Fisheries Society 137(1):357-363.

Hartman, K. J., and J. A. Sweka. 2003. Development of a bioenergetics model for Appalachian brook trout. Proceedings of the Annual Conference Southeastern Association of Fish and Wildlife Agencies 55(2001):38-51.

Hartman, K. J. 2017. Bioenergetics of Brown Bullhead in a Changing Climate. Transactions of the American Fisheries Society 146(4), 634-644.

Hewett, S. J., and B. L. Johnson. 1987. A generalized bioenergetics model of fish growth for microcomputers. University of Wisconsin, Sea Grant Institute, Technical Report WISSG87-245, Madison.

Hewett, S. J., and B. L. Johnson. 1992. Fish bioenergetics model 2. University of Wisconsin, Sea Grant Institute, Technical Report WIS-SG-92_250, Madison.

Jobling, M. 1995. Environmental biology of fishes. Chapman and Hall.

Kitchell, J. F., D. J. Stewart, and D. Weininger. 1977. Applications of a bioenergetics model to yellow perch (Perca flavescens) and walleye (Stizostedion vitreum vitreum). Journal of the Fisheries Board of Canada 34(10):1922-1935.

Kaiyala, K. J. and D. S. Ramsay. 2011. Direct animal calorimetry, the underused gold standard for quantifying the fire of life. Comparative Biochemistry and Physiology 158:252-264.

Krogh, A. 1914. The quantitative relation between temperature and standard metabolism in animals. Internationale Zeitschrift für Physikalisch-Chemische Biologie 1:491-508.

Lavoisier, A. L. and P.S. Laplace. 1783. Mémoire sur la chaleur 1783. In Oeuvres de Lavoisier 1862-1893, Vol. 2, pp. 283-333. Paris: Imprimerie Impériale.

Madenjian, C. P., and D. V. O'Connor. 1999. Laboratory evaluation of lake trout bioenergetics model. Transactions of the American Fisheries Society 128:802-814 
Mayfield, R. B., and J. J. Cech Jr. 2004. Temperature effects on green sturgeon bioenergetics. Transactions of the American Fisheries Society 133(4):961-970.

Meisner, J. D. 1990. Effect of climatic warming on the southern margin of the native range of Brook Trout, Salvelinus fontinalis. Canadian Journal of Fisheries and Aquatic Sciences 47:1065-1070.

Meier, K., M.M. Hansen, E. Normandeau, K.D. Mensberg, J. Frydenberg, P.F. Larsen, and L. Bernatchez. 2014. Local Adaptation at the Transcriptome Level in Brown Trout: Evidence from Early Life History Temperature Genomic Reaction Norms. Plos ONE $9(1): 1-13$

Morinville, G. R., and J.B. Rasmussen. 2003. Early juvenile bioenergetic differences between anadromous and resident Brook Trout (Salvelinus fontinalis). Canadian Journal of Fisheries and Aquatic Sciences 60(4):401-410.

Munch, S. B., and D.O Conover. 2002. Accounting for local physiological adaptation in bioenergetic models: testing hypotheses for growth rate evolution by virtual transplant experiments. Canadian Journal of Fisheries and Aquatic Sciences 59(2):393-403.

Nelson, J. A. 2016 Oxygen consumption rate v. rate of energy utilization of fishes: a comparison and brief history of the two measurements. Journal of Fish Biology 88:10-25

Ney, J. J. 1993. Bioenergetics modeling today: growing pains on the cutting edge. Transactions of the American Fisheries Society 122:736-748.

Norin, T. and T.D. Clark. 2016. Measurement and relevance of maximum metabolic rate in fishes. Journal of Fish Biology 88:122-151

Oleksiak, M. F., J.L. Roach, and D.L. Crawford. 2005 Natural variation in cardiac metabolism and gene expression in Fundulus heteroclitus. Nature genetics. 37(1):67.

Pilgrim, J. M., X. Fang, and H. G. Stefan. 1998. Stream temperature correlations with air temperatures in Minnesota: implications for climate warming. Journal of the American Water Resources Association 34:1109-1121.

Reidy, S. P., J.A. Nelson, Y. Tang, and S.R. Kerr. 1995. Post-exercise metabolic rate in Atlantic cod and its dependence upon the method of exhaustion. Journal of Fish Biology 47:377386.

Somero G.N. 2010. The physiology of climate change: how potentials for acclimatization and genetic adaptation will determine "winners" and "losers." Journal of Experimental Biology 213:912-920.

Soofiani, N. M., and I.G. Priede. 1985. Aerobic metabolic scope and swimming performance in juvenile cod, Gadus morhua L. Journal of Fish Biology 26:127-138. 
Stefan, H. G., and E. B. Preud'homme. 1993. Stream temperature estimation from air temperature. Water Resources Bulletin 29:27-45.

Stewart, D. J., D. Weininger, D. V. Rottiers, and T. A. Edsall. 1983. An energetics model for lake trout Salvelinus namaycush: application to the Lake Michigan population. Canadian Journal of Fisheries and Aquatic Sciences 40:681-698.

Stitt, B. C., G. Burness, K.A. Burgomaster, S Currie, J.L. McDermid, and C.C. Wilson. 2014. Intraspecific Variation in Thermal Tolerance and Acclimation Capacity in Brook Trout (Salvelinus fontinalis): Physiological Implications for Climate Change. Physiological and Biochemical Zoology 87(1):15-29.

Sweka, J. A., M.K. Cox. and K.J. Hartman. 2004. Gastric evacuation rates of brook trout. Transactions of the American Fisheries Society 133(1):204-210.

Thornton, K. W., and A. S. Lessem. 1978. A temperature algorithm for modifying biological rates. Transactions of the American Fisheries Society 107:284-287.

West, J. B. 2013. The collaboration of Antoine and Marie-Anne Lavoisier and the first measurements of human oxygen consumption. American Journal of Physiology. Lung Cellular and Molecular Physiology 305:775-785.

Whitledge, G. W., P. G. Bajer, and R. S. Hayward. 2006. Improvement of bioenergetics model predictions for fish undergoing compensatory growth. Transactions of the American Fisheries Society 135(1):49-54.

Whitledge, G. W., R. S. Hayward, D. B. Noltie, and N. Wang. 1998. Testing bioenergetics models under feeding regimes that elicit compensatory growth. Transactions of the American Fisheries Society 127(5):740-746.

Winberg, G. G. 1956. Rate of metabolism and food requirements of fishes. Belorussian University, Minsk. Translated from Russian, 1960: Fisheries Research Board of Canada Translation Series 194, Ottawa.

Winkler, L. 1888. Die Bestimmung des in Wasser Gelösten Sauerstoffes. Berichte der Deutschen Chemischen Gesellschaft 21:2843-2855.

van Poorten, B. T., and S. O. McAdam. 2010. Estimating differences in growth and metabolism in two spatially segregated groups of Columbia River white sturgeon using a field-based bioenergetics model. The Open Fish Science Journal 3:132-141. 


\title{
Chapter 2- Thermal Performance of Brook Trout in Consumption, Conversion Efficiency and Growth of four Central Appalachian Streams in West Virginia
}

\author{
Abstract \\ Growth of an individual is the end result of many physiological processes stemming from \\ the consumption of food items. These processes can be influenced by many variables including \\ temperature. Current bioenergetics models for Brook Trout Salvelinus fontinalis suggest growth \\ increases with temperature until an inflection point of $20.2^{\circ} \mathrm{C}$. With a warming climate, and \\ water temperatures expected to rise, the ability of a population to adapt to the warming \\ environment is crucial to the survival of the species. For this study we sought to see how spatial \\ variation would influence the specific consumption, conversion efficiency, and specific growth \\ at consumption maximum (C-Max) of four source populations of Brook Trout in West Virginia's \\ Central Appalachian Mountains. To accomplish this, we subjected the individual fish to \\ identical experiments regimes of 12 days of maximum consumption (C-Max) at three \\ temperatures $\left(12,16\right.$, and $\left.20^{\circ} \mathrm{C}\right)$. Parameters of specific consumption, conversion efficiency and \\ specific daily growth were calculated. The effects of source population and temperature \\ differences were determined using a general linear model and significant differences in model \\ coefficients $(\mathrm{p} \leq 0.05)$. By the end of the study we found that the low elevation stream, which \\ also experiences higher summer mean temperatures, significantly converted prey items energy \\ more efficiently and in turn grew significantly faster at elevated water temperatures. These \\ findings give hope that a population of cold-water fish can survive climate change if \\ temperatures rise at a slow enough pace to allow for adaptation.
}




\section{Introduction}

Brook Trout Salvelinus fontinalis are an important species in West Virginia, not only as the state fish, but also due to the high socioeconomic value the angling industry brings to rural parts of the state. Brook Trout have endured reductions in numbers and distribution in the central Appalachian Mountains. Factors such as high harvest rates, habitat degradation, reductions in water quality, and nonnative salmonid introductions have been reported as responsible for these declines (Larson and Moore 1985; Flebbe 1994; Marschall and Crowder 1996; Galbreath et al. 2001). The most remarkable disruption in the central Appalachian region is the negative effect of acid precipitation (Wigington et al. 1996). West Virginia generally has a sandstone dominated geology resulting in an estimated $25 \%$ of all streams being impaired because of a high rate of acid deposition and the sandstones poor buffering capacity (Sharpe et al. 1987; Welsh and Perry 1997; Clayton et al. 1998).

Brook Trout are considered an indicator species because of their intolerance to anthropogenic impacts and habitat degradation. Life history strategies and basic biological demands have become critical factors for biologists to measure in the light of habitat changes. Further, because of their reliance on cold water temperatures to fulfill their life history, Brook Trout may be especially vulnerable to climate change (Eaton and Scheller 1996). Mean air temperatures near the surface are expected to rise $3.5-4.2^{\circ} \mathrm{C}$ over the next 50 years (Bernstein et al. 2008). As air temperatures continue to rise as a result of global climate change, the same can be expected for water temperatures within the streams holding Brook Trout in central Appalachia as suggested by Meisner (1990), Stefan and Preud'homme (1993), and Pilgrim et. al. (1998). This could lead to cold water salmonid species such as Brook Trout having a $20 \%$ decrease in abundance (Casselman 2002) as a result of increased metabolic processes and reduced growth in 
a warming environment. While Brook Trout can withstand quick spikes in temperature up to $28.7^{\circ} \mathrm{C}$ (Carline and Machung 2001), a realistic sustainable short-term temperature is $25^{\circ} \mathrm{C}$ (Beitinger and Bennett 2000). As water temperatures rise, so does the metabolic rate of the individual fish. Metabolic costs are the largest uncontrollable energy loss a fish will endure. Current bioenergetics models suggest that the metabolic rate of Brook Trout continues to increase until the inflection point of $20.2 \mathrm{C}$ at which point the rate quickly drops (Hartman and Cox 2008). Unless the fish experiencing warm temperature extremes $\left(<20^{\circ} \mathrm{C}\right)$ can find thermal refugia, the species will likely perish.

Bioenergetics models are useful tools for fisheries management and research because they can predict consumption, growth, and production of fish in response to changes in factors such as water temperature, diet, and fish size or growth (Ney 1993, Chipps and Wahl 2008). Bioenergetics models have been developed for over 70 species of fish (Hartman and Kitchell 2008), and they can offer a low cost, simplified approach for addressing specific management questions and evaluating options. A fully parameterized bioenergetics model for Brook Trout currently exists (Hartman and Cox 2008) and has been beneficial to estimating energy flows in the systems and addressing many issues facing this species.

Though there are many advantages to utilizing the published bioenergetics model for Brook Trout (Hartman and Cox 2008), it comes with limitations. The current model was developed using the average fish from the West Virginia Division of Natural Resources trout hatchery program. While many other species models rely on hatchery strains (Madenjian and O’Connor 1999, Madenjian et al. 2000, Tyler and Bolduc 2008), hatchery fish may not be an actual representation of wild fishes (McDermid et al 2010). These fish are many generations removed from wild fish and have been artificially selected for fast growth with optimal 
conversion efficiencies while maintaining a physical appearance considered desirable by the hatchery staff. While having a validated bioenergetics model is important, when using a model based on non-representative individuals it begs to question whether it is appropriate to use. Researchers understand using parameters from other species could produce results that are unreliable or biased, particularly when the behavior or physiology of the species varies (Ney 1993, Trudel and Welch 2005, Chipps and Wahl 2008, Keskinen et al. 2008) such is the case in wild versus hatchery fish. Models based on hatchery fish do not include any form of spatial variation. Since Brook Trout exhibit differences in growth and metabolic rate in higher latitudes than those found in lower latitudes (McDermid et al. 2012), the same might be assumed for varying elevations or thermal regimes a stream undergoes.

For this study, we set out to determine if there was a discernable difference in the consumption, conversion efficiencies and specific growth between populations of Brook Trout in the Central Appalachian Mountains of West Virginia in the face of a warming climate. By detecting a difference, we hope to allow for a better understanding of the spatial variation of Brook Trout consumption, growth and conversion efficiencies, as well as consideration to account for such variation.

\section{Methods}

Overall Experimental Design- This experiment was part of a larger project looking at both the maximum consumption rate (C-max) and routine metabolic rate (RMR) of the same individuals. Each set of RMR measurements were separated by a period of 3 weeks. Experiments were conducted at 3 temperatures starting at $20^{\circ} \mathrm{C}$, reducing to $16^{\circ} \mathrm{C}$ and $12^{\circ} \mathrm{C}$, respectively. Each temperature consisted of a fasting period, measurement for size before growth experiments, a 12-day growth period during which time fish were fed ad libitum (C-max), followed by fasting 
periods, end growth measurements (same used for metabolic calculations), metabolic measurements, and temperature adjustments also acting as a fasting period for the next temperature (Table 1). All temperature changes were from warmer to cooler to reduce stress on the organism and reduce acclimation time. Space limitations did not allow all fish to be run simultaneously, necessitating a second series of experiments at each temperature for both growth at C-max and RMR.

Study area- We selected four streams; three from the Ohio River drainage (North Fork Red Run, Panther Run and Poca Run) and one from the Potomac River drainage (Little Low Place) (Figures 1,2) as our source populations (Table 2). Little Low Place (LLP) and Poca Run are very close geographically, with only a few kilometers and the eastern continental divide separating them. Poca and LLP are both high elevation, high gradient, well connected streams in the Monongahela National Forest. North Fork Red Run is also located in the Monongahela National Forest and is a poorly connected, high gradient, high elevation stream. Panther Run is a moderately connected stream with a low slope and low elevation. Panther run is located on private property, with gated access limiting fishing pressure. Little Low Place, North Fork Red Run, and Poca Run all have open access and either a road or logging road paralleling the stream for angling access.

Fish Collection- In July of 2018, approximately 24 juvenile Brook Trout were collected from each of 4 source population streams, (Panther, North Fork Red Run, Poca, Little Low Place (LLP)) using backpack elecrofishers (Figure 1,2). Specimens were collected at a rate of no more than one individual per habitat unit (pool, riffle, run), typically small back water eddy areas behind a rock in a riffle to limit the potential for sibling captures and increase genetic diversity. Fish were transported back to the Aquatic Ecophysiology Laboratory of West Virginia 
University. Upon returning to the laboratory, fish were marked with elastomer in the jaw, the fleshy cheek near the operculum, and caudal peduncle to denote source stream (Adams et al. 2000).

Quarantine and acclimation- Once fish were marked by source stream, they were then placed into self-contained cold-water recirculating tank units in quarantine, where fish were fed every third day to satiation as a maintenance ration. While in quarantine fish were monitored for any signs of infection or illness. Fish were kept in stream source isolation for a period of 28 days. Following the 28-day quarantine period, fish were placed into a common tank and fed $\mathrm{ad}$ libitum a diet of fly larvae every third day as a maintenance ration for $>60$ days.

For each of the two series of thermal regimes, a subsample of 24 individuals were removed and placed into individual 37L aquariums. Aquariums had the sides painted black to avoid external stimuli from other fish. Aquariums were covered with hardware cloth and mesh screen to prevent escape of subject fish and prey items and housed within a larger $1.2 \times 2.4 \mathrm{~m}$ steel tank to act as a thermal buffer (Figure 3). Water was controlled to each tank by ball valves. Each tank was equipped with an air stone. The experimental set up was part of a larger 8,000liter recirculating system equipped with physical and biological filters, UV sterilizer and commercial chilling unit allowing for temperature control of $+/-0.2^{\circ} \mathrm{C}$. Water quality was measured daily, and water changes made as necessary to maintain acceptable safe water quality parameters $\left(\mathrm{pH}, \mathrm{NH}_{3}-\mathrm{N}, \mathrm{NO}_{3}-\mathrm{N}\right)$. After being placed into the aquariums, fish were acclimated to the isolation of an individual aquarium for 30 days, again being fed to satiation every third day while adjusting to the individual aquariums.

Growth at C-Max- Following the individual acclimation period to the aquariums, fish were fasted for one week, anesthetized in a buffered tricaine methanesulfonate (MS-222, 
Western Chemical Inc, Ferndale, WA) solution of 1 g per 9 L of water, weighed for wet weight (WW) (nearest $0.1 \mathrm{~g}$ ), total length (TL), fork length (FL) and a modified standard length (SL). The modified SL used in this experiment was the point in which the caudal flesh transitioned from translucent to opaque, a measurement change used to reduce handling time. After measurement, fish were returned to the aquariums and allowed to recover for $24 \mathrm{~h}$.

At each of the three experimental temperatures $\left(20,16,12^{\circ} \mathrm{C}\right)$, fish were fed fly larvae (Diptera sp.) ad libitum daily for 12 consecutive days. Prior to feeding each day, larvae were batch weighed, and the average mass of prey was calculated. Prey was offered at a rate of 1.5 times the consumed count from the day prior and offered for $24 \mathrm{~h}$. Uneaten prey was recovered, counted and recorded the following day. Daily consumption was recorded as number of prey offered minus prey recovered multiplied by the average mass of the larvae offered. On the $13^{\text {th }}$ day, prey were removed, and the fish allowed to egest for 48-54 hours. Fish were again anesthetized and measured for WW, SL, TL, and FL. Growth was calculated as final weight minus initial weight. Total consumption was quantified as the total mass of larvae consumed. Specific consumption was calculated as the mass consumed divided by the starting mass of the individual. Daily specific consumption was calculated by dividing the specific consumption by the 12 days the experiment lasted. Specific growth was calculated by the growth of the individual fish divided by the average weight of the fish at a temperature from both the starting and ending wet weight. The resulting total growth was then divided by the 12 days of the experiment to represent the specific daily growth of an individual fish.

Statistical analysis- Consumption data were expressed as specific consumption (g consumed/g fish/ day) where the mass of the fish is the initial weight of the fish at the start of Cmax for a given temperature. Food conversion efficiency was expressed as g growth/ $\mathrm{g}$ 
consumed. Percent growth was calculated as $\frac{\operatorname{Growth}(g)}{\text { Average of Initial and Final Mass }(g)}$. Growth data were expressed as specific growth (percent growth/day). We utilized R 3.6.1 (R Core Team 2019) for all statistical analyses. The natural log of each parameter evaluated (specific consumption and growth) and the mass of the individuals was calculated and used for the analysis. For the conversion efficiency values which contained negative values, we use the natural $\log$ plus one $(\ln +1)$. Outliers were detected and removed using the Bonferroni outlier test. To test for differences between streams and temperatures an ANCOVA was ran for each of conversion efficiency, specific consumption and growth with stream population and temperature as covariates. A general linear model was ran to determine differences among streams and to determine if the effect of temperature differed among streams as indicated by significant differences in model coefficients $(\mathrm{p} \leq 0.05)$. The model form was form $\ln (Y)=$ Sream + Temperature $+\ln ($ Mass $)+$ Stream $*$ Temperature where Y equaled specific consumption, specific growth, or conversion efficiency. The residuals were then calculated for each model and a Shapiro- Wilk test then ran to test for normality. Differences in fish size were also tested for each of the three temperatures utilizing the ANOVA (fish mass stream population). A Tukey multiple comparison of means test was then run on each significant ANOVA model to determine where the differences occur and determine the extent of differences with $95 \%$ family-wise confidence levels.

\section{Results}

Our initial experimental design was to have 12 individuals from each stream population tested for routine metabolic rates from the original collection of 24 individuals per stream. However, due to mortality and losses beyond our control within the system we were unable to obtain this array. We were limited to a total of 47 fish from the four populations of Brook Trout 
that were tested for their specific daily consumption rates and conversion efficiencies (Panther $n=15$, LLP $n=13$, NF Red = 12, Poca n=7) (Table 3). These 47 Brook Trout ranged from 6.0$25.4 \mathrm{~g}$ and $72-121 \mathrm{~mm}$ in modified standard length at the start of the trials.

Specific Consumption- The general linear model for conversion efficiency (In(conversion efficiency $)=$ Stream + Temperature $+\ln ($ Mass $)+$ Stream $*$ Temperature $)$ revealed there was a significant effect of temperature on the conversion efficiency of an individual Brook Trout (Table 4). The model also indicated there was a significant stream by temperature interaction suggesting that the temperature had a different effect on conversion efficiency across streams. The coefficients from the global model indicated that Poca Run fish had a significantly higher intercept and a significantly lower slope than the other streams (Figure 4, Table 5). Our ShapiroWilks normality test indicated that the data were not normal (Figure 5).

Conversion efficiency- The general linear model for conversion efficiency (In(conversion efficiency $)=$ Stream + Temperature $+\ln ($ Mass $)+$ Stream $*$ Temperature $)$ revealed there was a significant effect of temperature on the conversion efficiency of an individual Brook Trout (Table 6). The ANCOVA also indicated there is a significant stream by temperature interaction suggesting that the temperature had a different effect on conversion efficiency across streams. Our coefficients from the global model indicated that Panther Run fish had a significantly higher slope than the other streams (Figure 6, Table 7). Our Shapiro- Wilks normality test indicated that our data were not normal (Figure 7).

Specific growth- The general linear model for specific growth $(\ln ($ specific growth $)=$ Stream + Temperature $+\ln ($ Mass $)+$ Stream $*$ Temperature $)$ revealed there was a significant effect of temperature on the specific growth of an individual Brook Trout (Table 8). The ANCOVA also indicated there was a significant stream by temperature interaction suggesting 
that the temperature has a different effect on conversion efficiency across streams. Our coefficients from the global model indicated that Panther Run fish had a significantly higher slope than the other streams (Figure 8, Table 9). Our Shapiro- Wilks normality test indicated that our data were not normal (Figure 9).

Size variation- All individual fish added mass during growth experiments at both 12 and 16-degrees. At 20 C, 4 individual fish lost mass (North Ford Red Run n=1, Poca n=1, Little Low Place $n=2$ ), while the rest exhibited increases in body mass to some extent over the 12-day growth experiments. Stream populations were found to have significant differences in initial size of the fish utilized in this experiment at $12(\mathrm{DF}=3, \mathrm{~F}=4.284, \mathrm{P}-\mathrm{V}$ alue $=0.01)$ and $16^{\circ} \mathrm{C}(\mathrm{DF}=3$, $\mathrm{F}=3.247, \mathrm{P}-\mathrm{Value}=0.0309$ ). At 20-degrees no significant difference occurred between stream populations (Figure 10). Tukey's HSD indicated that size differences occur at $12^{\circ} \mathrm{C}$ with Panther Run being larger than both Poca Run and Little Low Place fish (Figure 11). At $16^{\circ} \mathrm{C}$, Panther Run again appeared to be larger than Poca Run and Little Low Place fish (Figure 12).

\section{Discussion}

The results of this study indicate there are significant differences in the conversion efficiency, specific daily consumption, and specific daily growth between populations of Brook Trout. Poca Run individuals had a lower specific daily consumption slope coefficient while Panther Run individuals had a higher slope on the conversion efficiency coefficient. This increased conversion efficiency for Panther Run individuals related to higher growth rates as indicated by the higher slope coefficient for specific daily growth. As a result, Panther Run individuals were larger than the three other streams at the remaining temperatures $\left(12\right.$ and $\left.16^{\circ} \mathrm{C}\right)$. 
This size discrepancy could compound differences in streams if the smaller fish have a lower optimal temperature that increases as they grow which couldn't be accounted for in taking the natural log of the parameters and covariates. Despite the potential size biases, Panther Run fish maintained a higher slope indicating they were still able to grow efficiently at temperatures above what is considered the optimal range of Brook Trout. There may be several explanations as to why this is happening.

First of all, the stream temperatures, which roughly relate to elevation, maybe a factor. Historical temperature profiles on these three streams indicate Panther Run experiences an average of $2-4^{\circ} \mathrm{C}$ warmer summer mean stream temperature than Poca Run and Little Low Place (Figure 13). Based on the five-month period of July through November 2011, North Fork Red Run experiences similar annual temperature regimes as Poca Run and Little Low Place (Figure 14). This warmer temperature profile suggests that a population of Brook Trout is capable of thermal acclimation and adaptation to a warming climate as it relates to both conversion efficiency and specific consumption. McDermid et al. (2012) found Brook Trout from different hatchery populations exhibited variations in thermal performance. Brook Trout from southern hatchery origins had higher heat tolerances than those of more northern strain (McDermid et al 2012). Ours is the first study to document differences in C-max and conversion efficiency among wild populations of Brook Trout. While our four-study streams are of the same relative latitudinal degree, elevation is known to impact thermal regimes of water temperature (Pepin and Lundquist 2008).

While temperature profile of the streams is one possible explanation for this increased thermal performance of Panther Run fish, stream productivity may also play a role as well. Our four study streams lack a common dominant geological formation. The underlying bedrock 
formation can significantly influence the alkalinity of a stream. Streams found in a geology with a higher buffering capacity tend to be more productive. Almodóvar et al. (2006) looked at 10 streams containing Brown Trout Salmo trutta and found a significant positive correlation between production and alkalinity. Welsh and Perry (1997) also found a positive relationship between alkalinity and total species present in a given stream, with streams on the low end of alkalinity most likely being below the biological threshold of acid sensitive fish. Welsh and Perry (1997) looked at the same four bedrock types as present in our stream populations. Panther Run falls under the Pottsville bedrock type which is associated with the lowest $\mathrm{pH}$ and alkalinity. Since alkalinity is assumed lowest in Panther Run, we might infer that productivity is lowest as well based on Almodóvar et al. (2006). Being from a stream where productivity is lower, it is possible that the Panther Run individuals were predisposed to have a higher conversion efficiency.

Size differences were found to be significant after the initial 20-degree growth experiment as a result of Panther Run fish growing significantly better at $20^{\circ} \mathrm{C}$ than the other streams. We began the temperature sequence at 20-degrees to minimize the potential of mortality at the most stressful temperature since we wanted to get measures on individuals at all 3 temperatures. However, by performing better at $20^{\circ} \mathrm{C}$ than the other streams, fish from Panther Run were generally larger than the others at 16 and $12^{\circ} \mathrm{C}$. Thus, at 16 and 12-degrees we cannot rule out the fact that differences across streams were as a result of differences in size. Although specific rates (C-max and growth) would be expected to be higher in small fish than larger (Panther Run) fish (Hartman and Brandt 1995), differences in optimal temperature could differ between smaller and larger fish and this could also account for differences between streams at 12 and $16 \mathrm{C}^{\circ}$. Hartman and Brandt (1995) found that small Weakfish Cynoscion regalis had a 
smaller scope of growth than larger Weakfish. These size discrepancies could help explain our lack of normality in our data if there is a variation in RMR depending on size. Future experiments should either start at the lower temperatures and work to the warmer temperatures where differences were detected, or simply look at the warmer thermal tolerances to avoid any size inconsistencies. Despite the shortcomings of the experimental design, we were still able to determine that the lower elevation stream that experiences warmer summer water temperatures performed better at higher temperatures than the streams that don't experience these more extreme temperatures. This finding lends itself to support our hypothesis that the current Brook Trout bioenergetics model fails to encompass the full breadth of the population when looking at small size classes of Brook Trout from wild populations.

The variation of specific consumption, conversion efficiency and ultimately specific growth observed by individuals from within each population might suggest plasticity of a population. Having this plasticity may allow for some individuals to be better suited in warmer waters, while others for cooler water. These individuals could be ready to exploit the new conditions since they are genetically predisposed to help the population persist in warming waters (Schneider and Meyer 2017). While every effort was made to collect fish for this study before environmental pressures acted on the young of year in the wild, it is possible that the fish collected may have already been selective for or against by environmental pressures relating to water temperatures. We captured these fish and brought them back to our lab in early summer, hopefully limiting potential selective pressures as they relate to thermal tolerances.

In closing, our experiment only covered a small sampling of the native range of Brook Trout, even in the scale of the state of West Virginia. Despite the size bias in our sample at the cooler temperature trials and a less than ideal, uneven sample size, we still believe that these 
significant results should help researchers and managers when trying to account for energetic budgets of young Brook Trout. Consideration of the effect that latitudinal and elevational variation may have on a Brook Trout population's thermal acclimation and tolerances can allow for a better application of the published bioenergetics models. Lower elevations streams and those who may experience warmer seasonal waters tend to be less stressed and consume more prey and they can better convert the energy they consume. While variation within and between populations in specific consumption, conversion efficiency and specific growth rates may appear to complicate our results, in the larger picture such variation is good for the population and the species as a whole as these variations are the foundation of generational thermal adaptation. 


\section{References}

Adams, S.B., C.A. Frissell and B.E. Rieman. 2000. Movements of non-native Brook Trout in relation to stream channel slope. Transactions of the American Fisheries Society 129: 623-638.

Almodóvar, A., G.G. Nicola, and B. Elvira. 2006. Spatial variation in brown trout production: the role of environmental factors. Transactions of the American Fisheries Society 135(5):1348-1360.

Beitinger, T.L. and W.A. Bennett. 2000. Quantification of the role of acclimation temperature in temperature tolerance of fishes. Environmental. Biology of Fishes. 58(3):277-288.

Bernstein, L., P. Bosch, O. Canziani, Z. Chen, R. Christ, and K. Riahi. 2008. IPCC, 2007: Climate Change 2007. Synthesis Report.

Carline, R.F. and J. F. Machung. 2001. Critical Thermal Maxima of Wild and Domestic Strains of Trout. Transactions of the American Fisheries Society 130(6):1211-1216.

Casselman, J.M. 2002. Effects of temperature, global extremes, and climate change on year-class production of warmwater, coolwater, and coldwater fishes in the Great Lakes Basin. Pp. 39-59 in N.A. McGinn, ed. Fisheries in a changing climate. American Fisheries Society, Bethesda, MD.

Chipps, S. R., and D. H. Wahl. 2008. Bioenergetics modeling in the 21st century: reviewing new insights and revisiting old constraints. Transactions of the American Fisheries Society 137:298-313.

Clayton, J. L., E. S. Dannaway, R. Menendez, H. W. Rauch, J. J. Renton, S. M. Sherlock, and P. E. Zurbuch. 1998. Application of limestone to restore fish communities in acidified streams. North American Journal of Fisheries Management 18:347-360.

Eaton, J. G., and R.M. Scheller. 1996. Effects of climate warming on fish thermal habitat in streams of the United States. Limnology and oceanography 41(5):1109-1115.

Flebbe, P. A. 1994. A regional view of the margin: salmonid abundance and distribution in the southern Appalachian Mountains of North Carolina and Virginia. Transactions of the American Fisheries Society 123:657-667.

Galbreath, P. F., N. D. Adams, S. Z. Guffey, C. J. Moore, and J. L. West. 2001. Persistence of native southern Appalachian brook trout populations in the Pigeon River system, North Carolina. North American Journal of Fisheries Management 21:927-934.

Hartman, K. J., and S.B. Brandt. 1995. Comparative energetics and the development of bioenergetics models for sympatric estuarine piscivores. Canadian Journal of Fisheries and Aquatic Sciences 52(8):1647-1666.

Hartman, K. J., and M. K. Cox. 2008. Refinement and Testing of a Brook Trout Bioenergetics Model. Transactions of the American Fisheries Society 137(1):357-363. 
Hartman, K. J., and J.F. Kitchell. 2008. Bioenergetics modeling: progress since the 1992 symposium. Transactions of the American Fisheries Society 137(1):216-223.

Keskinen, T., J. Jääskel ̈ainen, T. J. Marjom äki, T. Matilainen, and J. Karjalainen. 2008. A bioenergetics model for Zander: construction, validation, and evaluation of uncertainty caused by multiple input parameters. Transactions of the American Fisheries Society 137:1741-1755.

Larson, G. L., and S. E. Moore. 1985. Encroachment of exotic rainbow trout into stream populations of native brook trout in the southern Appalachian Mountains. Transactions of the American Fisheries Society 114:195-203.

Madenjian, C. P., and D.V. O'Connor. 1999. Laboratory evaluation of a lake trout bioenergetics model. Transactions of the American Fisheries Society 128(5):802-814.

Madenjian, C. P., D.V. O'Connor and D.A. Nortrup. 2000. A new approach toward evaluation of fish bioenergetics models. Canadian Journal of Fisheries and Aquatic Sciences 57(5):1025-1032.

Marschall, E. A., and L. B. Crowder. 1996. Assessing population responses to multiple anthropogenic effects: a case study with brook trout. Ecological Applications 6(1):152167

McDermid, J. L., W.N. Sloan, C.C. Wilson, and B.J. Shuter. 2010. Early life history variation among hatchery-and wild-origin lake trout reared in a hatchery environment. Transactions of the American Fisheries Society 139(1): 21-28.

McDermid J.L., F.A. Fischer, M. Al-Shamlih, W.N. Sloan, N.E. Jone and C.C. Wilson. 2012. Variation in acute thermal tolerance within and among hatchery strains of brook trout. Transactions of the American Fisheries Society 141:1230-1235.

Meisner, J. D. 1990. Effect of climatic warming on the southern margin of the native range of Brook Trout, Salvelinus fontinalis. Canadian Journal of Fisheries and Aquatic Sciences 47:1065-1070.

Ney, J. J. 1993. Bioenergetics modeling today: growing pains on the cutting edge. Transactions of the American Fisheries Society 122:736-748.

Pepin, N. C., and J.D. Lundquist. 2008. Temperature trends at high elevations: patterns across the globe. Geophysical Research Letters 35(14).

Pilgrim, J. M., X. Fang, and H. G. Stefan. 1998. Stream temperature correlations with air temperatures in Minnesota: implications for climate warming. Journal of the American Water Resources Association 34:1109-1121.

R Core Team. 2019. R: A language and environment for statistical computing. R Foundation for Statistical Computing, Vienna, Austria. URL https://www.R-project.org/.

Schneider, R.F. and A. Meyer. 2017. How plasticity, genetic assimilation and cryptic genetic variation mat contribute to adaptive radiations. Molecular Ecology 26(1):330-350. 
Sharpe, W. E., V. G. Leibfried, W. G. Kimmel, and D. R. DeWalle. 1987. The relationship of water quality and fish occurrence to soils and geology in an area of high hydrogen and sulfate ion deposition. Water Resources Bulletin 13:619-631.

Stefan, H. G., and E. B. Preud'homme. 1993. Stream temperature estimation from air temperature. Water Resources Bulletin 29:27-45.

Trudel, M., and D. W. Welch. 2005. Modeling the oxygen consumption rates in Pacific Salmon and steelhead: model development. Transactions of the American Fisheries Society 134:1542-1561.

Tyler, J. A., and M.B. Bolduc. 2008. Individual variation in bioenergetic rates of young-of-year rainbow trout. Transactions of the American Fisheries Society 137(1):314-323.

Wigington, P. J., Jr., J. P. Baker, D. R. DeWalle, W. A. Kretser, P. S. Murdoch, H. A. Simonin, J. Van Sickle, M. K. McDowell, D. V. Peck, and W. R. Barchet. 1996. Episodic acidification of small streams in the northeast United States: episodic response project. Ecological Applications 6:374-388.

Welsh, S. A., and S. A. Perry. 1997. Acidification and fish occurrence in the upper Cheat River drainage, West Virginia. Journal of the American Water Resources Association 33(2):423-429. 
Figures and Tables

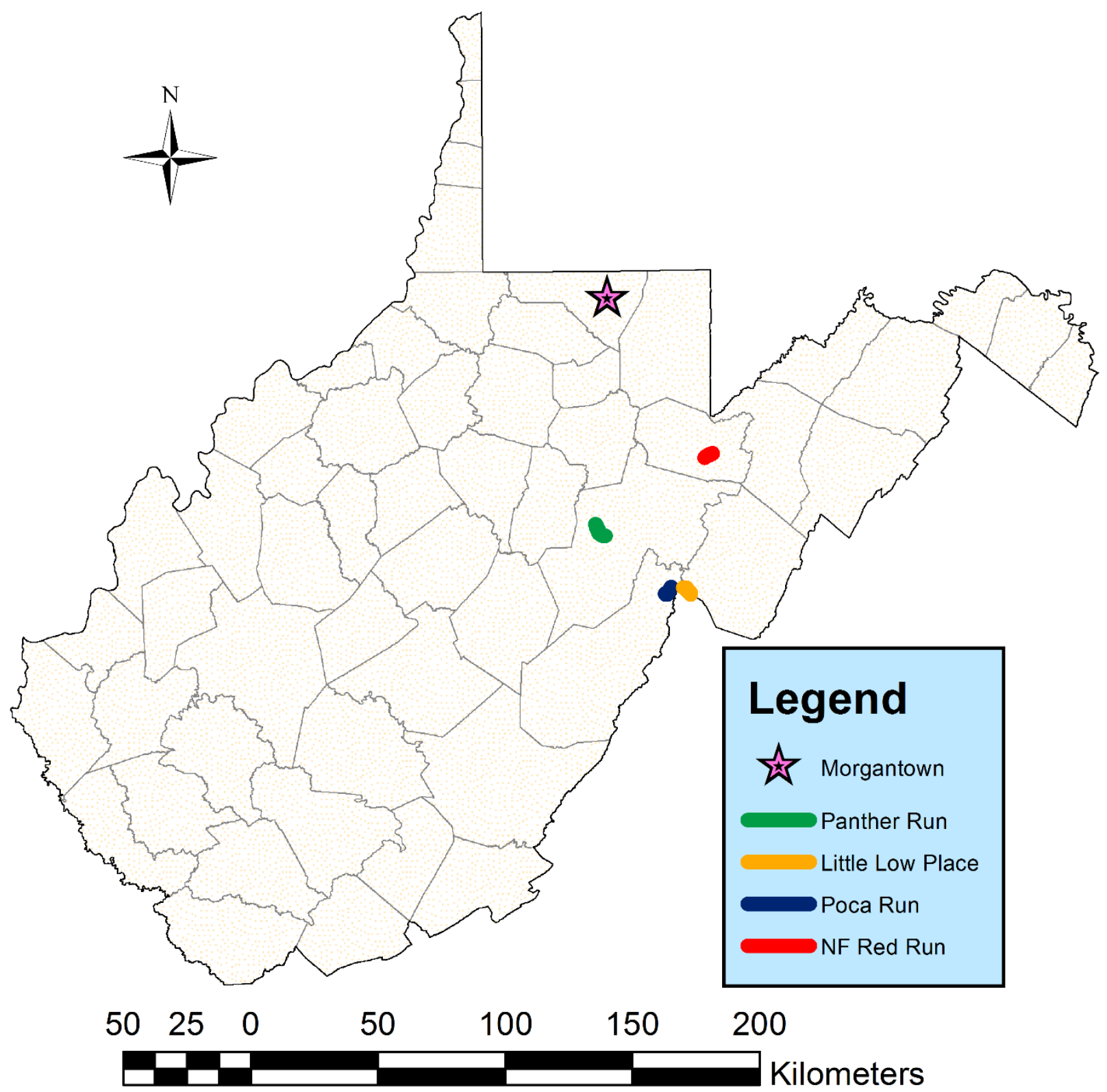

Figure 1. Statewide extent map of West Virginia showing the location of the four source streams used for the populations used in this experiment. 


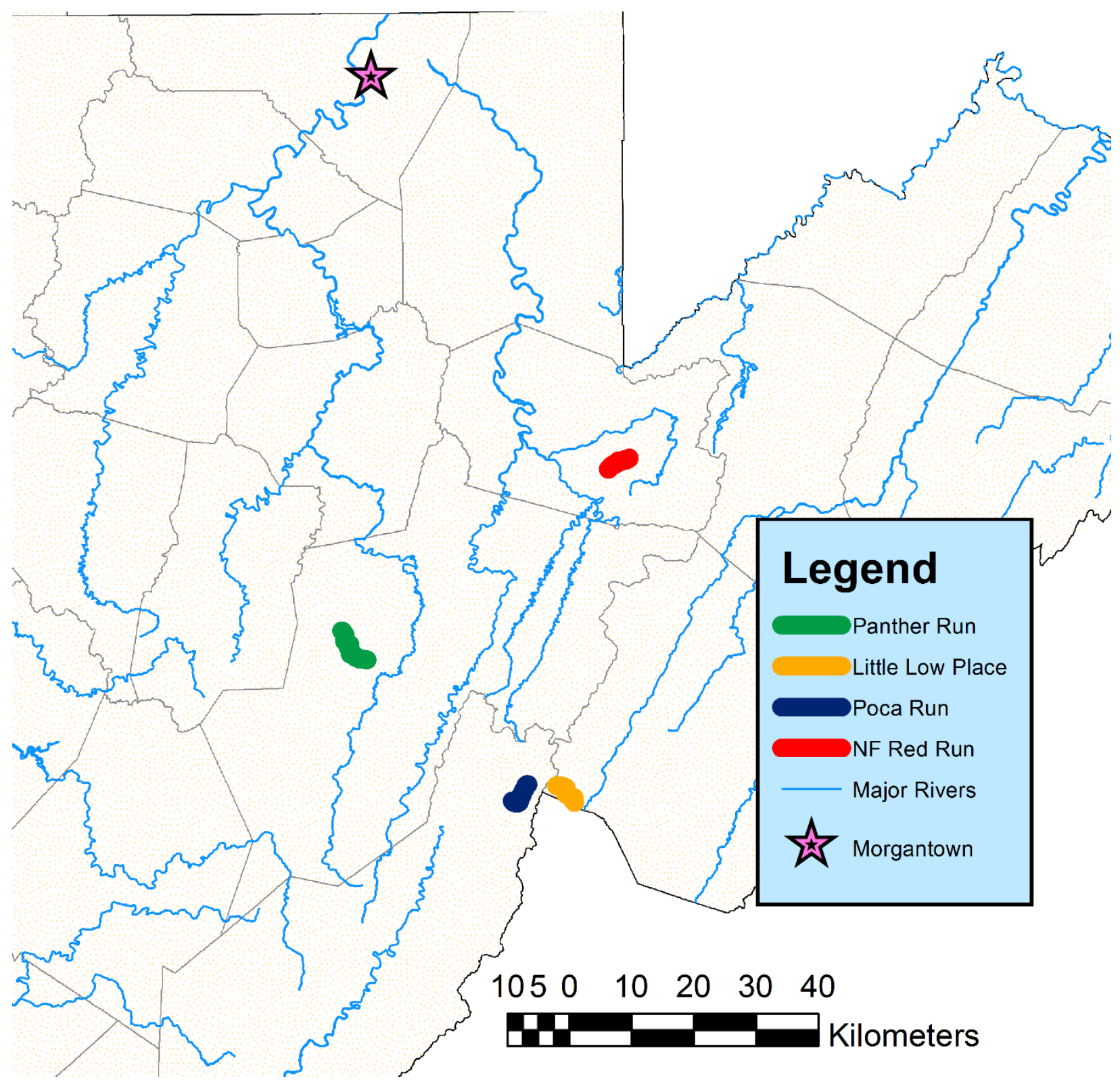

Figure 2. Regional extent map showing the location of the four source populations used in this experiment. 


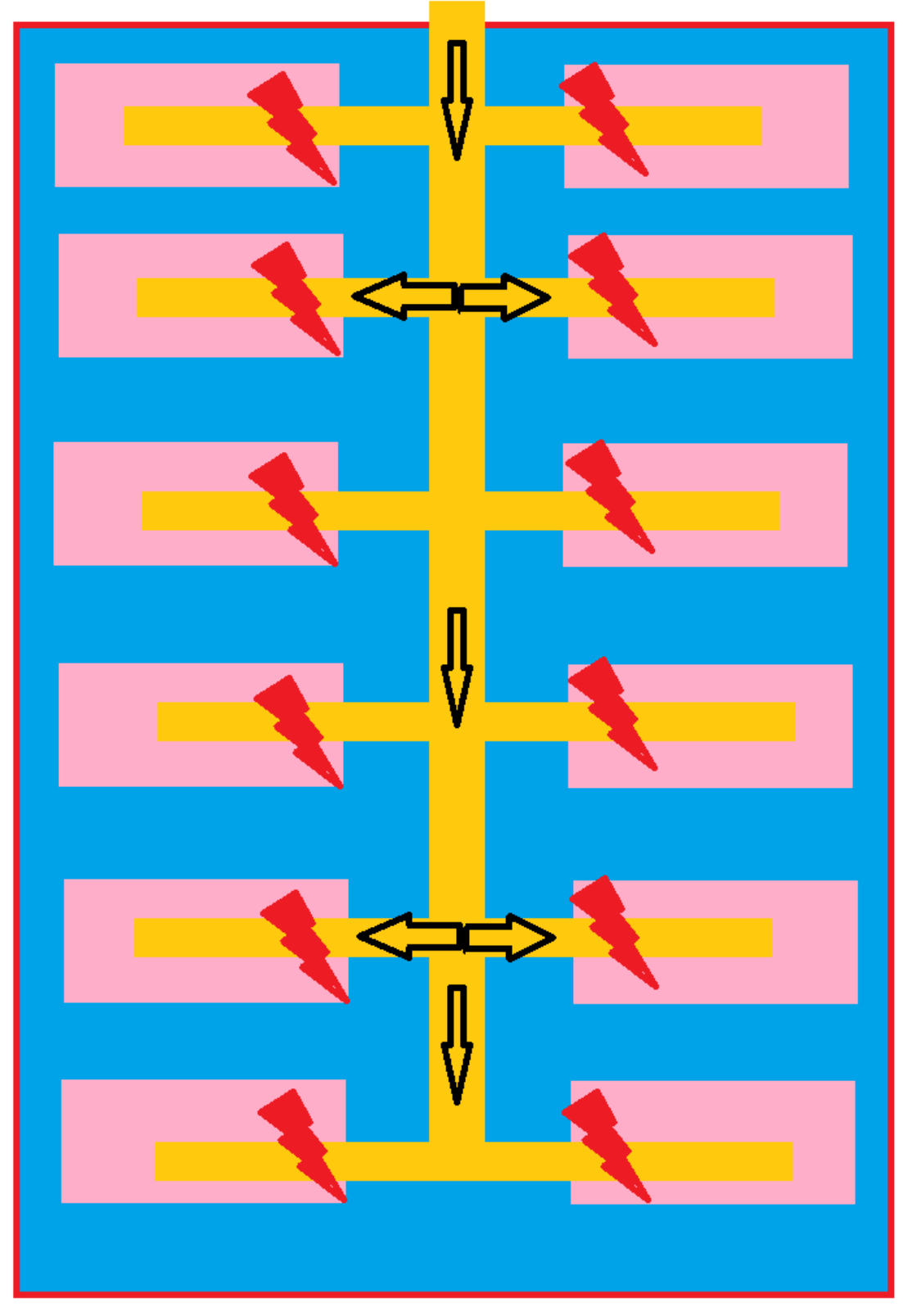

$1.2 \times 2.4 \mathrm{~m}$ steel tank

37.51 aquarium

PVC pipe providing water flow

Ball valve to control water flow rate

Figure 3. Graphical representation of the tank set up of the aquariums housed within the larger steel tanks used for the consumption experiments. Arrow indicate flow direction of water. 

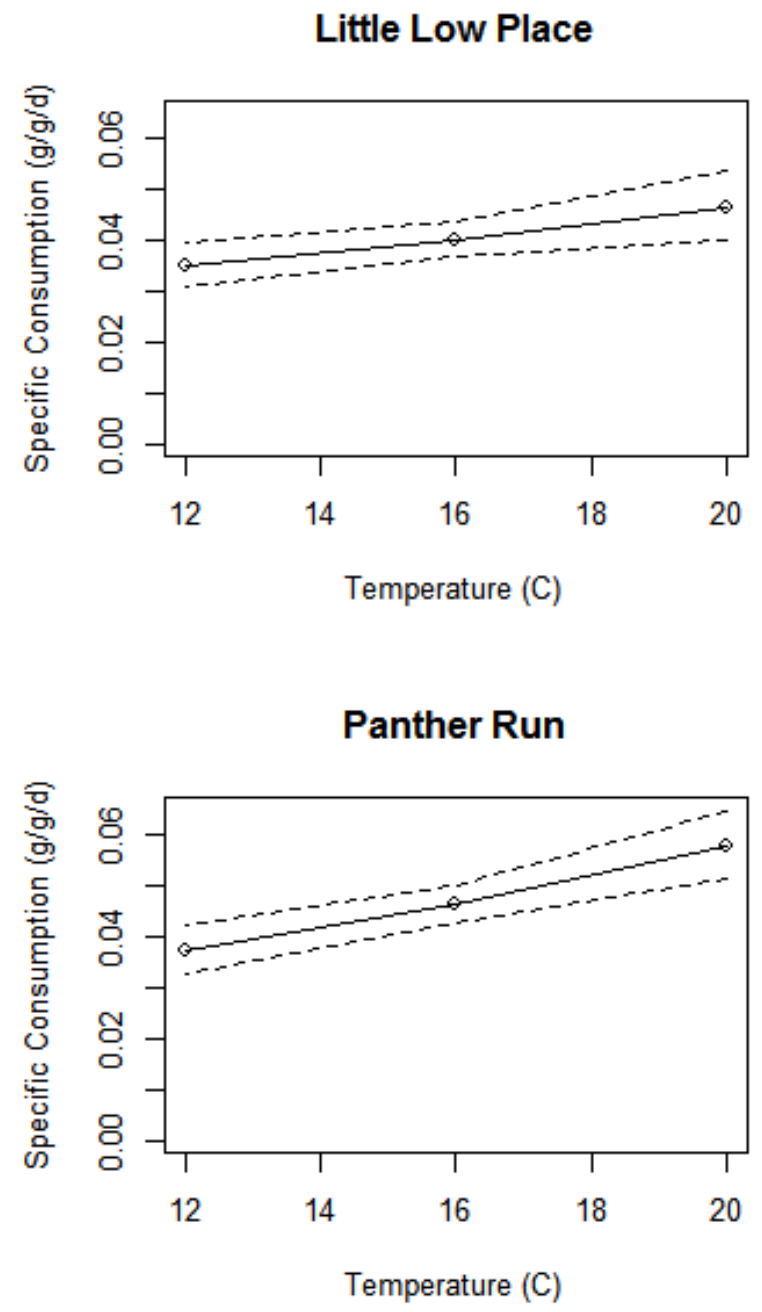

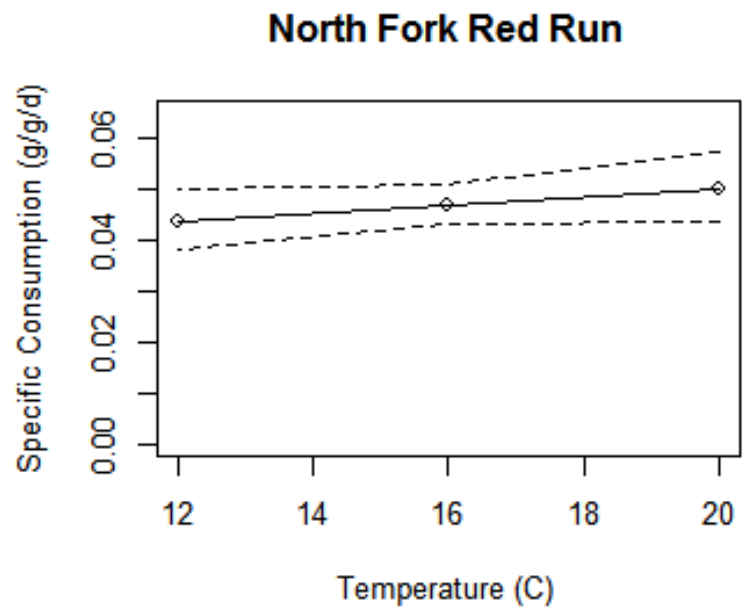

Poca Run

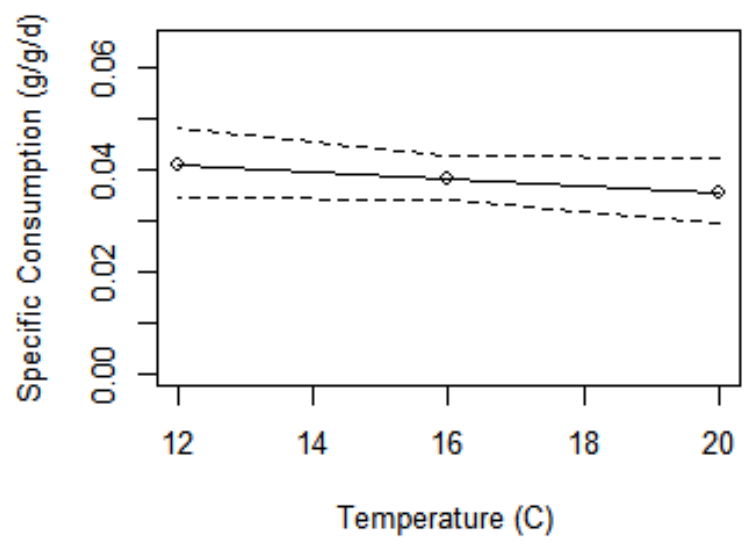

Figure 4. Specific consumption estimates for each of the for streams across the three experimental temperatures utilizing the general linear model $\ln ($ specific consumption $)=$ Stream + Temperature $+\ln ($ Mass $)+$ Stream $*$ Temperature. $95 \%$ confidence intervals are indicated by the dashed lines. 


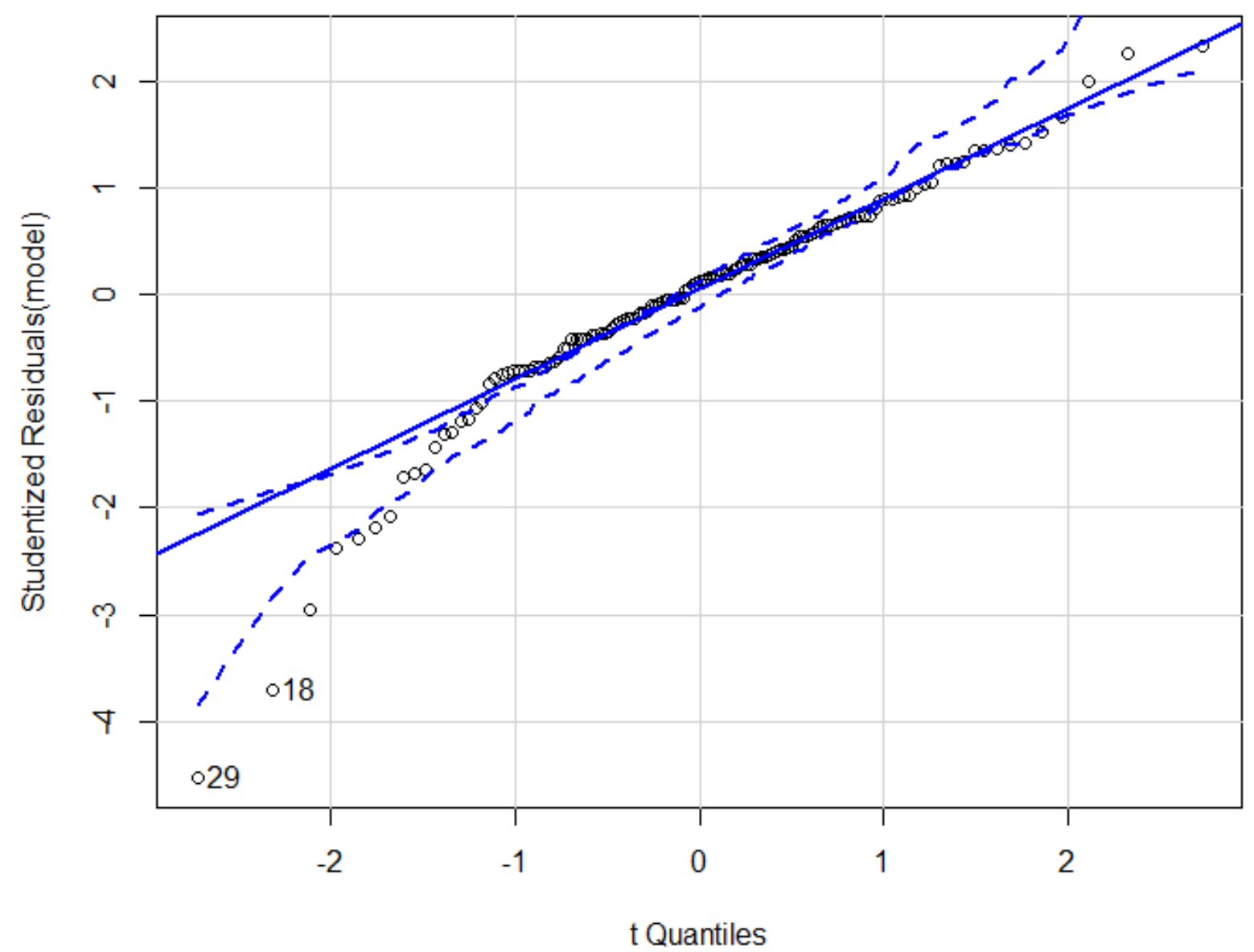

Figure 5. QQ plot representing the residuals of the specific consumption general linear model for the Brook Trout used in the consumption experiments. Here we see the lower tails are outside the $95 \%$ confidence intervals. 

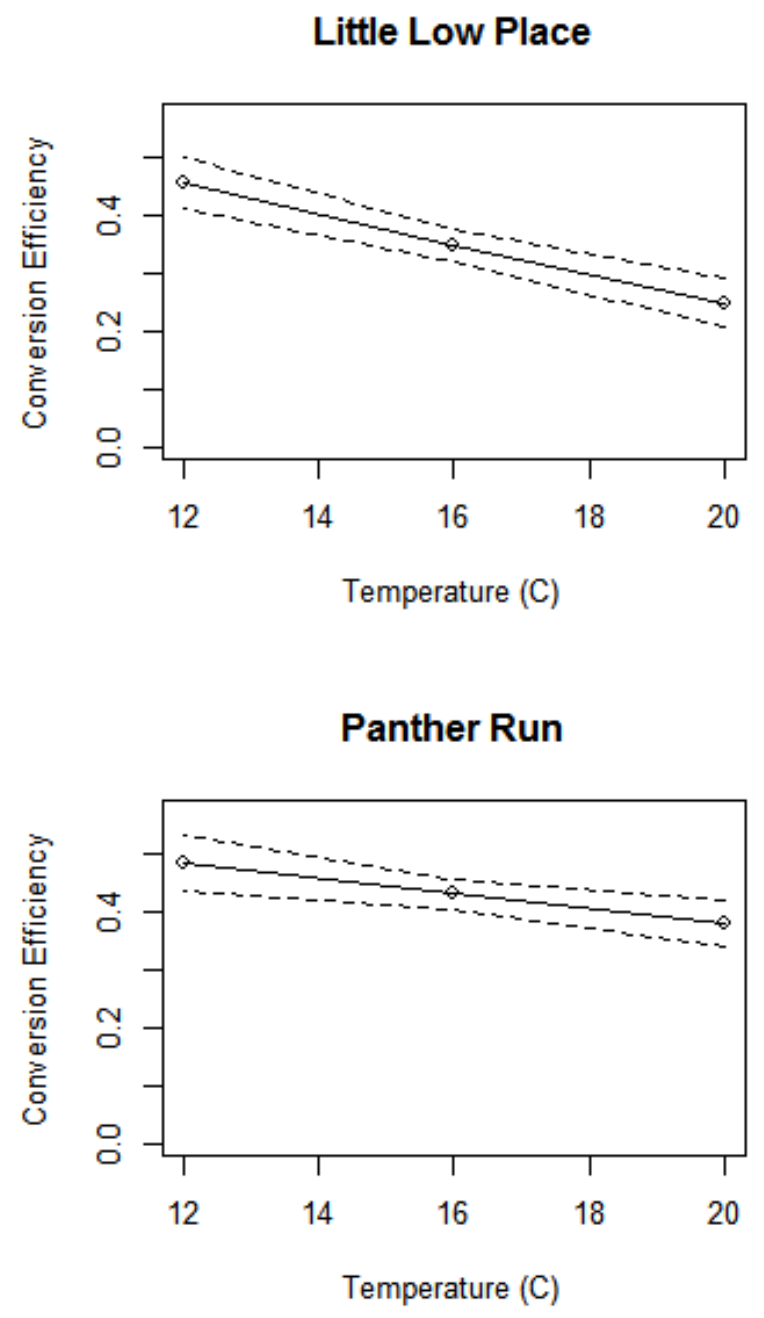
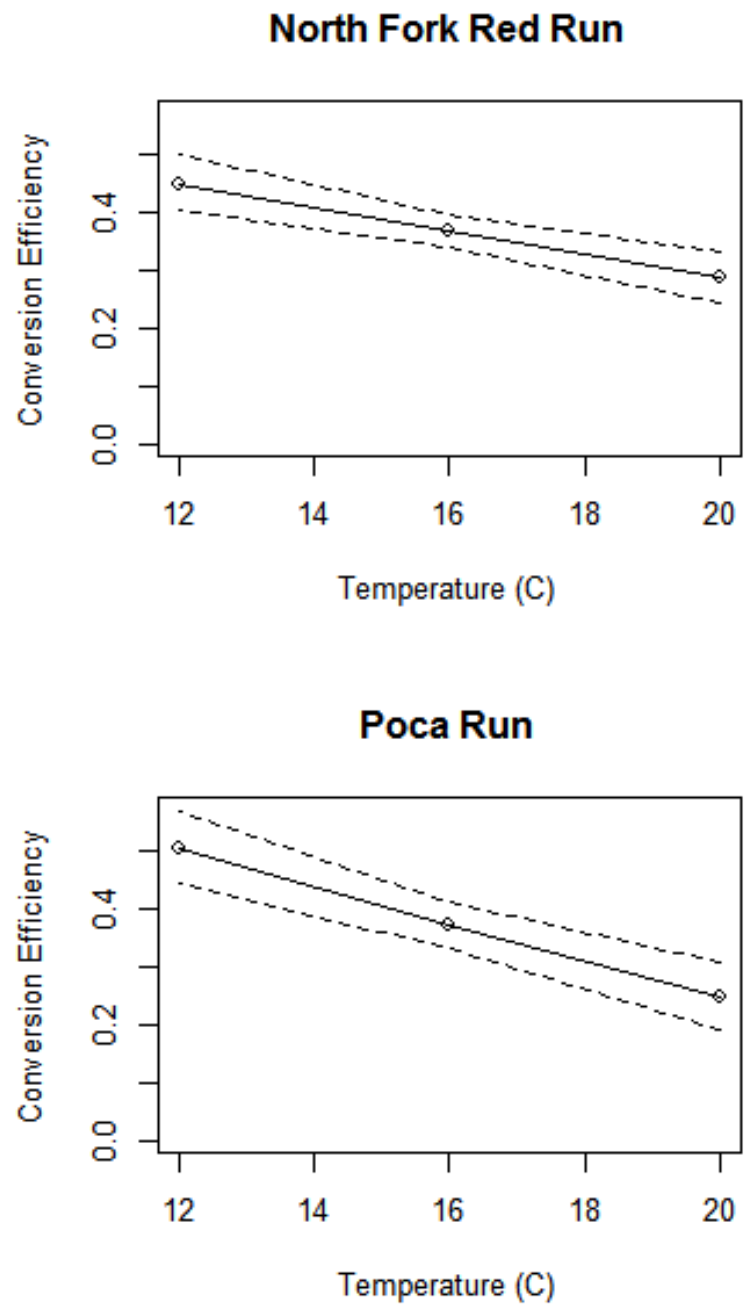

Figure 6. Specific consumption estimates for each of the for streams across the three experimental temperatures utilizing the general linear model $\ln ($ conversion efficiency) $=$ Stream + Temperature $+\ln ($ Mass $)+$ Stream $*$ Temperature. $95 \%$ confidence intervals are indicated by the dashed lines. 


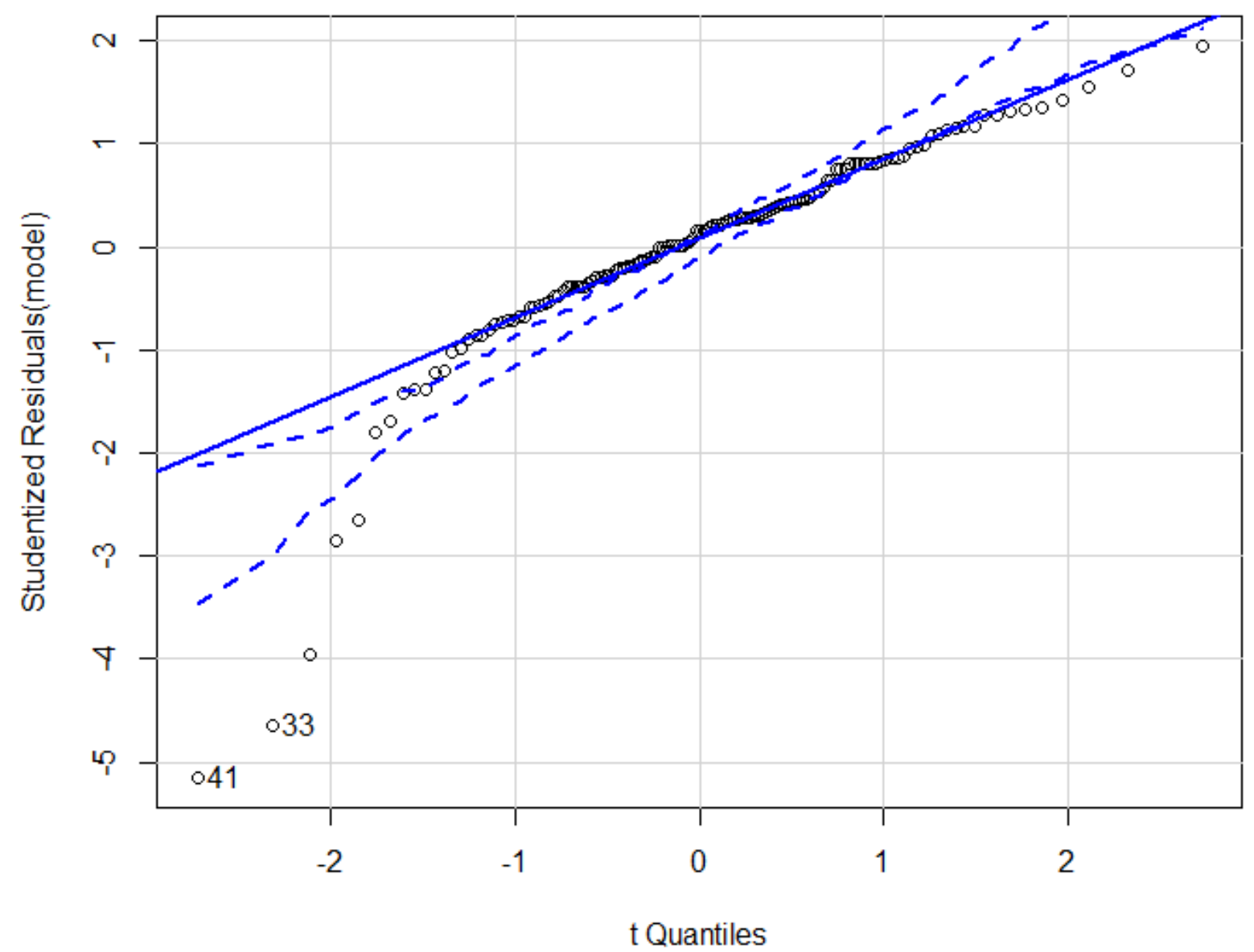

Figure 7. QQ plot representing the residuals of the conversion efficiency general linear model for the Brook Trout used in the consumption experiments. Here we see the lower tails are outside the $95 \%$ confidence intervals. 
Little Low Place

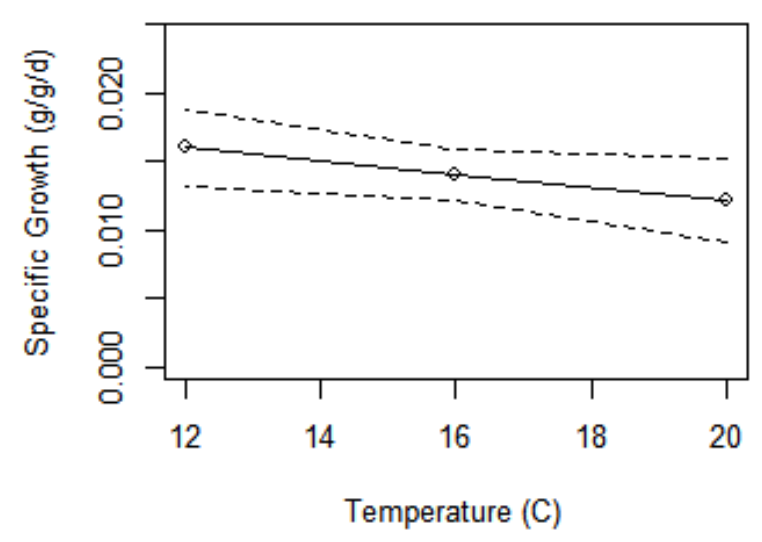

Panther Run

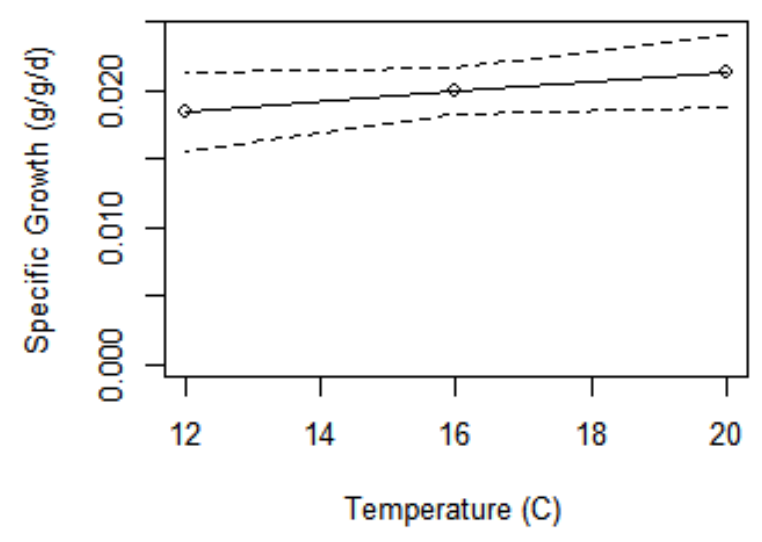

North Fork Red Run

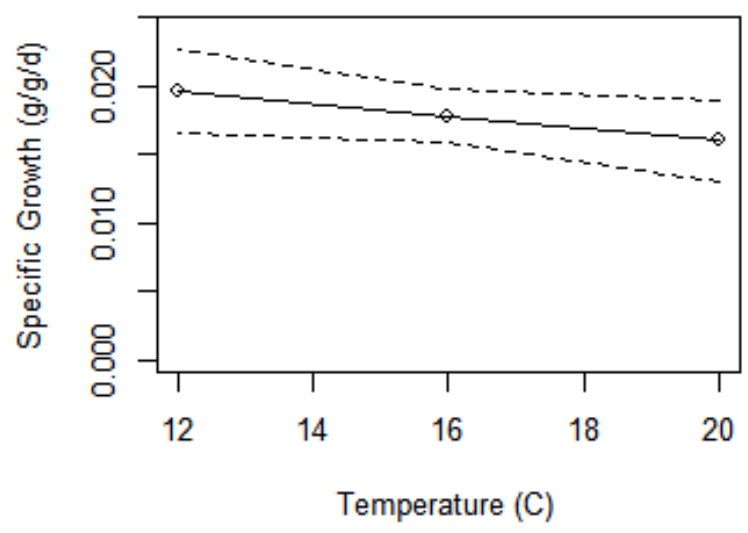

Poca Run

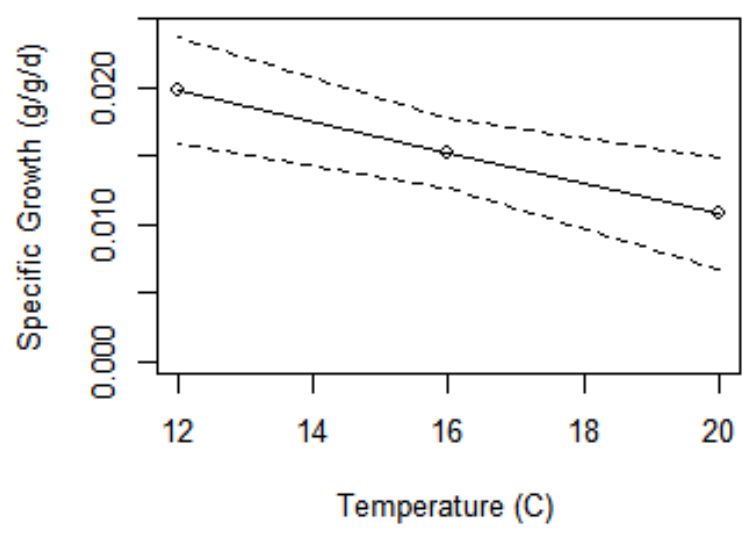

Figure 8. Specific consumption estimates for each of the for streams across the three experimental temperatures utilizing the general linear model $\ln ($ specific daily growth $)=$ Stream + Temperature $+\ln ($ Mass $)+$ Stream $*$ Temperature. $95 \%$ confidence intervals are indicated by the dashed lines. 


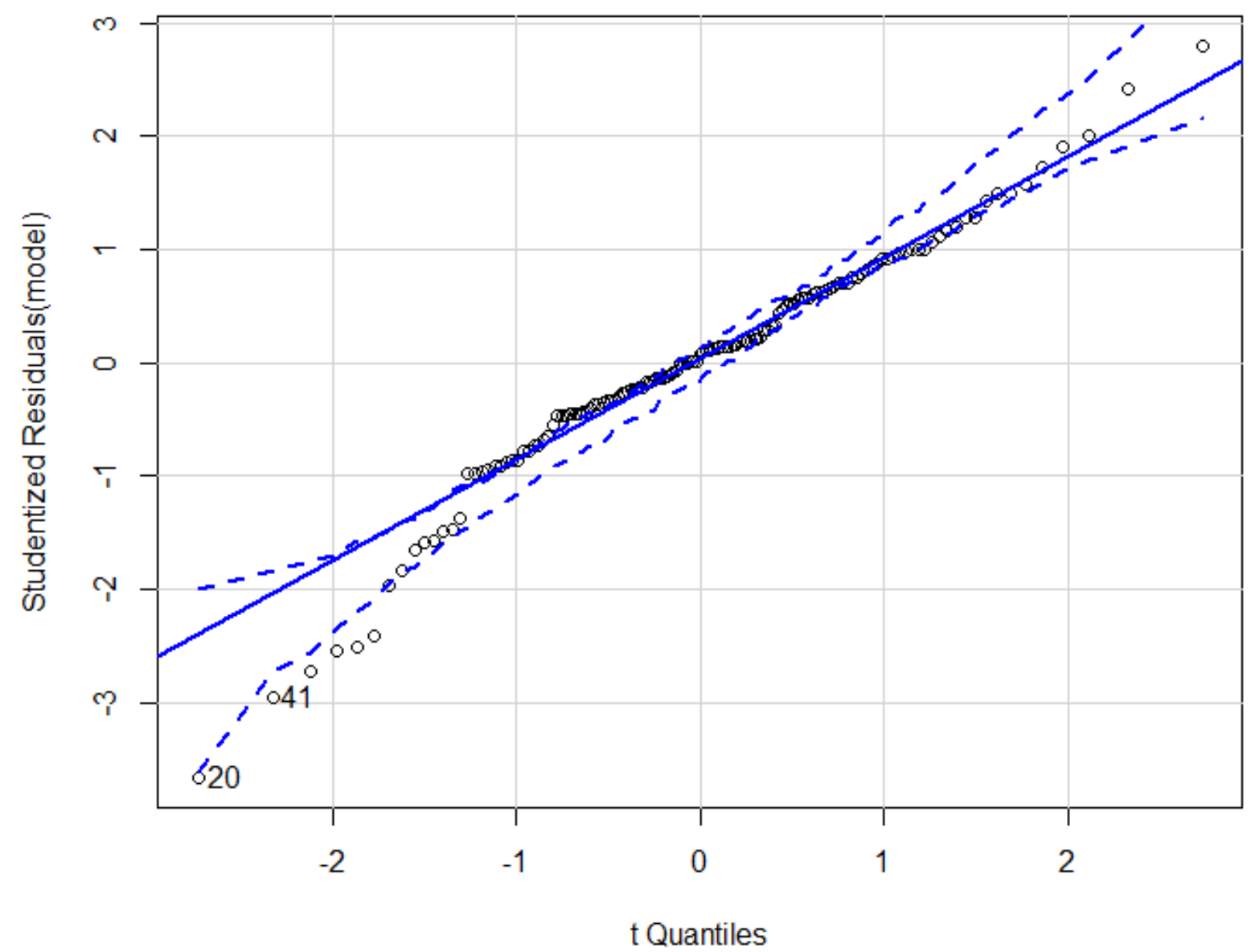

Figure 9. QQ plot representing the residuals of the specific growth general linear model for the Brook Trout used in the consumption experiments. Here we see the lower tails are outside the 95\% confidence intervals. 


\section{0-Degree Differences in Fish Mass by Population}

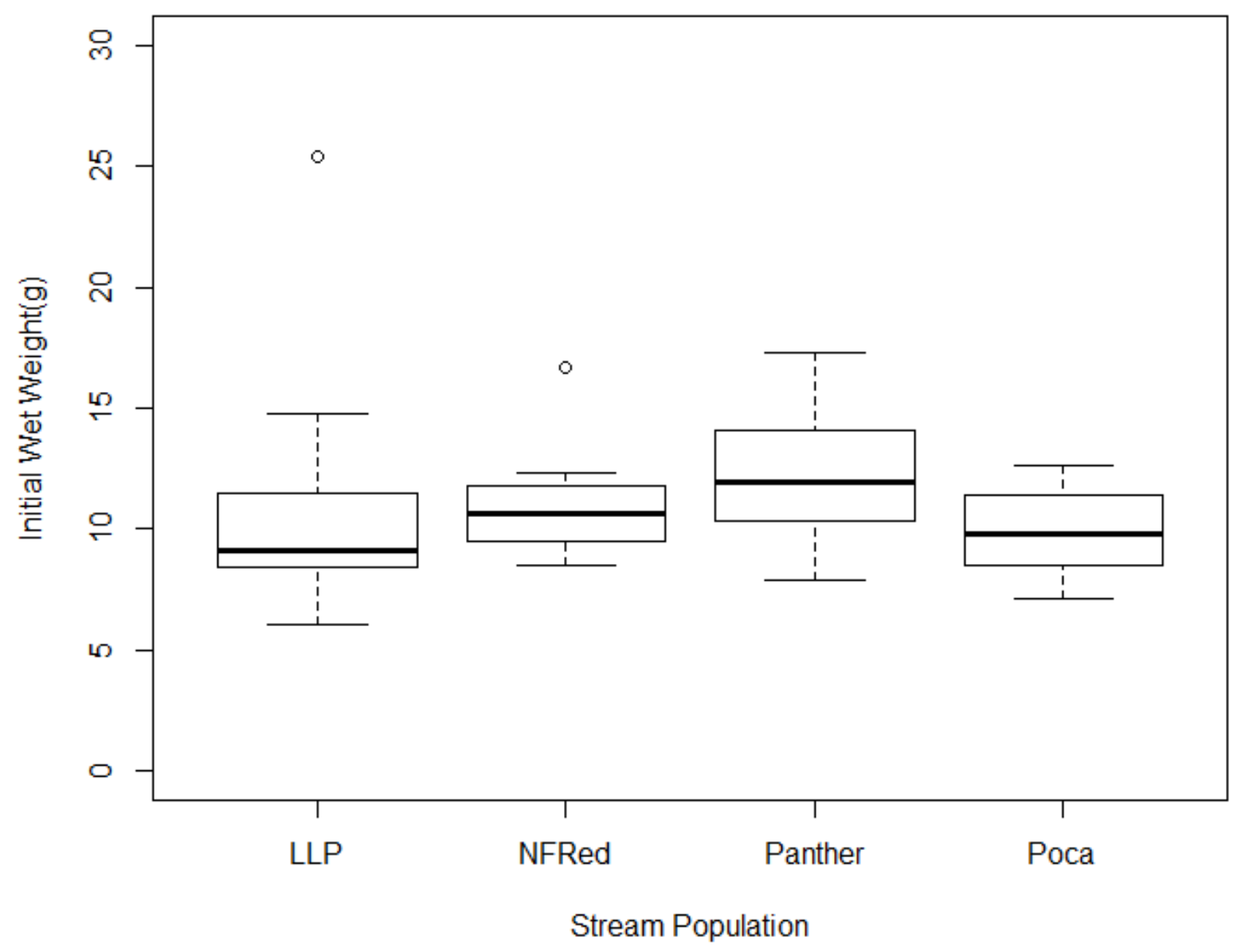

Figure 10. Boxplot representing the 20-degree size differences of the Brook Trout used in the consumption experiments. Here LLP represents Little Low Place, NF Red is North Fork Red Run, Panther is Panther Run and Poca is Poca Run. Little Low Place and North Fork Red Run have outliers. 


\section{2-Degree Differences in Fish Mass by Population}

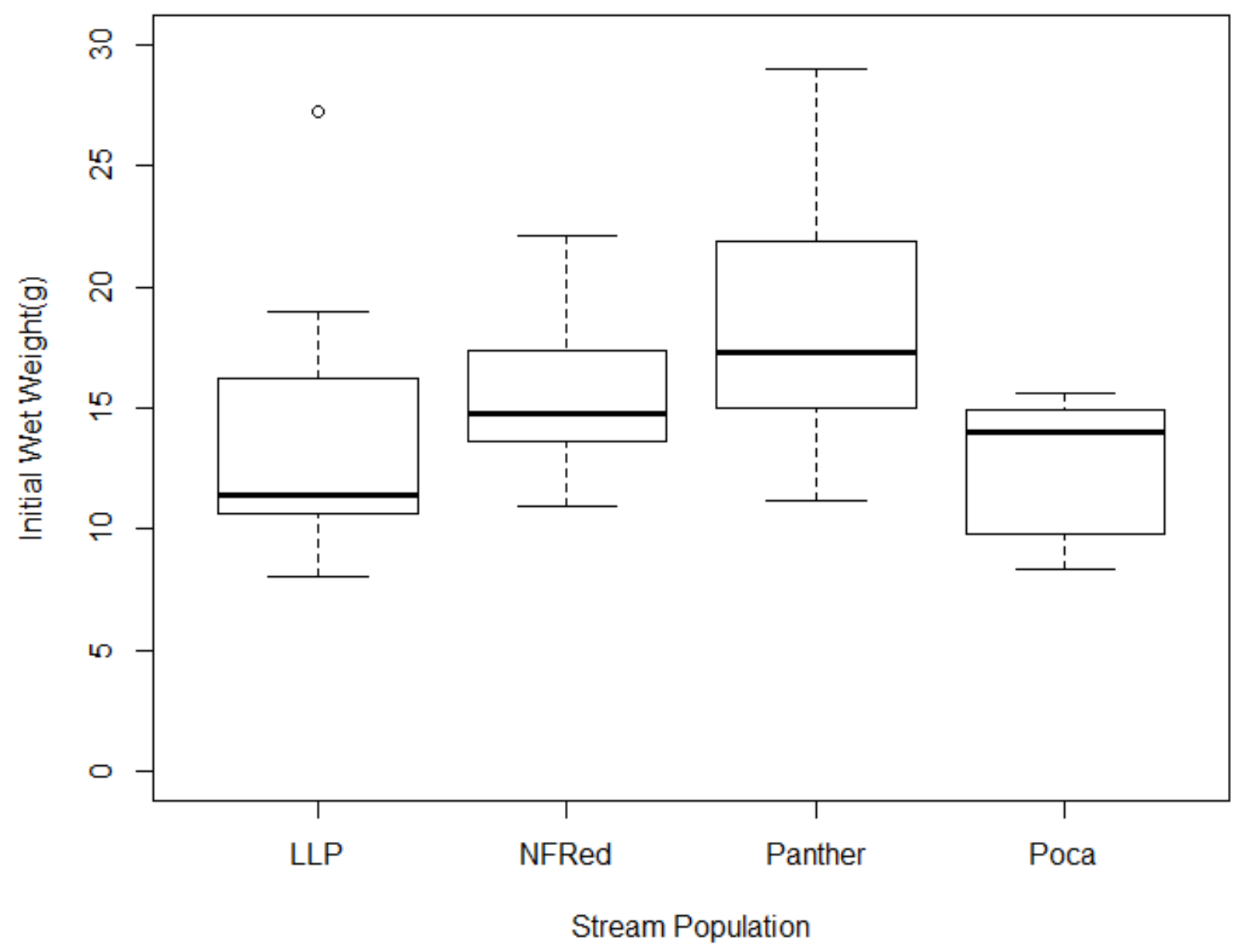

Figure 11. Boxplot representing the 12-degree size differences of the Brook Trout used in the consumption experiments. Here LLP represents Little Low Place, NF Red is North Fork Red Run, Panther is Panther Run and Poca is Poca Run. Little Low Place has a high outlier here in this plot. 


\section{6-Degree Differences in Fish Mass by Population}

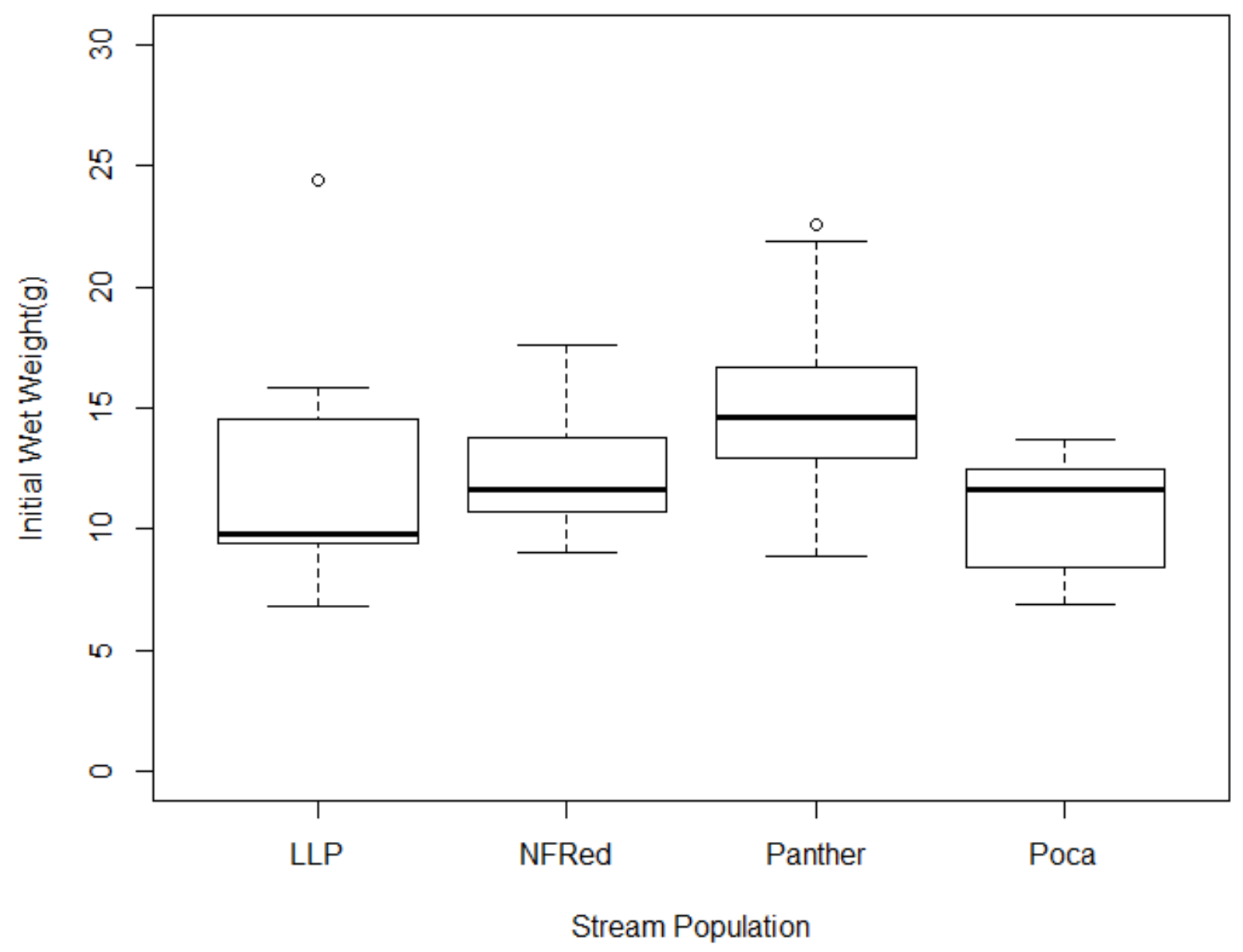

Figure 12. Boxplot representing the 16-degree size differences of the Brook Trout used in the consumption experiments. Here LLP represents Little Low Place, NF Red is North Fork Red Run, Panther is Panther Run and Poca is Poca Run. Little Low Place and Panther Run have outliers. 


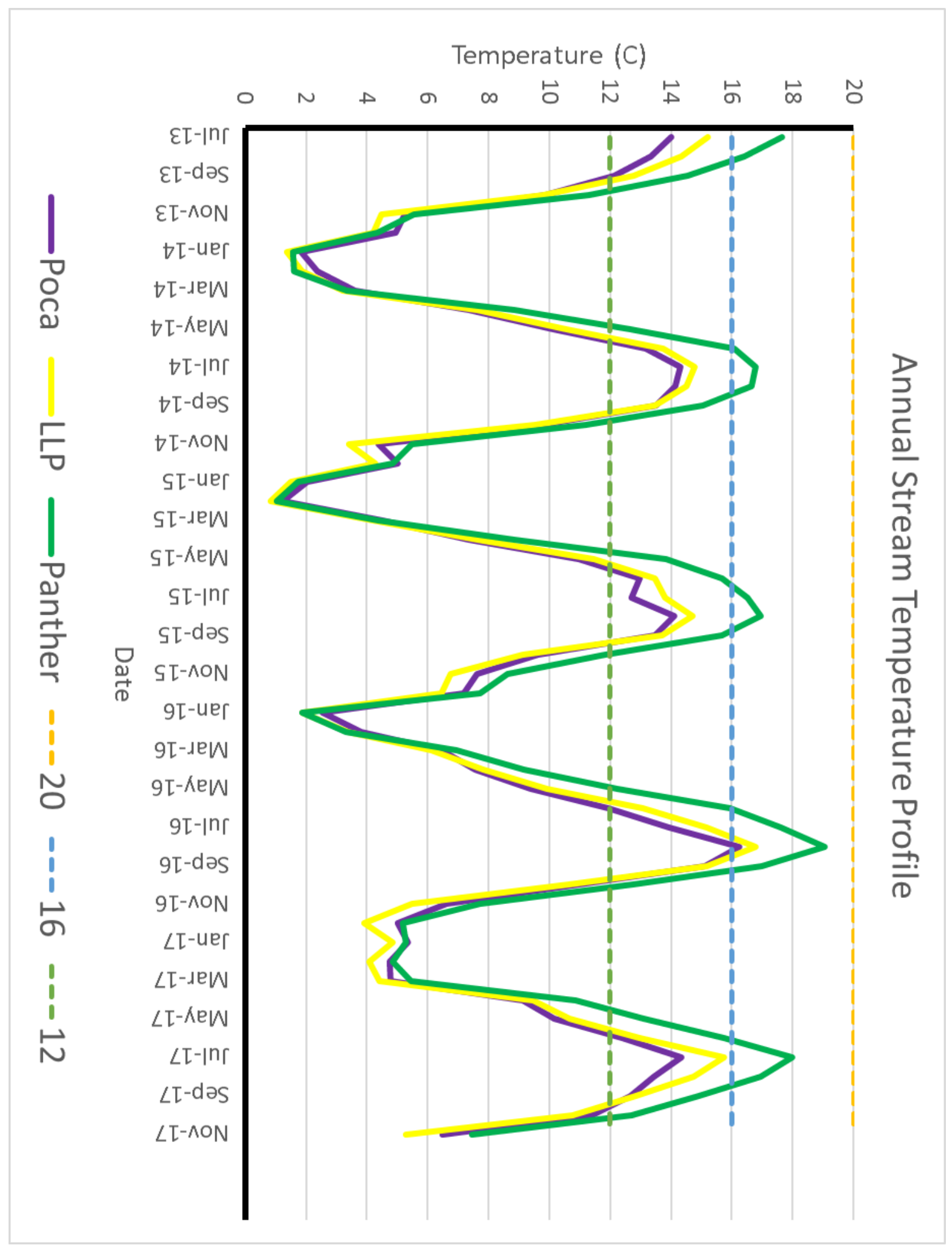

Figure 13. Plot of the mean stream temperatures profiles of Little Low Place, Panther Run, and Poca Run from July 2013 through March 2018. 


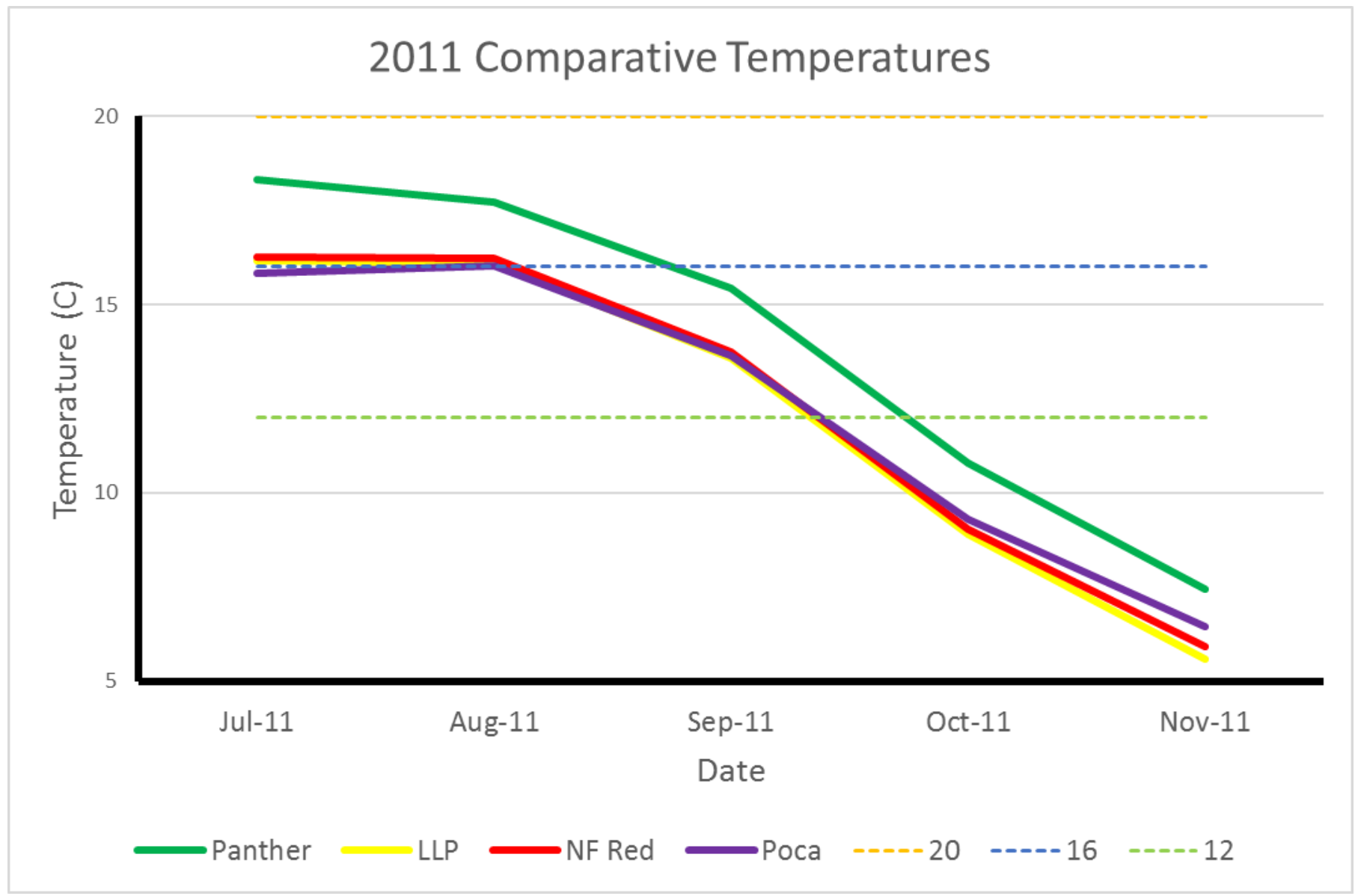

Figure 14. Plot of stream thermal profiles comparing Little Low Place, North Fork Red Run, Panther Run and Poca Run from 2011. Data trends show North Fork Red Run following similar temperature profiles as Little Low Place and Poca Run and being lower than Panther Run. 
Table 1. Depiction of the overall experimental design encompassing both consumption and routine metabolic experiments. Red boxes indicate fasting days for C-max experiments, green boxes are C-max experimental days, yellow boxes are measurement and thermal acclimation days, grey boxes indicate acclimation days to the metabolic chambers, blue boxes are days in which routine metabolic rates were measured.

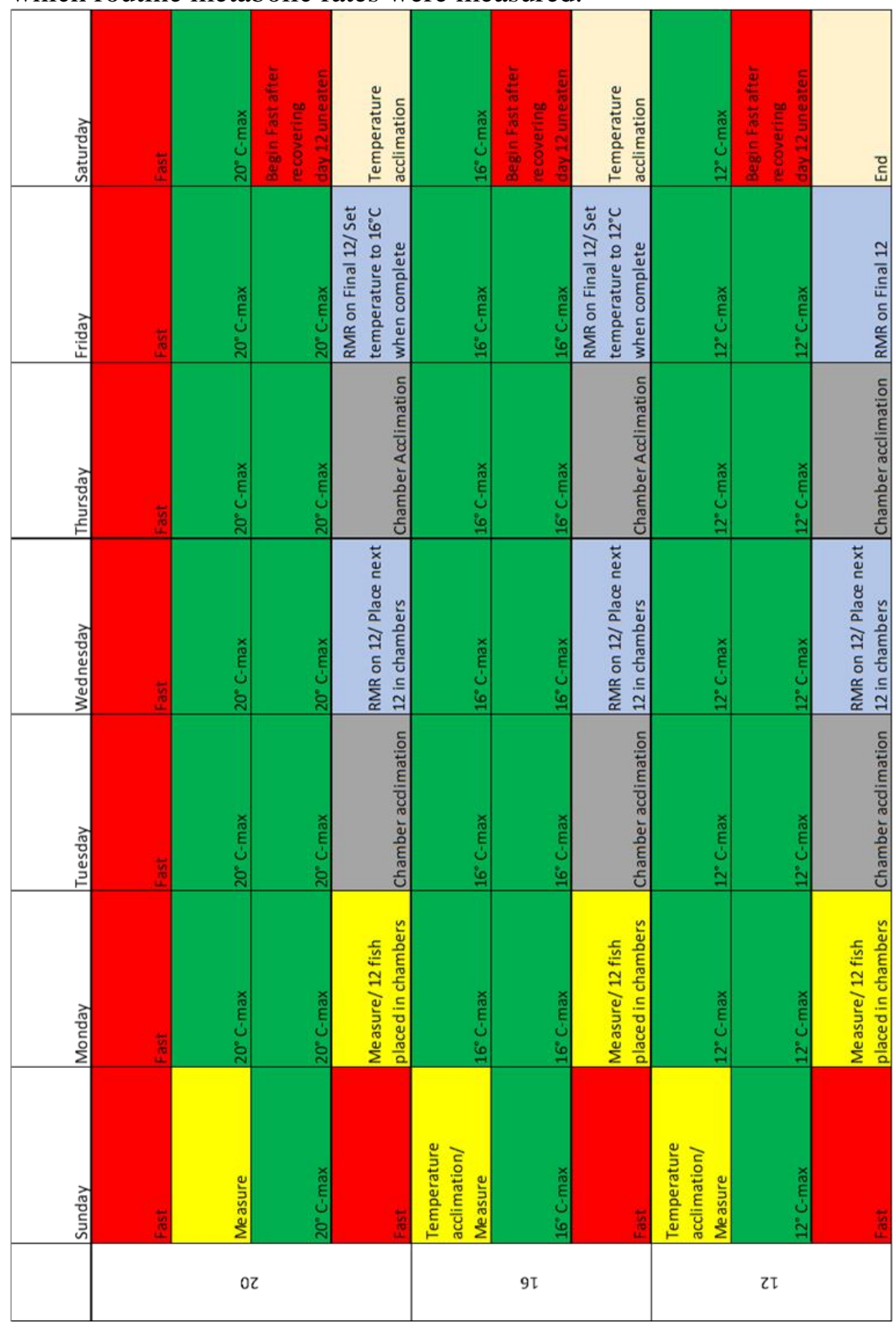


Table 2. Indicates the stream name, abbreviation used in models, stream elevation at sample location, stream slope, bedrock geological type and drainage area for the four streams used as source populations of fish in this experiment.

\begin{tabular}{lccccc}
\hline & Abbreviation & Elevation(m) & Slope $\%$ & $\begin{array}{c}\text { Bedrock } \\
\text { geological type }\end{array}$ & $\begin{array}{c}\text { Drainage area } \\
\left(\mathrm{km}^{2}\right)\end{array}$ \\
\hline $\begin{array}{l}\text { Little Low } \\
\begin{array}{l}\text { Place } \\
\text { North Fork }\end{array}\end{array}$ & LLP & 970 & 13.2 & Hampshire & 5.5107 \\
$\begin{array}{l}\text { Red Run } \\
\text { Panther Run } \\
\text { Poca Run }\end{array}$ & Panther & 942 & 13.1 & Mauch chunk & 13.8924 \\
\hline
\end{tabular}


Table 3. Represents the breakdown of sample sizes of fish by temperature from the four populations tested for specific daily consumption and conversion efficiencies. Between the $16^{\circ} \mathrm{C}$ and $12^{\circ} \mathrm{C}$ experiment, a North Fork Red Run fish perished resulting in a decrease in sample size. The deceased fish was included in the analysis at 16 and 20-degrees.

\begin{tabular}{lccc}
\hline & $20^{\circ} \mathrm{C}$ & $16^{\circ} \mathrm{C}$ & $12^{\circ} \mathrm{C}$ \\
\hline Little Low Place & 13 & 13 & 13 \\
North Fork Red Run & 12 & 12 & 11 \\
Panther Run & 15 & 15 & 15 \\
Poca Run & 7 & 7 & 7 \\
\hline
\end{tabular}


Table 4. ANCOVA table from the model looking at specific daily consumption as an interactive function of $\ln$ (specific daily consumption $)=$ Stream + Temperature $+\ln ($ Mass $)+$ Stream*Temperature indicating that specific consumption rate is significantly influenced by the source population of the fish, the temperature at which it is experiencing, the size of the fish and the interaction of temperature by stream.

\begin{tabular}{llllll}
\hline & $\begin{array}{l}\text { Degrees of } \\
\text { Freedom }\end{array}$ & $\begin{array}{l}\text { Sum of } \\
\text { Squares }\end{array}$ & Mean Square & F Value & P-Value \\
\hline Population & 3 & 2.229 & 0.7430 & 12.203 & $4.48 \mathrm{e}-07$ \\
Temperature & 1 & 0.401 & 0.4008 & 6.583 & 0.011450 \\
lnMass & 1 & 0.743 & 0.7434 & 12.209 & 0.000654 \\
Stream * Temperature & 3 & 0.883 & 0.2945 & 4.836 & 0.003195 \\
Residuals & 128 & 7.794 & 0.0609 & & \\
\hline
\end{tabular}


Table 5. ANCOVA coefficients table from the model looking at specific daily consumption as an interactive function of $\ln ($ specific daily consumption $)=$ Stream + Temperature $+\ln ($ Mass $)+$ Stream*Temperature indicating Poca Run has a significantly higher intercept and a significantly lower slope coefficients as it related to the temperature interaction.

\begin{tabular}{lllll}
\hline & Estimate & $\begin{array}{l}\text { Standard } \\
\text { Error }\end{array}$ & T Value & P- Value \\
& & 0.31910 & -14.354 & $<2 \mathrm{e}-16$ \\
\hline Intercept (LLP) & -4.58035 & 0.29671 & 1.541 & 0.125784 \\
North Fork Red Run & 0.45723 & 0.27770 & -0.597 & 0.551823 \\
Panther & -0.16568 & 0.33738 & 2.375 & 0.019016 \\
Poca & 0.80139 & 0.01297 & 2.769 & 0.006452 \\
Temperature & 0.03591 & 0.08007 & 3.659 & 0.000369 \\
Natural log of Mass & 0.29298 & 0.01824 & -1.038 & 0.301450 \\
North Fork Red Run * Temperature & -0.01893 & 0.01695 & 1.141 & 0.255864 \\
Panther Run * Temperature & 0.01934 & 0.02076 & 2.575 & 0.011149 \\
Poca Run * Temperature & -0.05347 & & & \\
\hline
\end{tabular}


Table 6. ANCOVA table from the model looking at the conversion efficiency as an interactive function of $\ln$ (conversion efficiency) $=$ Stream + Temperature $+\ln ($ Mass $)+$ Stream*Temperature indicating that the conversion efficiency is significantly influenced by the source population of the fish, the temperature at which it is experiencing, the size of the fish and the interaction of temperature by stream.

\begin{tabular}{llllll}
\hline & $\begin{array}{l}\text { Degrees of } \\
\text { Freedom }\end{array}$ & $\begin{array}{l}\text { Sum of } \\
\text { Squares }\end{array}$ & $\begin{array}{l}\text { Mean } \\
\text { Square }\end{array}$ & F Value & P-Value \\
\hline Population & 3 & 0.0570 & 0.01902 & 5.110 & 0.0026 \\
Temperature & 1 & 0.2889 & 0.28891 & 77.629 & $7.54 \mathrm{e}-15$ \\
lnMass & 1 & 0.0133 & 0.01327 & 3.565 & 0.06127 \\
Stream * Temperature & 3 & 0.0387 & 0.01289 & 3.463 & 0.01832 \\
Residuals & 128 & 0.4764 & 0.00372 & & \\
\hline
\end{tabular}


Table 7. ANCOVA table from the model looking at the conversion efficiency as an interactive function of $\ln$ (conversion efficiency) $=$ Stream + Temperature $+\ln ($ Mass $)+$ Stream*Temperature indicating Panther Run has a significantly higher slope coefficient meaning that it will convert energy better as temperature increases.

\begin{tabular}{lllll}
\hline & Estimate & Standard Error & T Value & P- Value \\
\hline Intercept (LLP) & 0.684435 & 0.074991 & 9.127 & $1.30 \mathrm{e}-15$ \\
North Fork Red Run & -0.055410 & 0.073057 & -0.758 & .04496 \\
Panther & -0.102701 & 0.068454 & -1.500 & 0.1360 \\
Poca & 0.086341 & 0.084387 & 1.023 & 0.3082 \\
Temperature & -0.019192 & 0.003098 & -6.195 & $7.37 \mathrm{e}-09$ \\
Natural log of Mass & -0.029574 & 0.019107 & -1.548 & 0.1241 \\
North Fork Red Run * Temperature & 0.004337 & 0.004473 & 0.970 & 0.3340 \\
Panther Run * Temperature & 0.010179 & 0.004152 & 2.451 & 0.0156 \\
Poca Run * Temperature & -0.004323 & 0.005223 & -0.828 & 0.4093 \\
\hline
\end{tabular}


Table 8. ANCOVA table from the general linear model looking at the specific daily growth as an interactive function of $\ln ($ specific daily growth $)=$ Stream + Temperature $+\ln ($ Mass $)+$ Stream*Temperature indicating that the specific daily growth is significantly influenced by the source population of the fish, the temperature at which it is experiencing, the size of the fish and the interaction of temperature by stream.

\begin{tabular}{llllll}
\hline & $\begin{array}{l}\text { Degrees of } \\
\text { Freedom }\end{array}$ & $\begin{array}{l}\text { Sum of } \\
\text { Squares }\end{array}$ & Mean Square & F Value & P-Value \\
\hline Population & 3 & 0.001163 & 0.0003878 & 12.731 & $2.39 \mathrm{e}-07$ \\
Temperature & 1 & 0.000309 & 0.0003089 & 10.141 & 0.00182 \\
lnMass & 1 & 0.000112 & 0.0001123 & 3.685 & 0.05709 \\
Stream * Temperature & 3 & 0.000367 & 0.0001224 & 4.016 & 0.00902 \\
Residuals & 130 & 0.003960 & 0.0000305 & & \\
\hline
\end{tabular}


Table 9. ANCOVA coefficients table from the model looking at the specific daily growth as an interactive function of $\ln ($ specific daily growth $)=$ Stream + Temperature $+\ln ($ Mass $)+$ Stream*Temperature indicating Panther Run has a significantly higher slope coefficient meaning that it will grow more as temperature increases.

\begin{tabular}{lllll}
\hline & Estimate & $\begin{array}{l}\text { Standard } \\
\text { Error }\end{array}$ & T Value & P- Value \\
\hline $\begin{array}{llll}\text { Intercept (LLP) } \\
\text { North Fork Red Run }\end{array}$ & $\begin{array}{l}1.177 \mathrm{e}-02 \\
\text { 3.328e-03 }\end{array}$ & $\begin{array}{l}6.771 \mathrm{e}-03 \\
6.510 \mathrm{e}-03\end{array}$ & $\begin{array}{l}1.738 \\
0.511\end{array}$ & 0.0845 \\
& & & & 0.6101 \\
Panther & $-7.569 \mathrm{e}-03$ & $6.165 \mathrm{e}-03$ & -1.228 & 0.2217 \\
Poca & $1.128 \mathrm{e}-02$ & $7.470 \mathrm{e}-03$ & 1.510 & 0.1335 \\
Temperature & $-4.778 \mathrm{e}-04$ & $2.761 \mathrm{e}-04$ & -1.731 & 0.0859 \\
Natural log of Mass & $3.655 \mathrm{e}-03$ & $1.708 \mathrm{e}-03$ & 2.140 & 0.0342 \\
North Fork Red Run * & $2.506 \mathrm{e}-05$ & $3.960 \mathrm{e}-04$ & 0.063 & 0.9469 \\
Temperature & & & & \\
Panther Run * Temperature & $8.358 \mathrm{e}-04$ & $3.741 \mathrm{e}-04$ & 2.235 & 0.0271 \\
Poca Run * Temperature & $-6.300 \mathrm{e}-04$ & $4.575 \mathrm{e}-04$ & -1.377 & 0.1708 \\
\hline
\end{tabular}




\title{
Chapter 3- Thermal Performance of Routine Metabolic Rates from four Populations of Brook Trout in West Virginia's Central Appalachian Mountains.
}

\author{
Abstract \\ Growth of an individual is the end result of many physiological processes stemming from \\ the consumption of food items. These processes can be influenced by many variables including \\ temperature. Energy budgets of an individual fish can vary based on genetics and acclimation. \\ Only energy consumed in excess of metabolic costs can be assimilated as new growth of the \\ individual. Current bioenergetics models for Brook Trout Salvelinus fontinalis suggest growth \\ increases with temperature until an inflection point of $20.2^{\circ} \mathrm{C}$. With a warming climate, and \\ water temperatures expected to rise, the ability of a population to adapt to the warming \\ environment is crucial to the survival of the species. For this study we sought to see how spatial \\ variation would influence the routine metabolic rate (RMR) of four source populations of Brook \\ Trout in West Virginia's Central Appalachian Mountains. RMR measurements were taken on 47 \\ individuals at three temperatures $\left(12,16\right.$, and $\left.20^{\circ} \mathrm{C}\right)$. The effects of source population and \\ temperature differences were determined using a general linear model and significant differences \\ in model coefficients $(\mathrm{p} \leq 0.05)$. Routine metabolic rates were found to be significantly different \\ with two populations having a higher intercept but a lower slope coefficient than the other two \\ populations. These findings give hope that a population of cold-water fish can survive climate \\ change if temperatures rise at a slow enough pace to allow for adaptation.
}




\section{Introduction}

Brook Trout Salvelinus fontinalis have endured reductions in numbers and distribution in the central Appalachian Mountains. Factors such as high harvest rates, habitat degradation, reductions in water quality, and nonnative salmonid introductions have been suggested as the causation (Larson and Moore 1985, Flebbe 1994, Marschall and Crowder 1996, Galbreath et al. 2001). The most remarkable disruption in the central Appalachian region is the negative effect of acid precipitation (Wigington et al. 1996). West Virginia generally has a sandstone dominated geology resulting in an estimated $25 \%$ of all streams being impaired because of a high rate of acid deposition and the sandstones poor buffering capacity (Sharpe et al. 1987, Welsh and Perry 1997, Clayton et al. 1998). Brook Trout are an important species in West Virginia, not only as the state fish, but also due to the high socioeconomic value the angling industry brings to rural parts of the state.

Mean air temperatures near the earth's surface are expected to rise $3.5-4.2^{\circ} \mathrm{C}$ over the next 50 years (Bernstein et al. 2008). As air temperatures continue to rise as a result of global climate change, the same can be expected for water temperatures within the streams holding Brook Trout in central Appalachia as suggested by Meisner (1990), Stefan and Preud'homme (1993), and Pilgrim et. al. (1998). This could lead to cold water salmonid species such as Brook Trout having a 20\% decrease of abundance (Casselman 2002) as a result of increased metabolic processes and reduced growth in a warming environment. While Brook Trout can withstand quick spikes in temperature up to $28.7^{\circ} \mathrm{C}$ (Carline and Machung 2001), a realistic sustainable short-term temperature is $25^{\circ} \mathrm{C}$ (Beitinger and Bennett 2000). As water temperatures rise, so does the metabolic rate of the individual fish. Metabolic costs are the largest uncontrollable energy loss a fish will endure. Current bioenergetics models suggest that the metabolic rate of 
Brook Trout continues to increase until the inflection point of $20.2 \mathrm{C}$ at which point the rate quickly drops (Hartman and Cox 2008). Unless the fish experiencing warm temperature extremes $\left(<20^{\circ} \mathrm{C}\right)$ can find thermal refugia, the species will likely perish.

Adaptation of Brook Trout to warming water temperatures can occur at both the individual level and the population level (Meier et al. 2014). At the individual level, seasonal acclimation to temperatures allow for a greater range of thermal tolerance (Jobling 1995). Population level adaptation is a result of natural selection, selecting against the lesser tolerant individuals who cannot thrive and reproduce under the increased temperatures. These thermal tolerances have also been shown to vary between population origins (Stitt et al. 2014), suggesting that selective pressures have allowed past individual level characteristics to be found within the whole population of a given area. Since headwater streams are fairly stable in their thermal patterns, with low mean temperatures, the fish inhabiting them should be adapted to perform within those temperature regimes.

Understanding how much energy is used by a fish to survive is crucial to understanding how much energy in needed to promote growth of an individual. Unlike humans that have determinant growth potential, meaning we hit a "full-sized" frame, fish can keep growing larger and larger due to indeterminate growth. This indeterminate growth can only take place after routine metabolic costs are met. Metabolism experiments using routine metabolic rate (RMR) are used to determine how much energy a fish uses in normal functional operation of the individual, i.e. just sustaining life for itself by circulation, osmoregulation, spontaneous swimming, and routine activity (Barbieri et al. 2002). To determine the RMR, a fish is placed into a closed vessel and allowed to respire for a period of time (Atkins and Benfey 2008, Lefrançois et al. 2001, Powell et al. 2005). Total consumption of oxygen $\left(\mathrm{MO}_{2}\right)$, defined as: 
oxygen initial -oxygen end, is recorded within the vessel. The measured consumption of oxygen can then be converted to energy consumed by the individual by use of calorimetry (Nelson 2016). Energy equivalents of oxygen consumption states that for every $1.0 \mathrm{mg}$ of oxygen consumed, 3.38 - 3.42 calories (14,141.92-14,309.28 joules) of energy are used (Elliott and Davison 1975). Knowing how much energy must be consumed for day to day operations of the fish help bioenergetics models simulate how much more energy than the RMR must be consumed to account for the growth of an individual.

Fish bioenergetics models can be very complex, using anywhere from 12 to more than 30 parameters (Beauchamp et. al 1989, Stockwell and Johnson 1997, Madenjian and Connor 1999). Each of these parameter estimates brings its own level of uncertainty with it. The current model for Brook Trout (Hartman and Cox 2008), as with many other species (Madenjian and Connor 1999, Madenjian et al. 2000, Tyler and Bolduc 2008), take advantage of hatchery fish to develop the estimates of parameters used. While hatchery fish are a good source population to start with because of their cheap, readily available nature, they don't encompass the breadth of the wild population's genetics and therefore potential variation. Hatchery fish, like those used in Hartman and Cox (2008), are the result of selective breeding to do well in the hatcheries. Hatchery fish are not a true representation of wild fishes (McDermid et al 2010). An understanding of spatial variation of metabolic rates for Brook Trout is thought necessary to accurately predict the metabolic costs associated with different populations. These costs can then be used to solve for unknown parameters specific to the population in question.

The objective of this study was to determine if we could detect a population level difference in Routine Metabolic Rate (RMR) between four headwater streams in the central Appalachian Mountains of West Virginia. RMR was conducted over a range of temperatures to 
account for the influence temperature plays on Brook Trout metabolic rates in a warming climate. By detecting a difference, we hope to allow for a better understanding of the spatial variation of Brook Trout routine metabolic rate, as well as consideration to account for such variation.

\section{Methods}

Fish Collection- To evaluate whether differences in thermal performance exist among Brook Trout populations we selected 4 streams of varying elevation for source populations. Elevation can influence stream characteristics in several ways including gradient, energy inputs and thermal regime. In July of 2018, approximately 24 juvenile Brook Trout were collected from each of the streams: Panther Run, North Fork Red Run, Poca Run, Little Low Place (LLP), using backpack elecrofishers (Table 1; Figure 1,2). Fish were collected at a rate of no more than one individual per habitat unit (riffle, run or pool), typically small back water eddy areas behind a rock in a riffle to increase our chances of genetic variation. Fish were transported back to the Aquatic Ecophysiology Laboratory of West Virginia University. Upon returning to the laboratory fish were marked with elastomer in the jaw, the fleshy cheek near the operculum, and caudal peduncle to denote source stream (Adams et al. 2000).

Quarantine and Acclimation- Once fish were marked by source stream, they were then placed into self-contained cold-water recirculating tank units in quarantine, where fish were fed every third day to satiation as a maintenance ration. While in quarantine fish were monitored for any signs of infection or illness. Fish were kept in stream source isolation for a period of 28 
days. Following the 28-day quarantine period, fish were placed into a common tank and fed to satiation every third day as a maintenance ration.

The physical design of the experimental tank units allowed for a maximum of 24 individuals to be tested simultaneously. To attain a higher sample size, experiments were run in two separate series of trials, with each series experiencing the same thermal sequence $(20,16$, $12^{\circ} \mathrm{C}$ ). For each of the two series of thermal sequence experiments, a subsample of 24 individuals were removed and placed into individual 37L aquariums. Aquariums had the sides painted black to avoid external stimuli of other fish. Aquariums were covered with hardware cloth and mesh screen to prevent escape of subject fish and prey items and housed within a larger 1.2x2.4m steel tank to act as a thermal buffer (Figure 3). Water was controlled to each aquarium by ball valves. Each aquarium was equipped with an air stone. The experimental set up was part of a larger 8,000-liter recirculating system equipped with physical and biological filters, UV sterilizer and commercial chilling unit allowing for temperature control of $+/-0.2^{\circ} \mathrm{C}$. Water quality was measured daily, and water changes made as necessary to maintain acceptable safe water quality parameters $\left(\mathrm{pH}, \mathrm{NH}_{3}-\mathrm{N}, \mathrm{NO}_{3}-\mathrm{N}\right)$. After being placed into the aquariums, fish were acclimated to the isolation of an individual aquarium for 30 days, again being fed to satiation every third day while adjusting to the individual aquariums.

Routine Metabolic Chambers- Chambers used to conduct routine metabolic rates were constructed using commercially available 6" (152.4mm) schedule 40 PVC pipe, fitted with a solid $1 / 4 "(6.35 \mathrm{~mm})$ plexiglass bottom and a plexiglass top flange and removable top cover to place and recover the fish (Figure 4). A neoprene gasket was placed between the flange and top cover to make the fit watertight. The top cover is equipped with a portal to allow for the dissolved oxygen (DO) probe to be inserted into the chamber, plugged with a rubber stopper 
when not in use. Each chamber was fitted with inflow and outflow tubing, each equipped with valves to control flow to and from the chamber. An electric pump was inserted into each chamber to allow for even mixing of the water following each respiration period. Chamber volume was approximately $1,649 \mathrm{ml}$ with $75 \mathrm{ml}$ displaced by the electric pump. Chambers were immersed in $37.5 \mathrm{~L}$ aquariums to allow for thermal buffering. To further aid in thermal buffering the aquarium were kept within the larger $1.2 \times 2.4 \mathrm{~m}$ steel tank.

Overall Experimental Design- This experiment was part of a larger project looking at both the c-max and routine metabolic rate of the same individuals, a period of 3 weeks occurred between each set of RMR measurements. Experiments were conducted at 3 temperatures starting at $20^{\circ} \mathrm{C}$, reducing to $16^{\circ} \mathrm{C}$ and $12^{\circ} \mathrm{C}$, respectively. Each temperature consisted of a fasting period, measurement for size before growth experiments, a 12-day growth period during which time fish were fed ad libitum (C-max), followed by fasting periods, end growth measurements (same used for metabolic calculations), metabolic measurements, and temperature adjustments also acting as a fasting period for the next temperature (Table 2). All temperature changes were from warmer to cooler to reduce stress on the organism and reduce acclimation time.

Experimentation- Following the individual acclimation period, and the initial $20^{\circ} \mathrm{C}$ maximum consumption rate (C-max) experiment (as part of the larger experimental design), fish were fasted for 48 hours to allow for near complete evacuation of the digestive tract. After fasting fish were anesthetized in a buffered tricaine methanesulfonate (MS-222) solution of $1 \mathrm{~g}$ per $9 \mathrm{~L}$ of water, weighed for wet weight (WW) (nearest $0.1 \mathrm{~g}$ ), total length (TL), fork length (FL) and a modified standard length (SL). The modified SL used in this experiment was the point in which the caudal flesh transitioned from translucent to opaque, a measurement change 
used to reduce handling time. After measurement, 12 fish were placed into the metabolic chambers and allowed to acclimate for $>36$ hours.

Dissolved oxygen (DO) measurements were taken on routinely active fish using YSI Pro ODO (calibrated to zero $\left[\mathrm{Na}_{2} \mathrm{SO}_{3}\right]$ and $100 \%$ saturation at the beginning of each day) following acclimation to the metabolic chamber. Fish were fasted for a period of 96-144 h before RMR measurements were taken. Initial dissolved oxygen and the start time was recorded, the flow turned off to individual chambers and fish allowed to respire. Fish were allowed to freely move within the chamber at all times, with or without flow. Flow was turned off for a period of 0.30 to $1.25 \mathrm{~h}$ depending on the temperature and size of fish to achieve a change in oxygen concentrations of $1 \mathrm{mg} / \mathrm{l}$, with more time required for smaller fish. After allowing the fish to respire, the pump was turned on to allow for adequate mixing of the water within the chamber. The end dissolved oxygen and time was recorded after mixing occurred. Flow was resumed and allowed to flow through the chamber for a period of at least 2 times the elapsed time the flow was ceased to the chambers before beginning the next respiration measure $(>0.60$ to $2.50 \mathrm{~h})$. A total of 3 metabolic measurements were taken for each individual Brook Trout and the average was considered the rate of oxygen consumption for that observation (Hartman and Cox 2008). Background bacterial respirations were also accounted for in an empty chamber for the same time periods as the Brook Trout metabolic rate measures. After completion of the first 12 fish metabolic rates, fish were returned to their respective aquarium, and the other 12 fish were acclimated $(>36 \mathrm{~h})$, and respiration measured. After completion of the second set of fish's metabolic rates measured, they were returned to their aquarium and the temperature reduced to the next test temperature. Temperatures were decreased at a rate of $0.25^{\circ} \mathrm{C} / \mathrm{hr}$, allowing the next temperature profile to be achieved in 16 hours. In doing so we were able to allow the individuals 
to acclimate for a period of 48 hours at each temperature before beginning the next round of $\mathrm{C}$ max and routine metabolic rate experiments.

Statistical analysis- Metabolism data were formatted into a standardized $\left(\mathrm{g} \mathrm{O}_{2} / \mathrm{g}\right.$ fish/day) format. The average of the three metabolic measurements was used for analysis. We utilized R 3.6.1 (R Core Team 2019) for all analyses. The natural log of the mean routine metabolic rate and mass of the individuals was calculated and used for the analysis. Outliers were detected and removed using the Bonferroni outlier test. To test for differences between streams and temperatures an ANCOVA using the model (mean metabolic rate $\sim$ temperature * stream population) was used. The residuals were then calculated for the ANCOVA model and a Shapiro- Wilk test was then run to test for normality of the data. Differences in fish size were also tested for each of the three temperatures utilizing the ANOVA (fish mass stream population). A general linear model was ran to determine differences among streams and to determine if the effect of temperature differed among streams as indicated by significant differences in model coefficients $(\mathrm{p} \leq 0.05)$.

\section{Results}

We collected $\sim 24$ individuals from each stream. Our initial experimental design was to have 12 individuals from each stream population tested for routine metabolic rates. However, due to mortality, escapees, and losses beyond our control within the system we were unable to obtain this array. We were limited to a total of 47 Brook Trout from the four populations tested for routine metabolic rate (Panther Run n=15, LLP n=13, NF Red Run n=12, Poca Run n=7) 
(Table 3). These 47 Brook Trout ranged from 6.0- 25.4g and 72-121mm in modified standard length at the start of the trials.

Routine metabolic rates increased with temperature (Figure 5) and decreased with size at each temperature (Figure 6). The general linear model revealed that there was a significant influence of temperature, stream, and the interaction of stream* temperature on the routine metabolic rate of Brook Trout (Figure 7, Table 4). Further analysis of the linear model revealed that North Fork of Red Run and Poca Run have significantly higher intercepts and lower slopes than the remaining streams than the global model (Table 5). The Shapiro-Wilks test is not significant indicating the data is normally distributed (Figure 8).

Size was found to be significantly different at all three temperatures between the four populations. At $20^{\circ} \mathrm{C}$ the ANOVA revealed there was a significant difference in size between populations $(\mathrm{DF}=3, \mathrm{~F}=3.433, \mathrm{P}-\mathrm{Value}=0.0251)$, and Tukey's test suggests that the significance fell in Panther Run being larger than Poca Run fish and almost significantly larger than Little Low Place fish (Figure 9). At $16^{\circ} \mathrm{C}$ there was a significant difference (DF=3, F= 5.207, PValue $=0.0039)$ with Panther Run fish significantly larger than Little Low Place and Poca Run (Figure 10) At $12^{\circ} \mathrm{C}$ analysis indicated a significant size difference $(\mathrm{DF}=3, \mathrm{~F}=4.696, \mathrm{P}-\mathrm{Value}=$ 0.00646) and Panther Run was determined to be significantly larger than Little Low Place and Poca Run (Figure 11).

\section{Discussion}

We found significant differences in the intercept and slope for the routine metabolic rate between two of our four populations across temperatures. Post-hoc tests looking at size comparisons of the four source streams indicated that there was a significant difference in size at 
all three temperatures of streams. The Panther Run fish were larger than those of Poca Run at all three temperatures. Panther Run fish were also larger than Little Low Place sourced fish at 12 and $16^{\circ} \mathrm{C}$. North Fork Red Run fish were not significantly different at any temperature from any of the other source populations. With size being a contributing factor of metabolic rates, as suggested by the current Brook Trout bioenergetics model (Hartman and Cox 2008) and other salmonid species (Cutts et al 2002), the larger the individual, the lower the RMR of the fish on a per gram scale. The size variation we had in our sample may have more confounding results which we are unable to account for. Further testing would need to be done to create a size dependency model for each stream so the individual fish can be standardized to a common size. By standardizing the fish to a common size, one could more readily draw conclusions between streams on a one to one ratio of fish from varying sizes.

It was determined that as a result of the experimental design used for this project, we inadvertently opened up a size bias in our sample of fish used. The fish from Panther Run grew faster during our $20^{\circ} \mathrm{C}$ consumption trials which preceded the RMR measurements, resulting in larger fish from Panther Run being tested for RMR for all three temperatures examined. Millidine et al (2009) suggest that the fish with higher standard metabolic rates have higher energy costs but can actually process meals faster as a result with the larger specific consumption leading to this discrepancy in fish size. This would allow these individuals to eat more and grow more, compounding the size differences. A size comparison of fish at the start of the consumption experiments that preceded the $20^{\circ} \mathrm{C}$ RMR experiments shows there is no significance difference in the initial size of the fish used (Figure 12). With an apparent difference in size between the four populations for the RMR experiments, we made an effort to correct for size by taking the natural log of the mass of the individuals. Further attempts to 
correct for size, such as a size dependency model, would only add more uncertainty to the data with the limited range of fish sizes. In addition to the fish mass biases, the uneven sample size can have a confounding effect on our results. Disease and cannibalism greatly reduced the individuals available for the second set of experimental fish leading to the uneven sample size.

Despite the setbacks, we were able to conclude that there is a discernable difference in RMR between populations of Brook Trout in the headwater streams in West Virginia's Central Appalachian Mountains across temperatures. Although we encompassed only a small portion of the native range of Brook Trout in West Virginia, our values are lower than those predicted with the current Brook Trout bioenergetics model (Hartman and Cox 2008) (Figure 13). Hartman and Cox (2008) fish were obtained for the Bowden State hatchery thus differences could be a result of selective pressures in the hatchery, favoring faster growth and therefore higher metabolic costs as suggested by Millidine et al. (2009) or reflect differences in their original source population. Wild fish may also potentially exhibit wider ranges of optimal ranges. Another reason for this difference with the earlier model is the longer periods of time in isolation prior to measuring RMR or the longer acclimation period to the chambers. Hartman and Cox (2008) allowed fish to acclimate for 24 hours, while we allowed fish to acclimate for $>36 \mathrm{~h}$, potentially reducing handling stress or acclimation biases and reducing the potential for attributing residual specific dynamic activity action to RMR. Further testing would need to be done with wild fish to determine if this hold true.

In addition to the significant differences in metabolic rates between populations, we were able to see a relatively large variation of routine metabolic rates. Tyler and Bolduc (2008) conducted an experiment similar to ours where they investigated individual values in the bioenergetics models and tested hatchery fish for both variation in c-max and standard metabolic 
rate. They too found a high level of variation around their parameters, indicating that some individuals had higher rates and other had lower rates around the mean, and encompass those findings to help add upper and lower limits to the Wisconsin Bioenergetics Model for Rainbow Trout (Oncorhynchus mykiss). In addition to this variation helping to provide confidence intervals to bioenergetics models, this level of variation could be beneficial to the populations if this variation relates to population stochasticity. Having young of the year individuals that do well at a different variety of temperatures would allow for the population to better be able to exploit the conditions from year to year. This exploitation could also result in the adaptation of the population to warming waters in the face of global climate change.

In conclusion, this was a very small sampling of the native range of Brook Trout, even in the scope of the state of West Virginia. While we found there to be a size bias in our sample and had a less than ideal, uneven sample size, we still believe that these results should help researchers and managers trying to account for energetic budgets of young Brook Trout. Consideration of the effect that latitudinal and elevational variation may have on a Brook Trout population's RMR can allow for a better application of the published bioenergetics models. Variation does exist and it is good for the population and the species. 


\section{References}

Adams, S.B., C.A. Frissell and B.E. Rieman. 2000. Movements of non-native Brook Trout in relation to stream channel slope. Transactions of the American Fisheries Society 129: 623-638

Atkins, M. E., and T. J. Benfey. 2008. Effect of acclimation temperature on routine metabolic rate in triploid salmonids. Comparative Biochemistry and Physiology Part A: Molecular \& Integrative Physiology 149(2):57-161.

Barbieri, E., I.R. Oliveira and P., Serralheiro. 2002. The use of metabolism to evaluate the toxicity of dodecil benzen sodium sulfonate (LAS-C12) on the Mugil platanus (mullet) according to the temperature and salinity. Journal of Experimental Marine Biology and Ecology 277(2):109-127.

Beauchamp, D. A., D.J Stewart, and G. L. Thomas. 1989. Corroboration of a bioenergetics model for sockeye salmon. Transactions of the American Fisheries Society 118(6):597607.

Beitinger, T.L. and W.A. Bennett. 2000. Quantification of the role of acclimation temperature in temperature tolerance of fishes. Environmental. Biology of Fishes 58(3):277-288.

Bernstein, L., P. Bosch, O. Canziani, Z. Chen, R. Christ, and K. Riahi. 2008. IPCC, 2007: Climate Change 2007. Synthesis Report.

Carline, R.F. and J. F. Machung. 2001. Critical Thermal Maxima of Wild and Domestic Strains of Trout. Transactions of the American Fisheries Society 130:6.

Casselman, J. M. 2002. Effects of temperature, global extremes, and climate change on yearclass production of warmwater, coolwater, and coldwater fishes in the Great Lakes basin. In American Fisheries Society Symposium (pp. 39-60). American Fisheries Society.

Clayton, J. L., E. S. Dannaway, R. Menendez, H. W. Rauch, J. J. Renton, S. M. Sherlock, and P. E. Zurbuch. 1998. Application of limestone to restore fish communities in acidified streams. North American Journal of Fisheries Management 18:347-360.

Cutts, C. J., N.B. Metcalfe and A.C. Taylor. 2002. Juvenile Atlantic salmon (Salmo salar) with relatively high standard metabolic rates have small metabolic scopes. Functional Ecology 16(1):73-78.

Elliott, J. M., and W. Davison. 1975. Energy equivalents of oxygen consumption in animal energetics. Oecologia 19(3):195-201.

Flebbe, P. A. 1994. A regional view of the margin: salmonid abundance and distribution in the southern Appalachian Mountains of North Carolina and Virginia. Transactions of the American Fisheries Society 123:657-667.

Galbreath, P. F., N. D. Adams, S. Z. Guffey, C. J. Moore, and J. L. West. 2001. Persistence of native southern Appalachian Brook Trout populations in the Pigeon River system, North Carolina. North American Journal of Fisheries Management 21:927-934. 
Hartman, K. J., and M. K. Cox. 2008. Refinement and Testing of a Brook Trout Bioenergetics Model. Transactions of the American Fisheries Society 137(1):357-363.

Jobling, M. 1995. Environmental biology of fishes. Chapman and Hall.

Larson, G. L., and S. E. Moore. 1985. Encroachment of exotic rainbow trout into stream populations of native Brook Trout in the southern Appalachian Mountains. Transactions of the American Fisheries Society 114:195-203.

Lefrançois, C., G. Claireaux, C. Mercier and J. Aubin. 2001. Effect of density on the routine metabolic expenditure of farmed rainbow trout (Oncorhynchus mykiss). Aquaculture 195(3-4):269-277.

Madenjian, C. P., and D.V. O'Connor. 1999. Laboratory evaluation of a lake trout bioenergetics model. Transactions of the American Fisheries Society 128(5):802-814.

Madenjian, C. P., D.V. O'Connor and D.A. Nortrup. 2000. A new approach toward evaluation of fish bioenergetics models. Canadian Journal of Fisheries and Aquatic Sciences 57(5):1025-1032.

Marschall, E. A., and L. B. Crowder. 1996. Assessing population responses to multiple anthropogenic effects: a case study with Brook Trout. Ecological Applications 6(1):152167.

McDermid, J. L., W.N. Sloan, C.C. Wilson, and B.J. Shuter. 2010. Early life history variation among hatchery-and wild-origin lake trout reared in a hatchery environment. Transactions of the American Fisheries Society 139(1):21-28.

Meier, K., M.M. Hansen, E. Normandeau, K.D. Mensberg, J. Frydenberg, P.F. Larsen, and L. Bernatchez. 2014. Local Adaptation at the Transcriptome Level in Brown Trout: Evidence from Early Life History Temperature Genomic Reaction Norms. Plos ONE 9(1):1-13

Meisner, J. D. 1990. Effect of climatic warming on the southern margin of the native range of Brook Trout, Salvelinus fontinalis. Canadian Journal of Fisheries and Aquatic Sciences 47:1065-1070.

Millidine, K. J., J.D. Armstrong and N.B. Metcalfe. 2009. Juvenile salmon with high standard metabolic rates have higher energy costs but can process meals faster. Proceedings of the Royal Society B: Biological Sciences 276(1664):2103-2108.

Nelson, J. A.. 2016. Oxygen consumption rate v. rate of energy utilization of fishes: a comparison and brief history of the two measurements. Journal of Fish Biology 88:10-25

Pilgrim, J. M., X. Fang, and H. G. Stefan. 1998. Stream temperature correlations with air temperatures in Minnesota: implications for climate warming. Journal of the American Water Resources Association 34;1109-1121.

Powell, M. D., D.J. Speare, J. Daley, and J. Lovy. 2005. Differences in metabolic response to Loma salmonae infection in juvenile Rainbow Trout Oncorhynchus mykiss and Brook Trout Salvelinus fontinalis. Diseases of aquatic organisms 67(3):233-237. 
R Core Team. 2019. R: A language and environment for statistical computing. R Foundation for Statistical Computing, Vienna, Austria. URL https://www.R-project.org/.

Sharpe, W. E., V. G. Leibfried, W. G. Kimmel, and D. R. DeWalle. 1987. The relationship of water quality and fish occurrence to soils and geology in an area of high hydrogen and sulfate ion deposition. Water Resources Bulletin 13:619-631.

Stefan, H. G., and E. B. Preud'homme. 1993. Stream temperature estimation from air temperature. Water Resources Bulletin 29:27-45.

Stitt, B. C., G. Burness, K.A. Burgomaster, S Currie, J.L. McDermid, and C.C. Wilson. 2014. Intraspecific Variation in Thermal Tolerance and Acclimation Capacity in Brook Trout (Salvelinus fontinalis): Physiological Implications for Climate Change. Physiological and Biochemical Zoology 87(1):15-29.

Stockwell, J. D., and B.M. Johnson. 1997. Refinement and calibration of a bioenergetics-based foraging model for kokanee (Oncorhynchus nerka). Canadian Journal of Fisheries and Aquatic Sciences 54(11):2659-2676.

Tyler, J. A., and M.B. Bolduc. 2008. Individual variation in bioenergetic rates of young-of-year Rainbow Trout. Transactions of the American Fisheries Society 137(1):314-323.

Welsh, S. A., and S. A. Perry. 1997. Acidification and fish occurrence in the upper Cheat River drainage, West Virginia. Journal of the American Water Resources Association 33(2):423-429.

Wigington, P. J., Jr., J. P. Baker, D. R. DeWalle, W. A. Kretser, P. S. Murdoch, H. A. Simonin, J. Van Sickle, M. K. McDowell, D. V. Peck and W. R. Barchet. 1996. Episodic acidification of small streams in the northeast United States: episodic response project. Ecological Applications 6:374-388. 
Figures and Tables

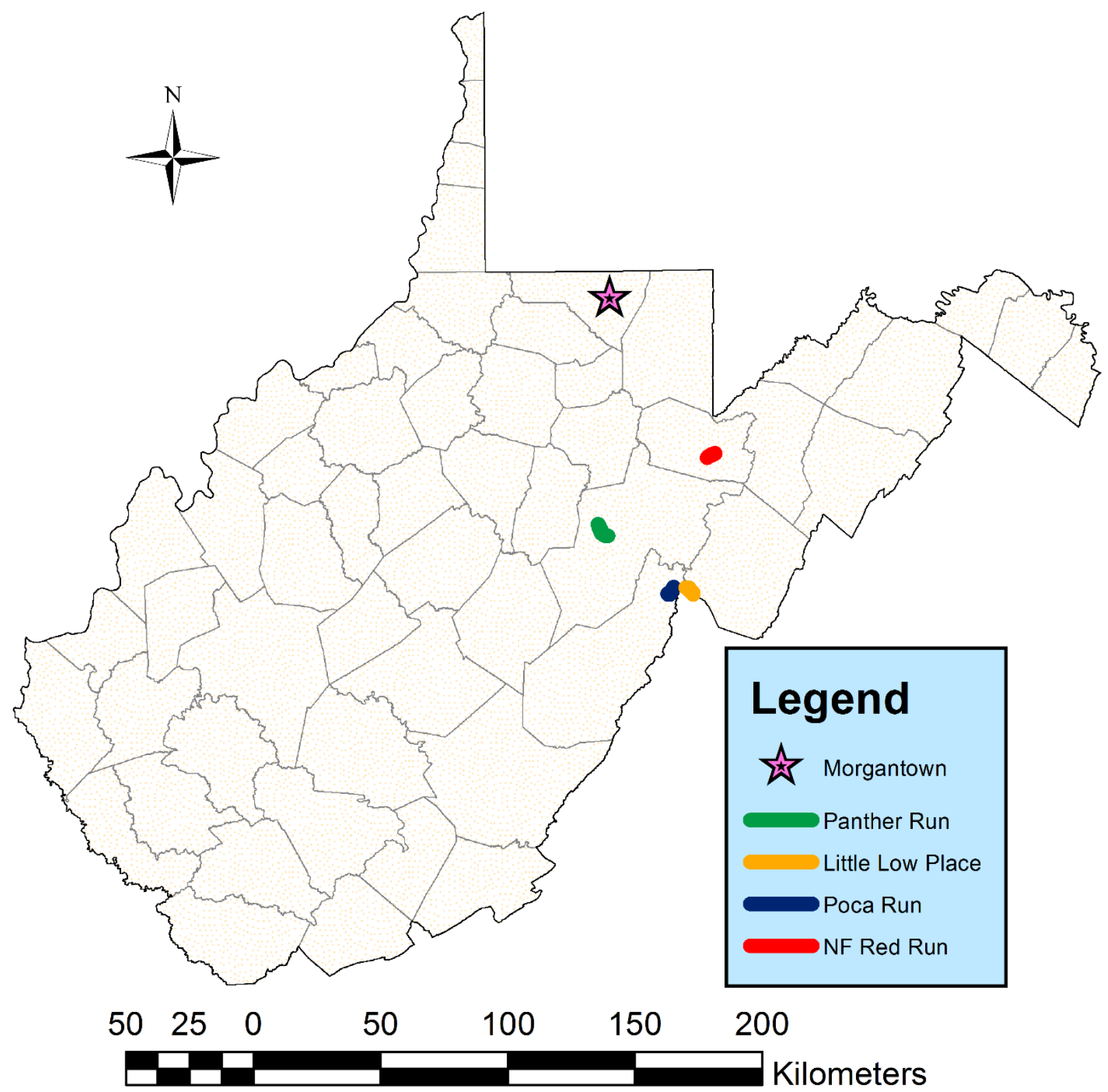

Figure 1. Statewide extent map showing the selected streams for source populations of fish used in the experiments. 


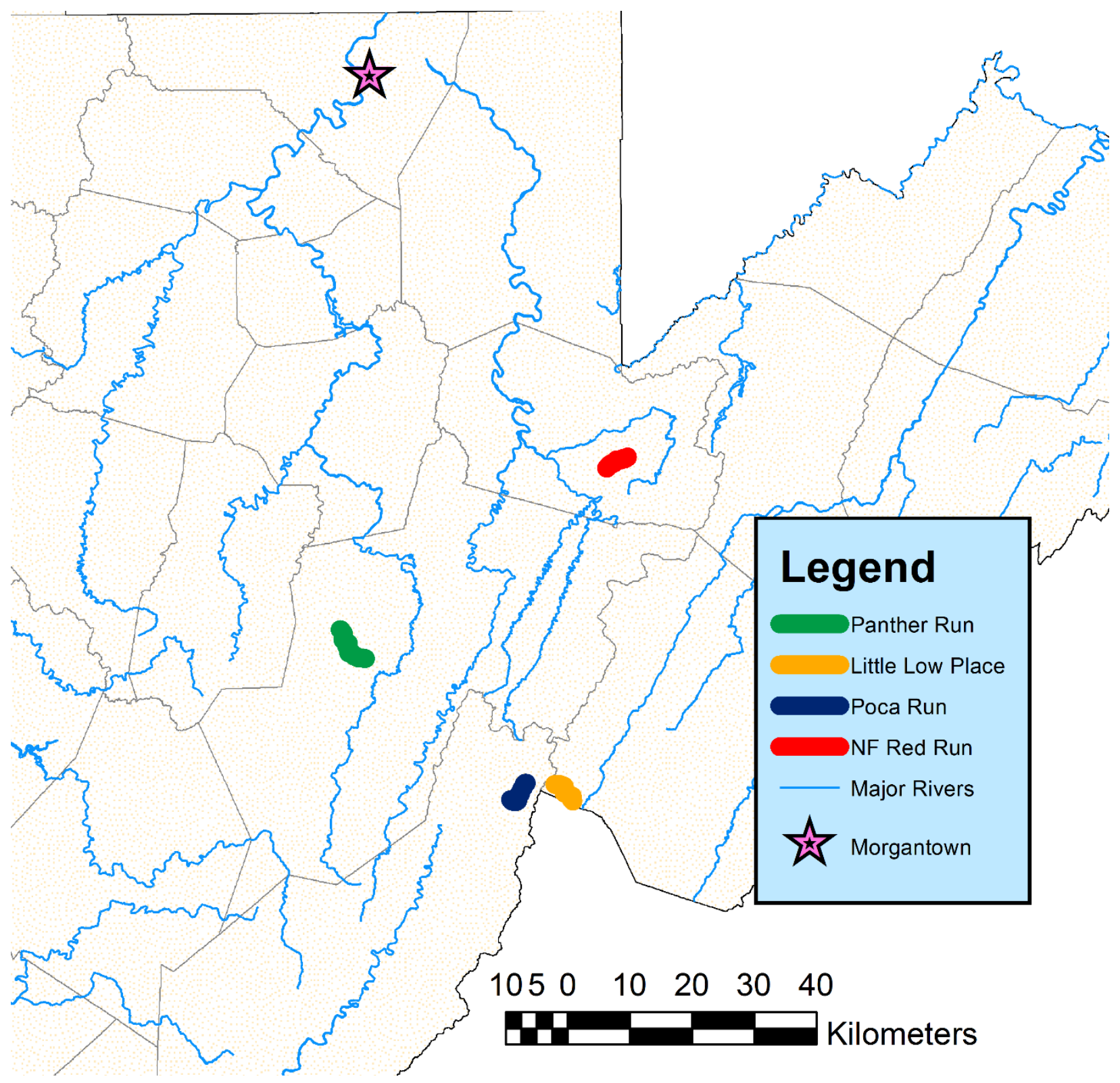

Figure 2. Regional extent map showing the selected streams for source populations of fish used in the experiments. 


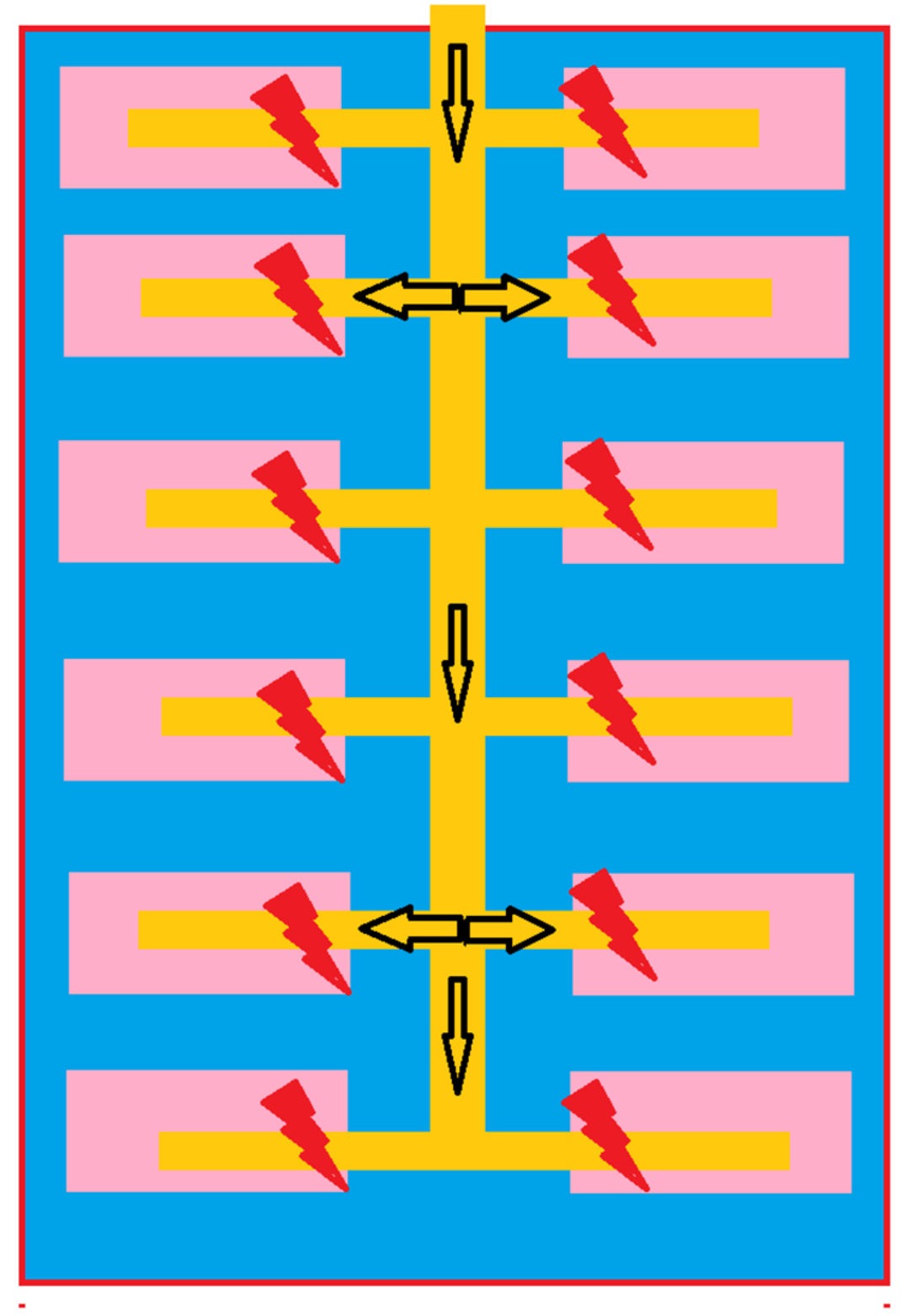

$1.2 \times 2.4 \mathrm{~m}$ steel tank

37.51 aquarium

PVC pipe providing water flow

Ball valve to control water flow rate

Figure 3. Diagram showing the tank set up used for C-Max experiments. Water flows from the chiller in the PVC pipe where it is diverted, and flows altered by the ball valves. All aquarium set in steel tanks to act as a thermal buffer. 


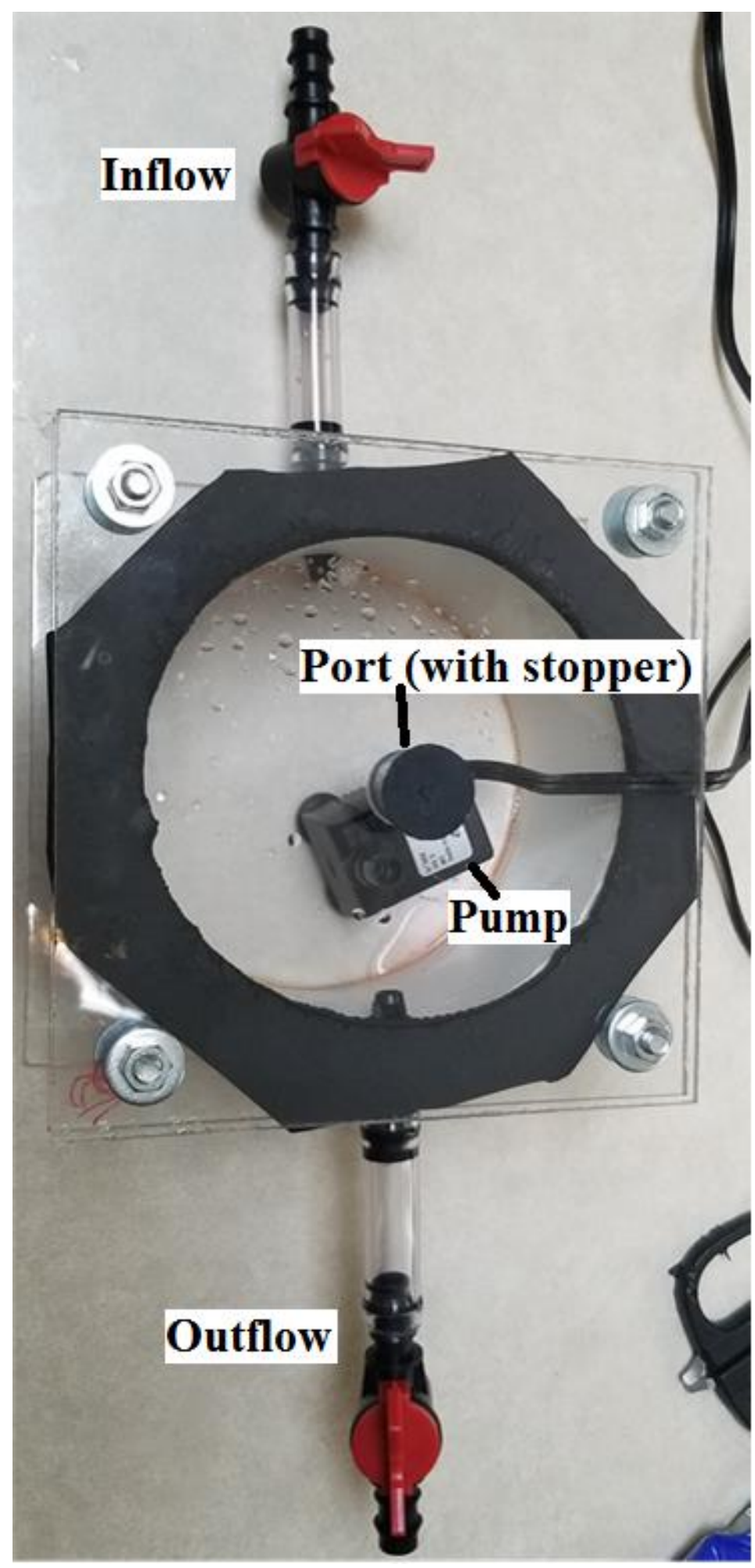

Figure 4. Image of the metabolic chambers used to determine routine metabolic rates of Brook Trout. Shown are the inflow and outflow fittings equipped with valves to alter flow, electric pump to mix the water following oxygen depletion experiments as well as port to allow insertion of the DO probe. 


\section{Global Temperature Influence on RMR}

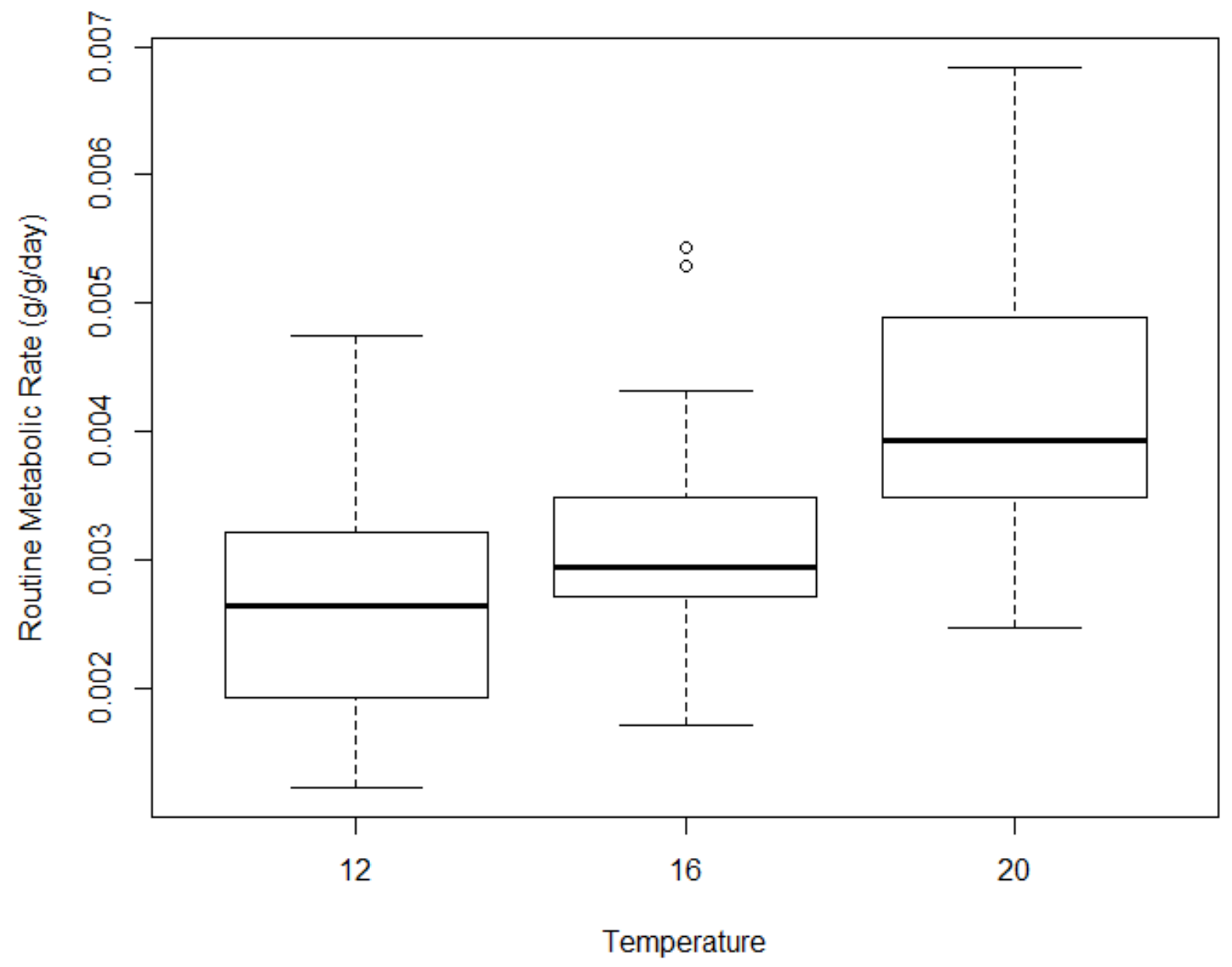

Figure 5. Boxplot representing the routine metabolic rates for all BROOK TROUT tested at each temperature 


\section{Global Size Influence on RMR}

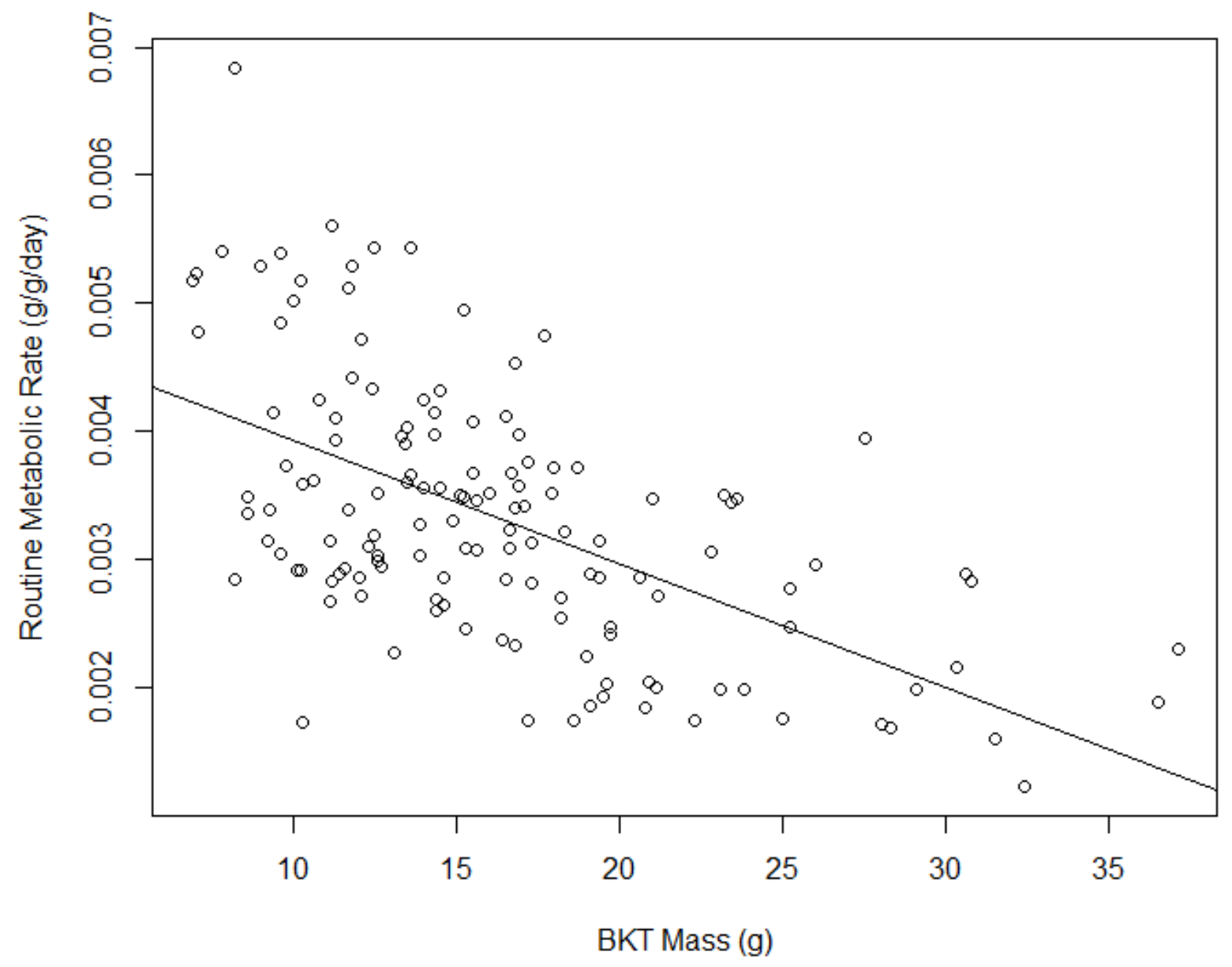

Figure 6. Scatterplot representing the influence of size on the routine metabolic rate of all fish tested at all three temperatures. 
Little Low Place

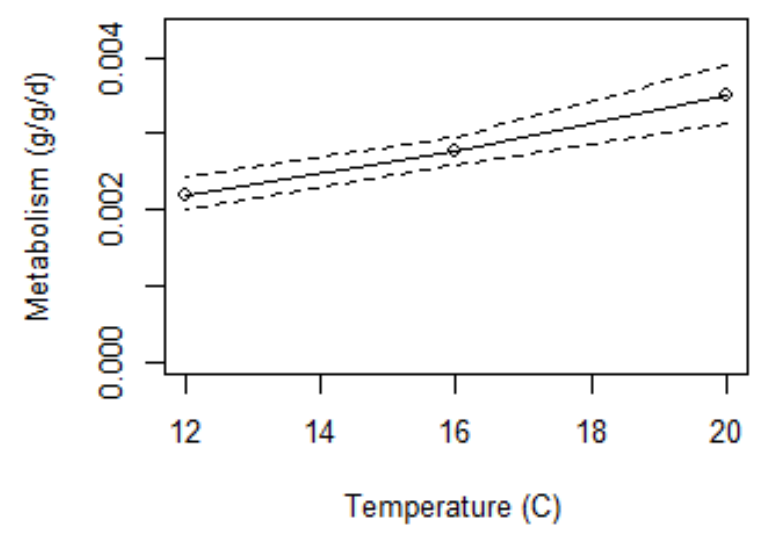

Panther Run

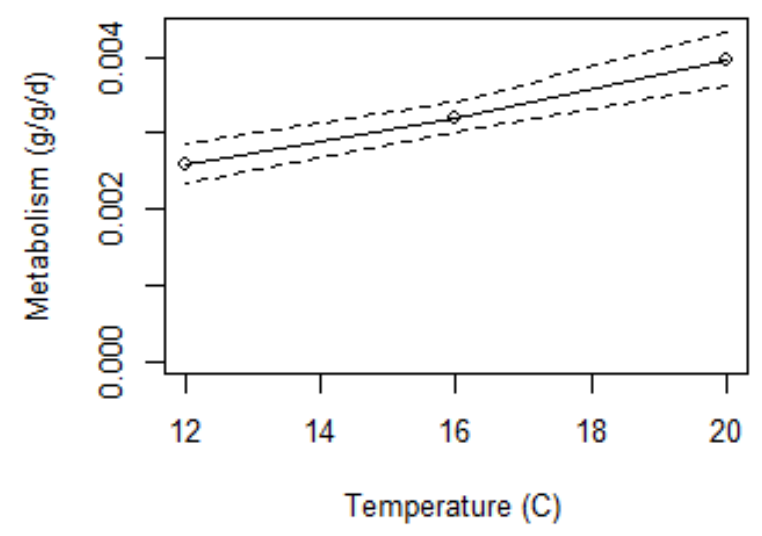

North Fork Red Run

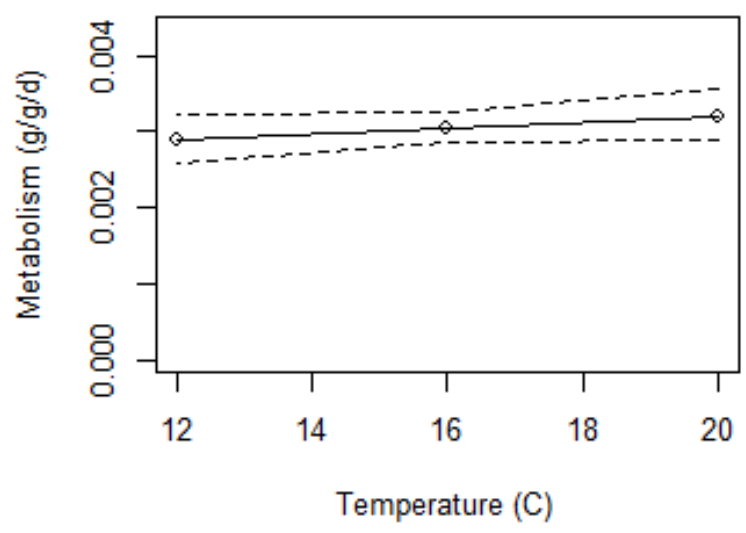

Poca Run

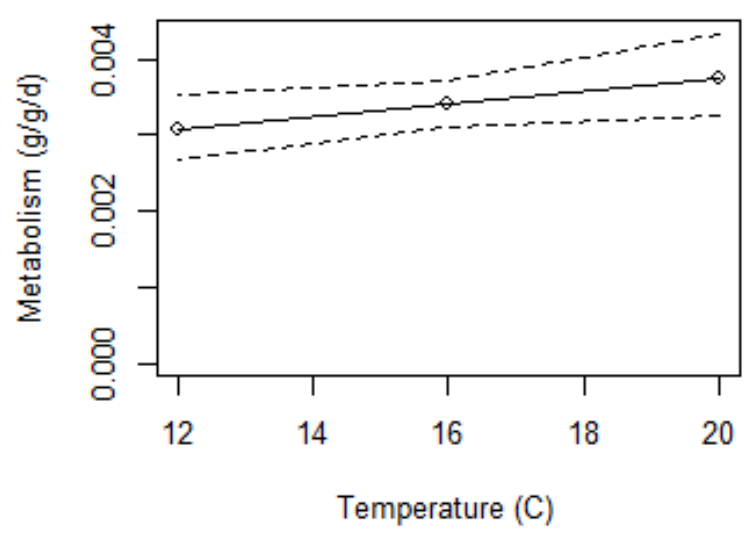

Figure 7. Routine metabolic rate estimates for each of the for streams across the three experimental temperatures utilizing the general linear model $\ln (($ routine metabolic rate $)=$ Stream + Temperature $+\ln ($ Mass $)+$ Stream $*$ Temperature. $95 \%$ confidence intervals are indicated by the dashed lines. 


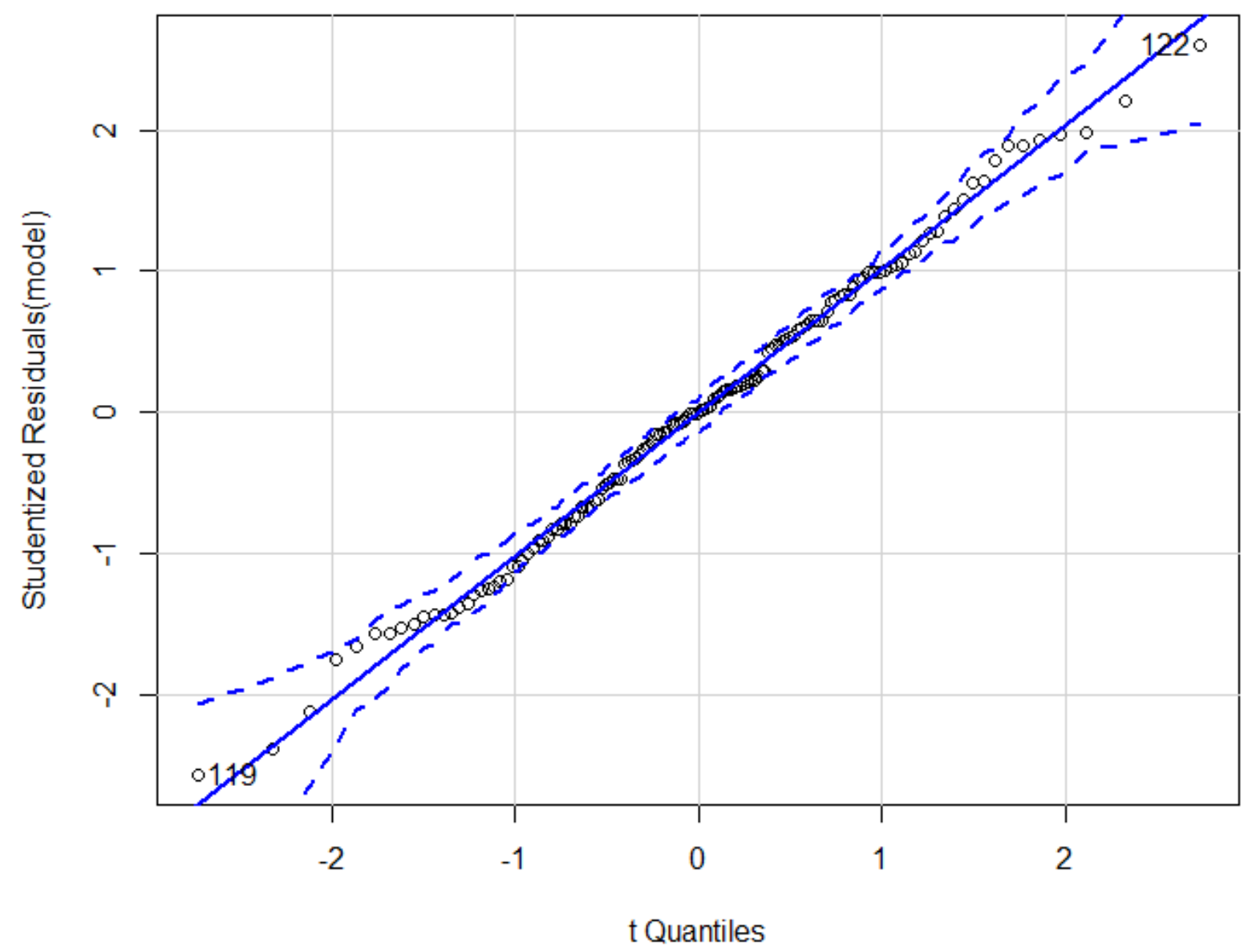

Figure 8. QQ plot representing the residuals of the routine metabolic rate general linear model for the Brook Trout used in the consumption experiments. Here we see the lower tails are outside the $95 \%$ confidence intervals 


\section{0 degree Size Comparison}

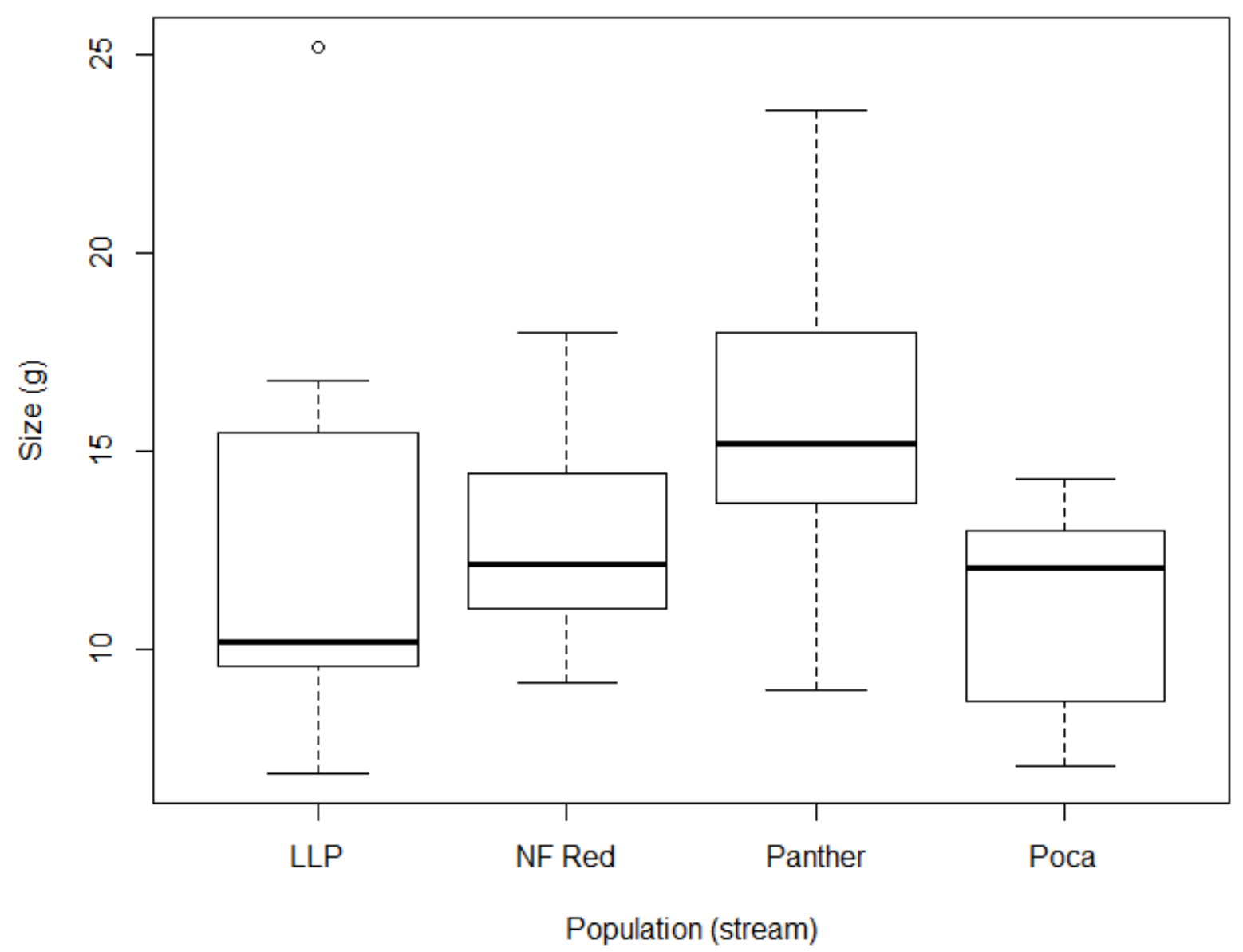

Figure 9. Boxplot of mass of fish from the four populations of fish used in RMR experiments at $20^{\circ} \mathrm{C}$. Here Panther Run fish are larger than those from Poca Run. In this figure, LLP is Little Low Place, NF Red is the North Fork of Red Run, Panther is Panther Run, and Poca is Poca Run. 


\section{6 degree Size Comparison}

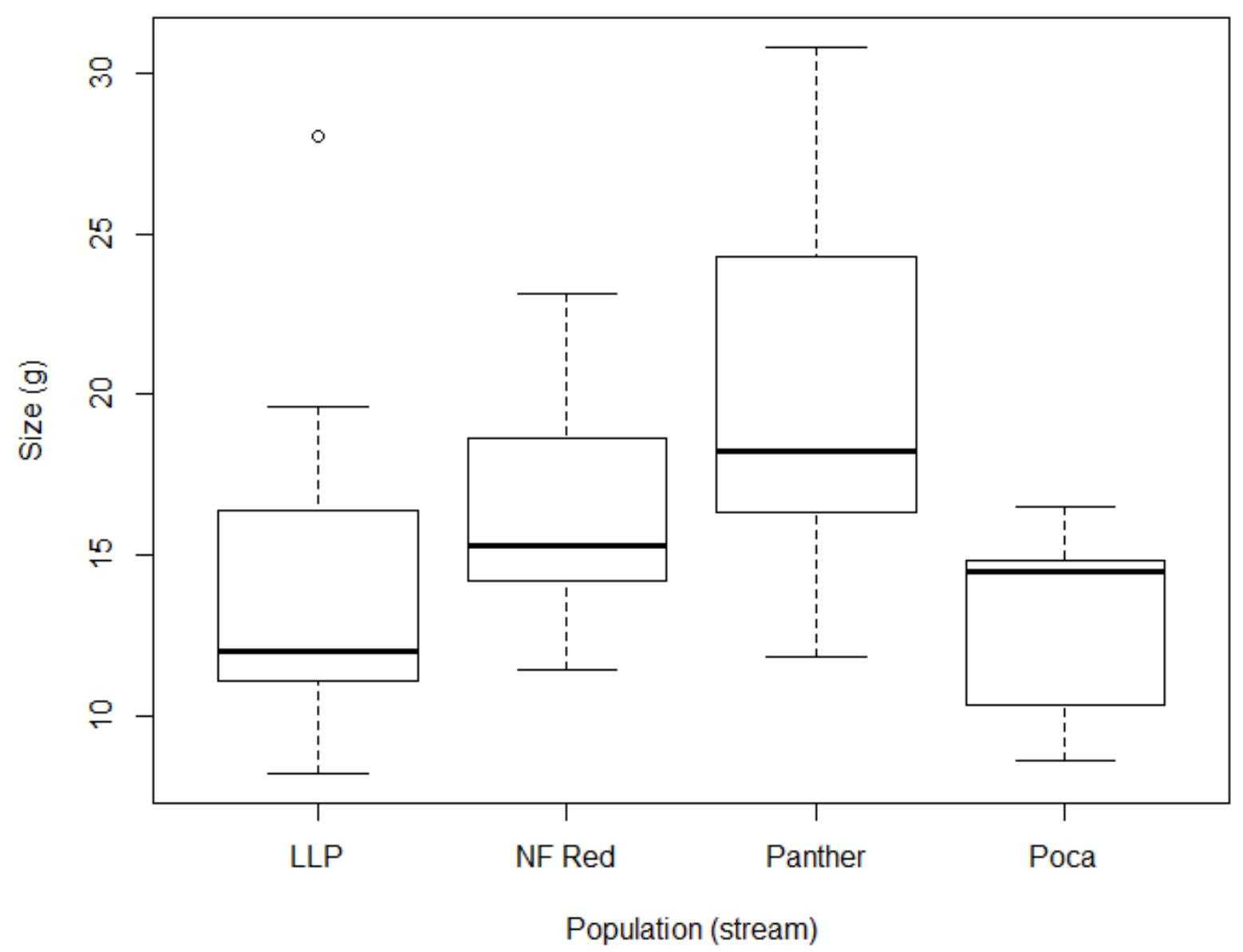

Figure 10. Boxplot of mass of fish from the four populations of fish used in RMR experiments at $16^{\circ} \mathrm{C}$. Here Panther Run fish are larger than those from Poca Run. For this boxplot LLP is Little Low Place, NF Red is the North Fork of Red Run, Panther is Panther Run, and Poca is Poca Run. 


\section{2 degree Size Comparison}

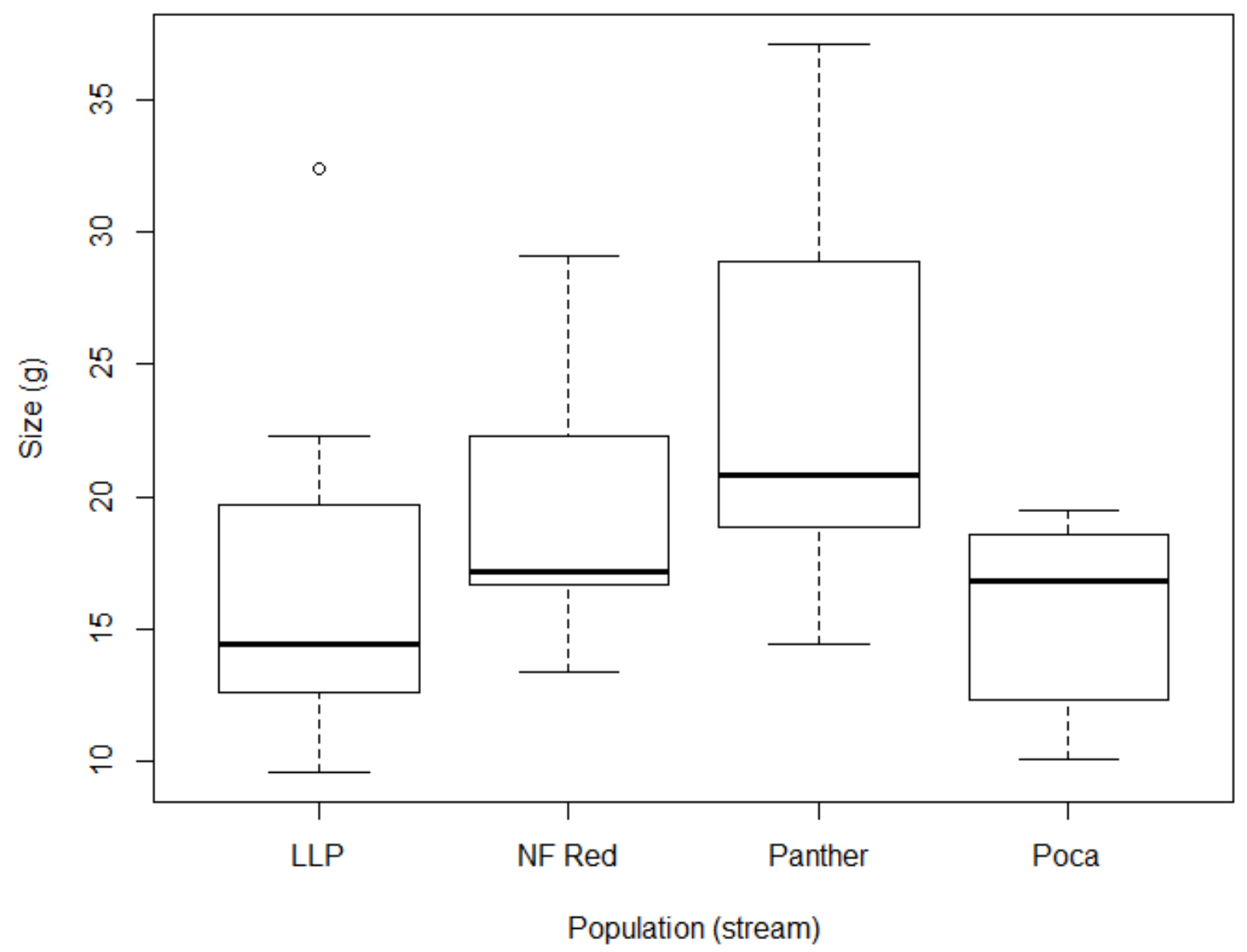

Figure 11. Boxplot of mass of fish from the four populations of fish used in RMR experiments at $12^{\circ} \mathrm{C}$. Here Panther Run fish are larger than those from Poca Run and Little Low Place. For this boxplot LLP is Little Low Place, NF Red is the North Fork of Red Run, Panther is Panther Run, and Poca is Poca Run. 


\section{0-Degree Differences in Fish Mass by Population}

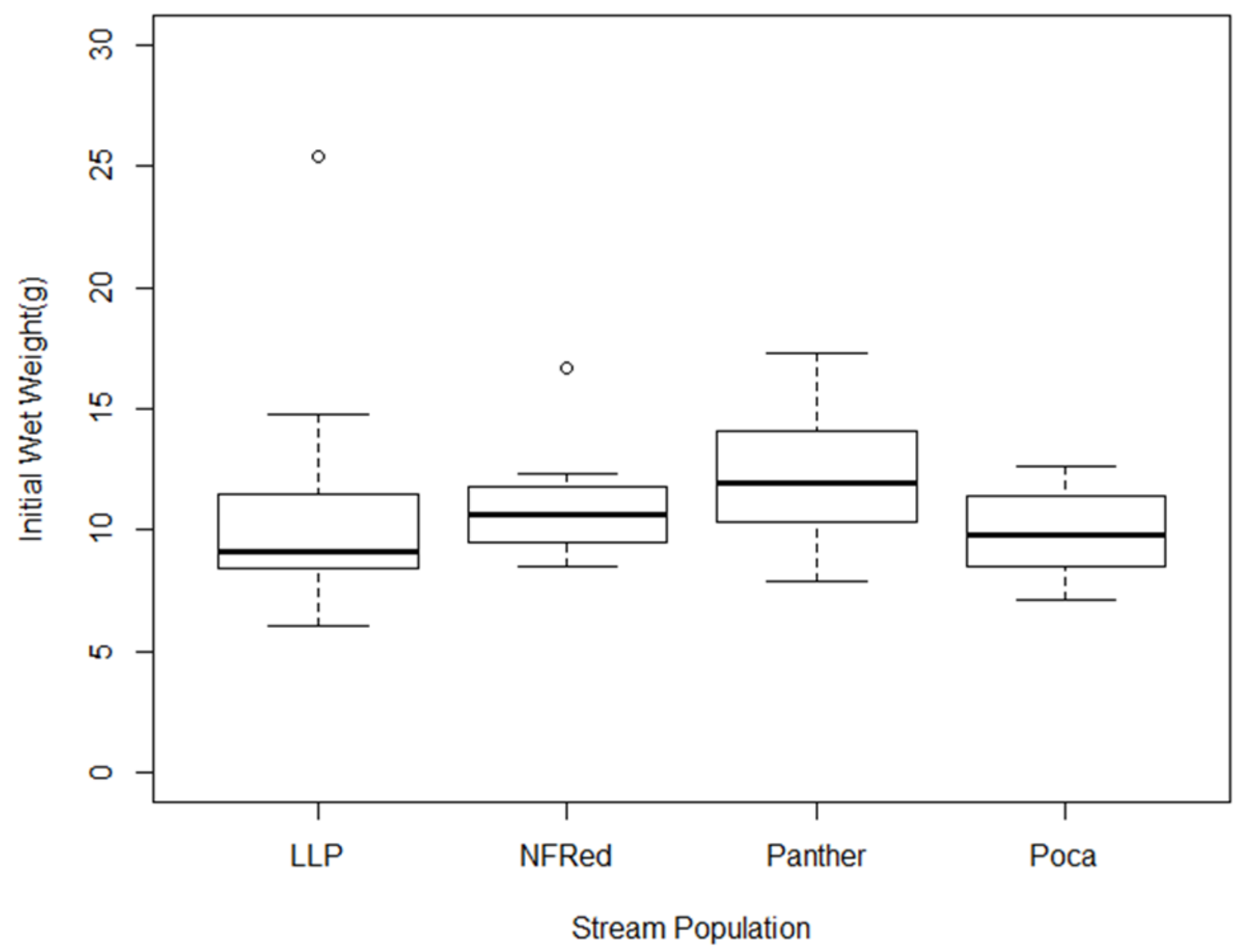

Figure 12. Boxplot of mass of fish from the four populations of fish used in RMR experiments at $20^{\circ} \mathrm{C}$ before the preceding C-max experiment. Here Panther Run fish are larger than those from Poca Run and Little Low Place. For this boxplot LLP is Little Low Place, NF Red is the North Fork of Red Run, Panther is Panther Run, and Poca is Poca Run. 


\section{Expected vs Measured}

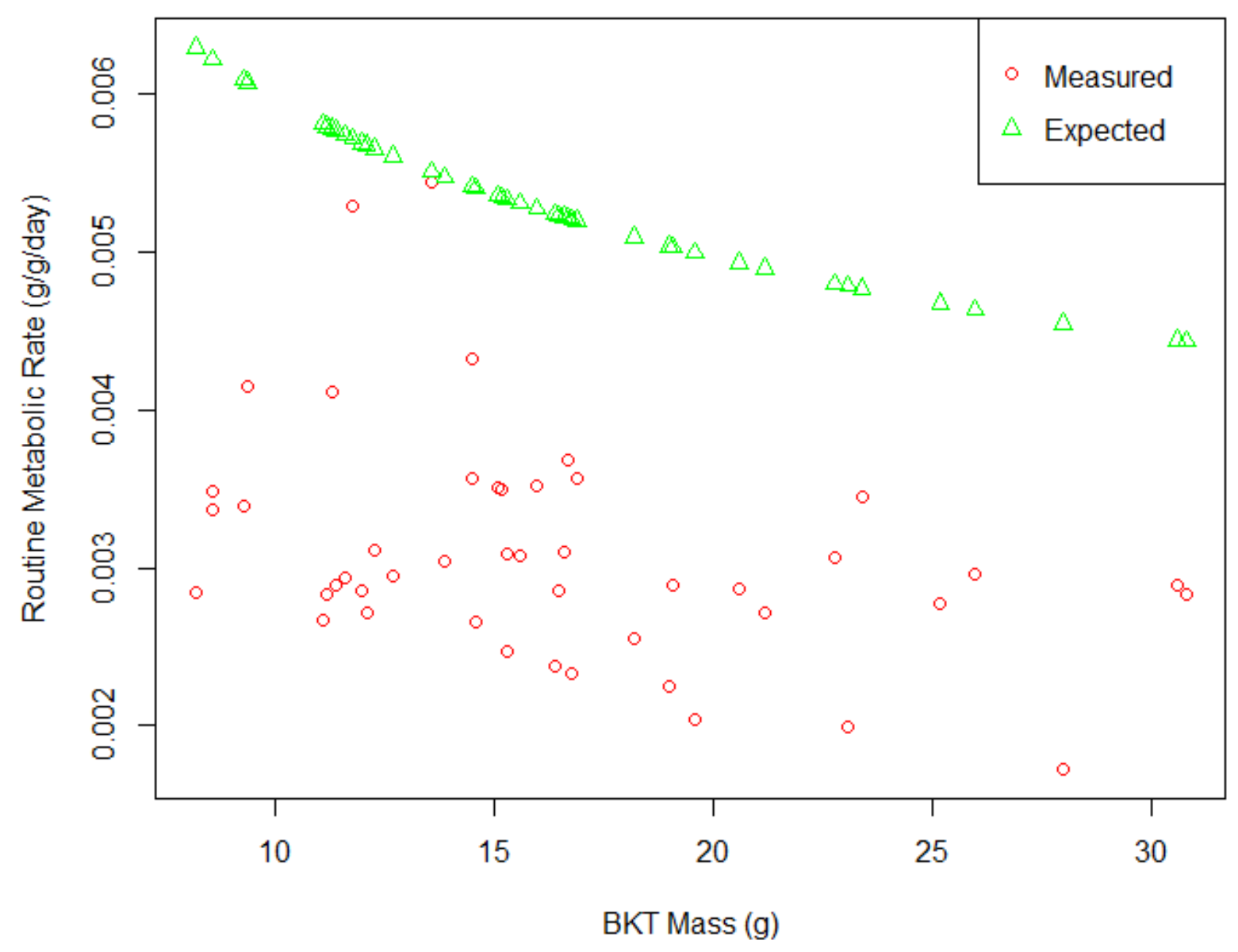

Figure 13. Scatter plot representing the mean RMR values from this experiment versus the expected values from the current bioenergetics model at $16^{\circ} \mathrm{C}$. 
Table 1. Indicates the stream name, abbreviation used in models, stream elevation at sample location, stream slope, bedrock geological type and drainage area for the four streams used as source populations of fish in this experiment.

\begin{tabular}{lccccc}
\hline & Abbreviation & Elevation(m) & Slope $\%$ & $\begin{array}{c}\text { Bedrock } \\
\text { geological type }\end{array}$ & $\begin{array}{c}\text { Drainage area } \\
\left(\mathrm{km}^{2}\right)\end{array}$ \\
\hline $\begin{array}{l}\text { Little Low } \\
\begin{array}{l}\text { Place } \\
\text { North Fork }\end{array}\end{array}$ & LLP & 970 & 13.2 & Hampshire & 5.5107 \\
$\begin{array}{l}\text { Red Run } \\
\text { Panther Run }\end{array}$ & Panther & 755 & 13.1 & Mauch chunk & 13.8924 \\
Poca Run & Poca & 1055 & 13.6 & Pottsville & 5.5098 \\
\hline
\end{tabular}


Table 2. Depiction of the overall experimental design encompassing both consumption and routine metabolic experiments. Red boxes indicate fasting days for C-max experiments, green boxes are C-max experimental days, yellow boxes are measurement and thermal acclimation days, grey boxes indicate acclimation days to the metabolic chambers, blue boxes are days in which routine metabolic rates were measured.

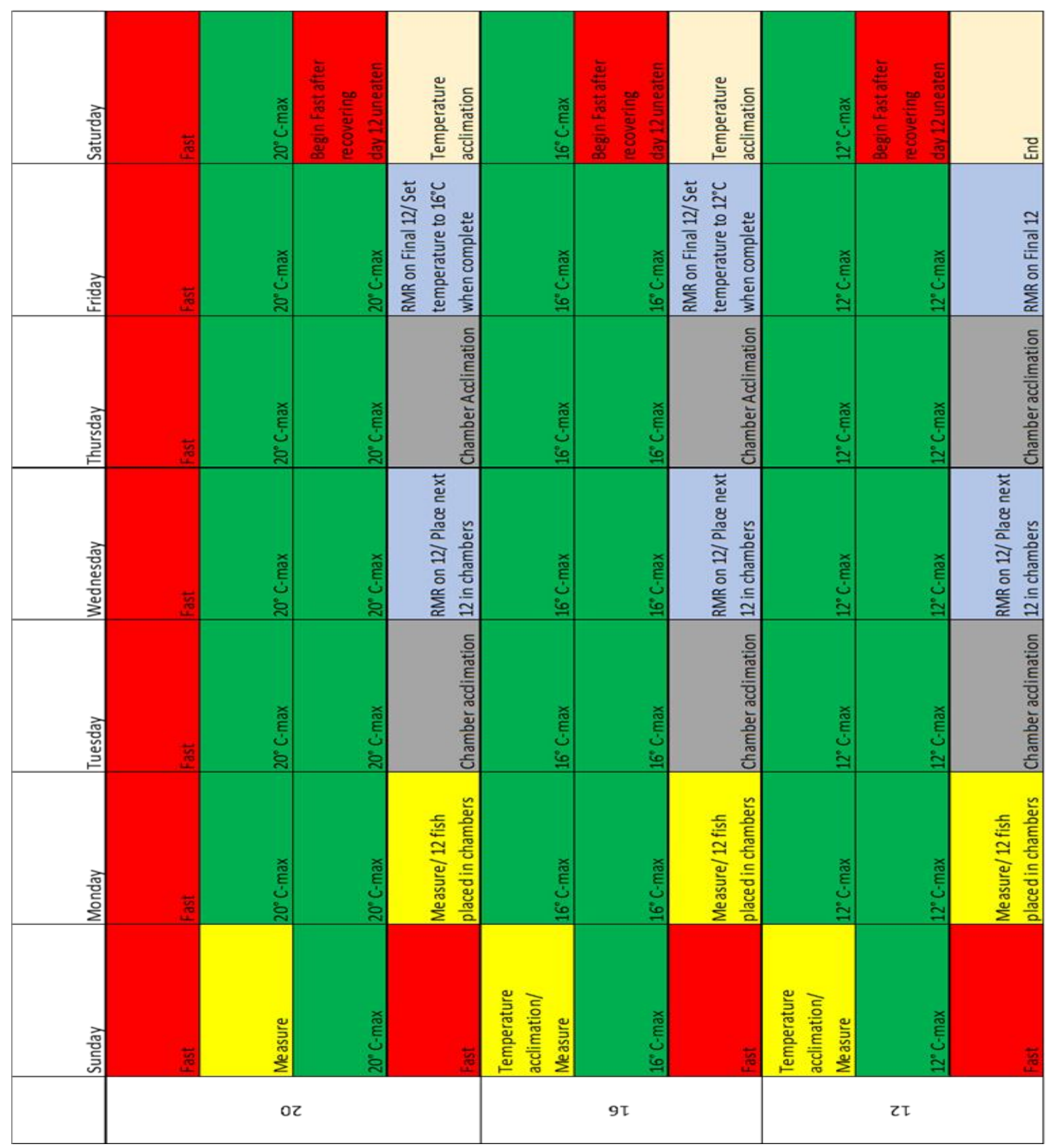


Table 3. Sample sizes of fish from each population used for each temperature in model calculations prior to outliers being removed. North Fork Red Run lost an individual between the 20 and $16^{\circ} \mathrm{C}$ experiments.

\begin{tabular}{llll}
\hline & $20^{\circ} \mathrm{C}$ & $16^{\circ} \mathrm{C}$ & $12^{\circ} \mathrm{C}$ \\
\hline Little Low Place & 13 & 13 & 13 \\
North Fork Red Run & 12 & 11 & 11 \\
Panther Run & 15 & 15 & 15 \\
Poca Run & 7 & 7 & 7 \\
\hline
\end{tabular}


Table 4. Representing the interactive ANVOCA output table on the natural log mean RMR values $(\ln (R M R)=$ Stream + Temperature $+\ln ($ Mass $)+$ Stream $*$ Temperature $)$. Here we see that all covariates are significant. Here lnMass is the natural $\log$ of the mass $(\mathrm{g})$ of an individual.

\begin{tabular}{llllll}
\hline & $\begin{array}{l}\text { Degrees of } \\
\text { Fredon }\end{array}$ & $\begin{array}{l}\text { Sum of } \\
\text { Squares }\end{array}$ & $\begin{array}{l}\text { Mean } \\
\text { Square }\end{array}$ & F value & $\begin{array}{l}\text { Probability } \\
(>\text { F })\end{array}$ \\
\hline Population & 3 & 0.868 & 0.289 & 7.642 & 0.00012 \\
Temperature & 1 & 5.184 & 5.184 & 133.661 & $>2 \mathrm{e}-11$ \\
lnMass & 1 & 2.010 & 2.010 & 51.836 & $4.44 \mathrm{e}-11$ \\
Population*Temperature & 3 & 0.531 & 0.177 & 4.565 & 0.00450 \\
Residuals & 129 & 5.003 & 0.039 & & \\
\hline
\end{tabular}


Table 5. Representing the estimates of the coefficients used to parameterize the global ANCOVA model for the RMR of Brook Trout used in this study. Here the intercept refers to the intercept of Little Low Place and the non-interactive value for temperature refers to the change that one degree of temperature changes has on the value of Little Low Place.

\begin{tabular}{lllll}
\hline & Estimate & $\begin{array}{l}\text { Standard } \\
\text { Error }\end{array}$ & T- Value & Probability $(>|\mathrm{t}|)$ \\
\hline Intercept & -5.59176 & 0.244480 & -22.872 & $<2 \mathrm{e}-16$ \\
North Fork Red Run & 0.812152 & 0.232529 & 3.497 & 0.000646 \\
Panther Run & 0.223459 & 0.220147 & 1.015 & 0.311985 \\
Poca Run & 0.734907 & 0.266560 & 2.757 & 0.006680 \\
Temperature & 0.057944 & 0.009885 & 5.862 & $3.61 \mathrm{e}-08$ \\
lnMass & -0.438546 & 0.059603 & -7.358 & $1.94 \mathrm{e}-11$ \\
North Fork Red Run:Temperature & -0.044936 & 0.012128 & -3.181 & 0.001840 \\
Panther Run: Temperature & -0.004924 & 0.013315 & -0.370 & 0.712112 \\
Poca Run: Temperature & -0.033184 & 0.016326 & -2.033 & 0.044149 \\
\hline
\end{tabular}

